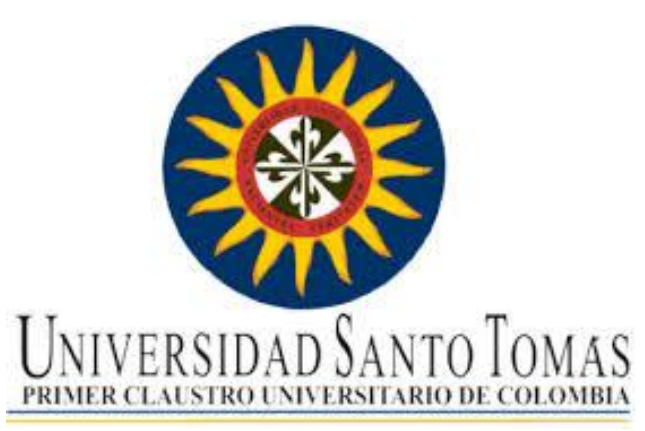

\title{
ESTUDIO DE LA ECONOMIA INFORMAL EN VILLAVICENCIO CON ENFOQUE NEOESTRUCTURAL
}

\author{
Astrid León Camargo
}

Universidad Santo Tomás

Facultad de Economía. Maestría en Ciencias Económicas

Bogotá, D.C. Colombia

2014 



\section{ESTUDIO DE LA ECONOMIA INFORMAL EN VILLAVICENCIO CON ENFOQUE NEOESTRUCTURAL}

Astrid León Camargo

Tesis presentada como requisito parcial para optar al título de:

Magíster en Ciencias Económicas

Director (a): Doctor Gustavo Díaz

Universidad Santo Tomás

Facultad de Economía. Maestría en Ciencias Económicas

Bogotá, D.C. Colombia

2014 



\section{Resumen}

La tesis presenta una contrastación del enfoque neoestructural, en la economía informal en Villavicencio. El objetivo del trabajo es caracterizar la economía informal en Villavicencio mediante un análisis de la estructura productiva. Se utilizan dos metodologías: la primera muestra los cambios en la productividad intrínseca de los $\mathrm{n}$ sectores y el cambio sectorial en la fuerza de trabajo en la ciudad de Villavicencio. La siguiente metodología despliega un modelo probit para identificar los principales determinantes estructurales sobre la economía informal. La mayoría de puntos propuestos por el enfoque neoestructuralista, concuerdan con la situación en Villavicencio. Los principales determinantes sobre la informalidad son: comercio y servicios, transporte, número de personas en el hogar y jefe de hogar. Se resalta la actividad comercio y servicios como importante factor para la existencia de la informalidad

Palabras claves: neoestructural, informal, heterogeneidad, dual, productividad, intrínseca, extrínseca, probit, estructural. 


\section{Contenido}

Pág.

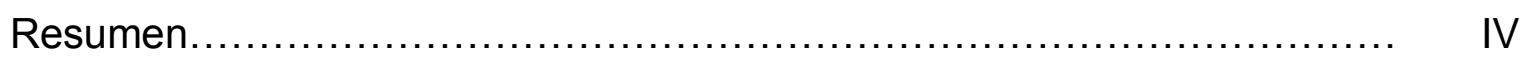

Lista de Gráficos............................................................. VII

Lista de Tablas................................................................. VIII

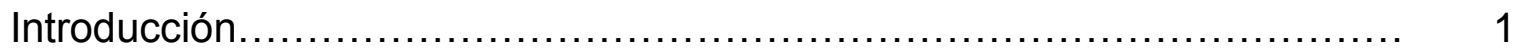

1. Marco teórico - marco conceptual - estado del arte.......................... 7

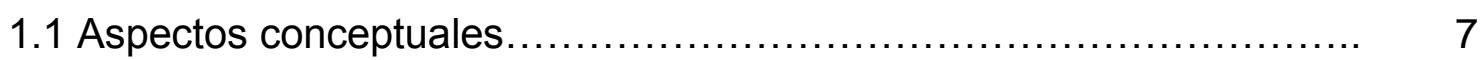

1.2 Aspectos teóricos..................................................... 12

1.3 La Economía informal y su relación con la escuela neoestructuralista. $\quad 17$

2. El empleo informal y el neoestructuralismo.............................. 27

2.1 Comparación de los enfoques de la economía informal del............. 43

DANE, neoestructuralismo y Víctor Tokman

3. Un modelo probit para los determinantes de la informalidad en............ 54 Villavicencio

3.1 Caracterización la economía informal en Villavicencio.................. 54

3.2 Estimación de un modelo probit para los determinantes de la.......... 63 informalidad en Villavicencio en los años 2008 y 2012

3.3 Resultados del modelo.................................................. 68

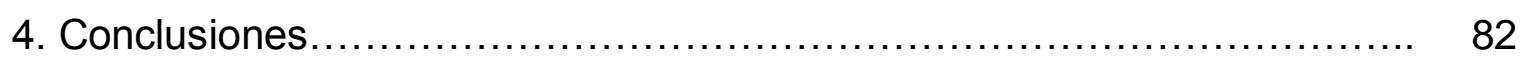




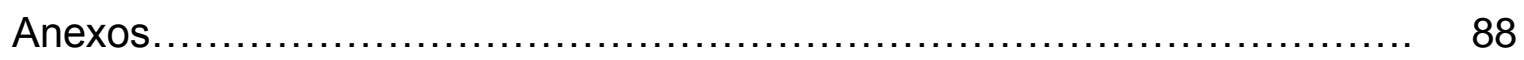

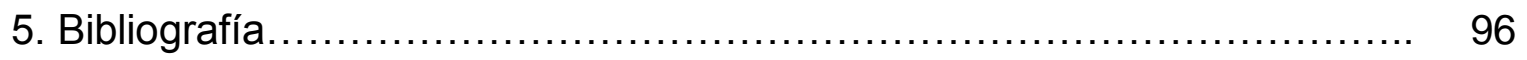




\section{Lista de Gráficos}

Gráfico 1. Productividad y composición en la fuerza de trabajo.................. 29 en un modelo dualista. 


\section{Lista de Tablas}

Pág.

Tabla 1. Taxonomía de la economía informal............................ 10

Tabla 2. Autores neoestructurales e informalidad......................... 23

Tabla 3. Valor agregado por empleado en Colombia, 1960 y $2003 \ldots \ldots \ldots \ldots .29$

Tabla 4. Variación anual y descomposición de la productividad laboral...... 31 promedio 1960-2003

Tabla 5. Composición sectorial y crecimiento del PIB en Meta.............. 37

Tabla 6. Descomposición de la productividad laboral en Villavicencio........ 38

Tabla 7. Participación de la productividad laboral en Villavicencio........... 39

Tabla 8. Comercio y servicios y la productividad laboral................... 42

Tabla 9. Cuadro comparativo de enfoques............................. 52

Tabla 10. Factores asociados a la informalidad en el enfoque ............... 67 Neoestructural

Tabla 11. Modelo Probit de informalidad para Villavicencio 2008 y 2012... 71 efectos marginales

Tabla 12. Significancia de las variables a un nivel del $1 \%$ y tendencia....... de las variables como determinantes sobre la informalidad

Tabla 13. Comparativo de la GEIH con el modelo probit en el año 2012.... 77

Tabla 14. Comparativo para afrontar el fenómeno de la informalidad........ 80

Tabla A.1 Información estadística de la informalidad en Villavicencio........ 88

Tabla A.2 Valores mínimos y máximos de probabilidad de modelos lineal... 91 y probit de los años 2008 y 2012 
Tabla A.3 Selección de modelos mediante criterio de Akaike y Schwartz... 91

Tabla A.4 Variables utilizadas en el modelo probit años 2008 y $2012 \ldots \ldots \ldots .92$

Tabla A.5 Modelo Probit de informalidad para Villavicencio años............ 93 2008 y 2012

Tabla A.6 Ajuste del Modelo.............................................. 94

Tabla A.7 Pruebas de hipótesis para contrastar la validez de probit......... 94 2008 y 2012

Tabla A.8. Matriz de clasificación.......................................... 95 


\section{Introducción}

El empleo informal es un fenómeno de reciente estudio, y es definido principalmente por la Organización Internacional del Trabajo -OIT- "las muy pequeñas unidades de producción y distribución de bienes y servicios, situadas en las zonas urbanas de los países en desarrollo; dichas unidades pertenecen casi siempre a productores independientes y trabajadores independientes que a veces emplean a miembros de la familia o a algunos asalariados o aprendices. Estas unidades disponen de muy poco o de ningún capital; utilizan técnicas rudimentarias y mano de obra escasamente calificada, por lo que su productividad es reducida; quienes trabajan en ellas suelen obtener ingresos muy bajos e irregulares, y su empleo es sumamente inestable" (Organización Internacional del Trabajo, 1991, p. 137). Uno de los primeros en trabajar el tema en el mundo y el primero en América Latina, Hernando de Soto, señala al Estado como el principal causante de su existencia, debido a las múltiples trabas para formalizar los negocios. Actualmente en un intento por favorecer la formalización, los Gobiernos de América Latina han facilitado los procesos de formalización, hasta el punto que en Colombia, registrar una empresa requiere llenar requisitos de fácil consecución y en un poco tiempo.

Las escuelas de pensamiento manejan el tema de la informalidad dada su importancia dentro de la equidad social y bienestar de la población. Los neoestructuralistas ${ }^{1}$ entienden la informalidad como resultante de una economía

\footnotetext{
${ }^{1}$ Un resumen que hace Berthomieu del neoestructuralismo y tomado de Franch-Davis es: "Esta
} 
dual donde empresas altamente tecnificadas en sus procesos de producción y administración, conviven con negocios pequeños que manejan relaciones mercantiles de sustentación, pero sin mayor valor agregado en sus procesos. Resolver la problemática informal es un paso a alcanzar los dos objetivos del neoestructuralismo: "desarrollar una base productiva en que se conjugarán un aumento continuo de la productividad, una inserción internacional competitiva y construir una sociedad más igualitaria y justa" (Bielschowsky, 2009, p. 174).

El análisis de esta investigación, en donde los factores estructurales inciden en la informalidad es explicado desde la visión neoestructuralista. Se contrastarán el enfoque neoestructuralista en el municipio de Villavicencio, capital del departamento del Meta y, centro político y económico de la región de la Orinoquia.

La poca vocación empresarial impide el montaje de empresas enormes que demanden grandes cantidades de empleo. La inversión social no responde a la creación de empleo que requiere la ciudad. Mientras el desempleo no cede, en diciembre de 2013 , del total de mano de obra ocupada, el $59.5 \%$ es informal, mayor al promedio nacional de 49.0\% (Departamento Administrativo Nacional de Estadística, 2014, p.2). En la ciudad de Villavicencio, los gobiernos municipales no han prestado mucha atención a la problemática de la informalidad. Los planes de desarrollo previos a 2008 apenas mencionaban la informalidad. El Plan de Desarrollo Municipal periodo 2008-2011 "Villavicencio ciudad decente de Colombia" enfrentó el tema con la recuperación del espacio público "de la informalidad a la formalidad". Básicamente es una medida coyuntural de tipo policiva, que no ayuda a mitigar el crecimiento de la informalidad. La pregunta de

corriente trata de reanudar la corriente estructuralista. De ese modo, incorpora una preocupación sistemática por la concepción y la ejecución de estrategias y políticas que posibiliten el equilibrio entre la inserción activa en los mercados exteriores y una mayor autonomía nacional. Procura preservar los equilibrios macroeconómicos y vela por la coordinación entre el corto y largo plazo, la concertación entre los sectores público y privado, y la construcción de una estructura productiva local, que implica mayor igualdad en la distribución" (Berthomieu, Ehrhart, \& Hernández-Bielma, 2005, p.27). 
la investigación es ¿cómo incide la estructura económica de la ciudad de Villavicencio en su economía informal? Para responder a este interrogante se tomaran en cuenta los enfoques estructuralista y neoestructuralista, los cuales señalan a la estructura económica como factor decisivo en la persistencia de la informalidad.

Las limitaciones de la investigación se encuentran en la información obtenida de las cuentas departamentales, base de datos del Departamento Administrativo Nacional de Estadística -DANE-, la cual se presenta para actividades económicas por departamento y no las requeridas por ciudades. Sin embargo son una buena aproximación a la situación de Villavicencio, porque la ciudad alberga el $50 \%$ de la población departamental.

El objetivo general de la investigación es caracterizar la economía informal en Villavicencio mediante un análisis de la estructura productiva a partir de un enfoque neoestructuralista. Los objetivos específicos son: Elaborar un marco teórico y conceptual de la informalidad; describir la estructura productiva en Villavicencio y su influencia en el empleo informal; y caracterizar el empleo informal en Villavicencio.

Se pretende analizar los determinantes de la informalidad en Villavicencio desde una visión crítica al enfoque neoestructuralista en su análisis dualista. El método utilizado es el deductivo, por cuanto a partir de teorías se constituye el marco referencial para entender la economía informal en Villavicencio. Se contrasta el enfoque neoestructural para explicar en parte el origen de la informalidad en Villavicencio.

Para realizar el primer objetivo se tomarán fuentes secundarias publicadas en textos de economía y estudios sobre la informalidad en Villavicencio. Como tipo de información se tomaron teorías o investigaciones que guían los elementos teóricos de la investigación. Una característica del marco teórico tiene que ver 
con la posición epistemológica, por tanto se utilizaron los elementos teóricos del enfoque neoestructural de pensamiento económico, para explicar el empleo informal en Villavicencio.

Para el cumplimiento del segundo objetivo se tomaron fuentes secundarias publicadas por el DANE, la Gobernación del Meta, Alcaldía de Villavicencio y demás entidades públicas y privadas del orden nacional, departamental y municipal que describen la evolución de la estructura productiva en Villavicencio.

Como soporte básico de trabajo se tomaron los resultados de la encuesta continua de hogares del DANE. Los datos recolectados por el DANE del sector informal se ajustaron a la definición y al objeto de la presente investigación. En el periodo de 2008 y 2012 se utilizó la Gran Encuesta Integrada de Hogares -GEIH. Esta información es el insumo para alimentar un modelo probit con variables de tipo estructural, para hallar los determinantes de la informalidad.

El avance en el campo respectivo está determinado por el reconocimiento explícito de los factores estructurales que involucran la existencia de la informalidad. Mientras los países con mayor adelanto tecnológico asocian la mayor productividad a la industria, no ocurre en América Latina, donde la mayor productividad se encuentra en los recursos naturales. El departamento del Meta no es la excepción; la producción agropecuaria y de minas y canteras, aportan el $35 \%$ de la productividad estructural, con el agravante que estos sectores expulsan mano de obra, y causan que las condiciones laborales se deterioren, originado por la transferencia de mano de obra a sectores menos productivos como comercio, restaurante y hoteles. Sin embargo recientemente una actividad se destaca por su poca productividad y fuerte atracción de mano de obra, los servicios financieros.

Su aplicación en el área investigada es identificar una problemática que influye significativamente en el nivel de las personas, el empleo informal, con la 
perspectiva de buscar un desarrollo que involucre el bienestar de la población, desde un punto de vista humano fundado en la dignidad, la justicia y la solidaridad.

La teoría neoestructuralista le confiere a la informalidad, el resultante de condiciones estructurales propias de América Latina, asociadas a la calificación de los trabajadores, la organización de los procesos de producción, la composición sectorial y la estructura del mercado.

Con el ánimo de ampliar el conocimiento de la economía informal, este trabajo pretende caracterizar la economía informal en Villavicencio mediante un análisis de la estructura productiva, e identificar otros factores asociados al fenómeno. En el primer capítulo se elabora un marco teórico y conceptual de la economía informal, el segundo capítulo presenta la estructura productiva del Meta y Villavicencio, el tercer capítulo asocia el empleo informal y el neoestructuralismo y el cuarto capítulo presenta un modelo probit para los determinantes de la informalidad en Villavicencio.

El avance en el tema de la informalidad se evidencia comparando el análisis del pensamiento neoestructuralista en el tema del empleo informal dentro del contexto de la ciudad de Villavicencio. Es un paso para reforzar la teoría. 


\section{MARCO TEÓRICO- MARCO CONCEPTUAL - ESTADO DEL ARTE:}

\subsection{ASPECTOS CONCEPTUALES}

Desde el inicio, la economía informal tuvo diferentes denominaciones: sector informal, economía subterránea, empleo informal, trabajo informal. En el seno de la Organización Mundial del Trabajo -OIT-, los informes le otorgaban diversos nombres. En América Latina el término de la informalidad se acuña a partir del estudio sobre Accra en Ghana elaborado por K. Hart y posteriormente consagrado en el informe de la "Misión Kenya" del programa mundial del empleo de la OIT, en la década de los setenta. En los años 70, el Programa Regional para el Empleo en América Latina -PREALC-, adscrito a la OIT introdujo y popularizó el término de economía informal.

Para Castells y Portes la informalidad es entendida no como un concepto individual, sino uno que surge de la institucionalidad. Es "un proceso de generación de ingreso caracterizado por un hecho central: su no regulación por instituciones sociales en un contexto social y legal donde actividades similares si lo están" (Castells \& Portes, 1989, p.15). 
Ramírez define como empresa informal a "la que se encuentra por debajo de ciertos parámetros en el empleo generado, en el valor de los activos o en el monto de ventas, el empresario es también trabajador y se descartan aquellas que por capital o conocimiento desde el principio operan en mercados formales". Señala que puede hablarse de microempresas cuando hay una cierta estabilidad y potencial de acumulación (Ramírez Guerrero, 1996, p.12).

Para Pérez Sainz no es necesario mantener el concepto de informalidad y se debería hablar de neoinformalidad. Un concepto que se redefine en un nuevo contexto formado por dos escenarios: el primero es el de bienes comercializables insertos en la globalización y el otro escenario se encuentra excluido en la dinámica económica (Pérez Sainz, 1995. p.37)

Gallart en el 2002 señaló el aporte que hace Tokman y Klein, cuando analizaron la evolución del concepto desde el nacimiento del término en Ghana, hasta la literatura reciente. La autora consideró que para Tokman y Klein la discusión se ha centrado en relacionar el concepto con su capacidad de cubrir el autoempleo, su codependencia con el sector formal, y su participación en los cambios en la economía y el mercado de trabajo. La informalidad es considerada desde su posición marginal, como receptora del excedente laboral en la ciudad. Los procesos de transformación sucedidos en los ochenta y noventa por el proceso de globalización, trajeron consigo disminución en el empleo público y por razones de competitividad, la desregulación en el sector moderno de la economía. Lo anterior condujo a una flexibilización en las actividades económicas y en el mercado laboral, que fortaleció a la economía informal (Gallart, 2003, p.6).

En la 90ª Reunión de LA OIT (2002), se comenzó a nombrar preferentemente el término de "economía informal" en vez de "sector informal", ampliándose el término al análisis ocupacional y abarcando más situaciones en el campo empresarial, tomándose tanto el enfoque de la "unidad productiva" como el de 
"las ocupaciones", a diferencia del criterio tradicional, centrado en la primera. La OIT caracteriza la situación de los trabajadores y empresarios informales así: (Organización Internacional del Trabajo, 2002, p.3):

- No están reconocidos por la ley y, por consiguiente, reciben poca o ninguna protección jurídica o social.

- $\quad$ Es raro que puedan organizar una representación eficaz o hacer oír su voz para que se reconozca y proteja su trabajo.

- Su acceso a la infraestructura y a las subvenciones públicas es limitado o Inexistente.

- $\quad$ El porcentaje de pobres que trabajan en el sector informal es mucho más alto que el de los que trabajan en la economía formal, y la proporción de mujeres pobres que trabajan en la economía informal es superior a la de los hombres pobres

- Hay actividades delictivas como el tráfico de drogas, el tráfico de personas y el blanqueo de dinero

- Impide aprovechar las oportunidades para adquirir y mantener calificaciones profesionales mediante métodos innovadores, así como aprendizaje y formación en el empleo.

- $\quad$ Ingresos muy bajos e irregulares.

El empleo informal definido por la OIT es una relación de trabajo, de derecho o de hecho, no está sujeta a la legislación laboral nacional, al impuesto sobre la renta, a la protección social o a determinadas prestaciones relacionadas con el empleo (preaviso al despido, indemnización por despido, vacaciones anuales pagadas, o licencia pagada por enfermedad, etc.) (Organización Internacional del Trabajo, 2003, p.99).

La XV resolución del CIET-Conferencia Internacional de Estadísticos del Trabajo-, describió el sector informal como "un conjunto de unidades dedicadas a la producción de bienes y o la prestación de servicios, con la finalidad primordial de 
crear empleos y generar ingresos para las personas que participan en esta actividad..." A su vez, la unidad económica para medir la informalidad es la "unidad de producción", definida como "toda unidad que participa en la producción de bienes y la prestación de servicios" (Trejo, 2003, p.131).

Schneider presentó una clasificación de la informalidad bajo las categorías de transacción ilícita o no y monetaria o no. La taxonomía también involucra la evasión de impuestos (Tabla 1).

Tabla 1. Taxonomía de la economía informal

\begin{tabular}{|c|c|c|c|c|}
\hline & \multicolumn{2}{|c|}{ Transacción monetaria } & \multicolumn{2}{c|}{ Transacción no monetaria } \\
\hline $\begin{array}{c}\text { Actividad } \\
\text { ilícita }\end{array}$ & $\begin{array}{c}\text { Contrabando, producción y } \\
\text { tráfico de drogas, comercio de } \\
\text { bienes robados, trata de bancas, } \\
\text { etc. }\end{array}$ & \multicolumn{2}{|c|}{$\begin{array}{c}\text { Trueque de drogas, bienes } \\
\text { robados, contrabando, etc. }\end{array}$} \\
\hline & $\begin{array}{c}\text { Evasión de } \\
\text { impuestos }\end{array}$ & $\begin{array}{c}\text { Elusión de } \\
\text { impuestos }\end{array}$ & $\begin{array}{c}\text { Evasión de } \\
\text { impuestos }\end{array}$ & $\begin{array}{c}\text { Elusión de } \\
\text { impuestos }\end{array}$ \\
\cline { 2 - 5 } $\begin{array}{c}\text { Ingreso propio } \\
\text { Actividad } \\
\text { lícita } \\
\text { seportado: } \\
\text { salarios, } \\
\text { sueldos y } \\
\text { ganancias } \\
\text { relacionadas a } \\
\text { producción y } \\
\text { prestación de } \\
\text { servicios } \\
\text { legales }\end{array}$ & $\begin{array}{c}\text { Descuentos a } \\
\text { ganpleados, } \\
\text { mancias al }\end{array}$ & $\begin{array}{c}\text { Trueque de } \\
\text { servicios y } \\
\text { bienes } \\
\text { producidos } \\
\text { legalmente. }\end{array}$ & $\begin{array}{c}\text { Trabajo cuenta } \\
\text { propia y } \\
\text { colaboración } \\
\text { entre vecinos. }\end{array}$ \\
& & & & \\
\hline
\end{tabular}

Fuente: Schneider F. (2002, p.4).

Lourdes Beneria dice que para definir la informalidad, se debe identificar primero el trabajo no informal como el empleo registrado, las actividades criminales, el trabajo doméstico, agropecuario y trabajo en organizaciones filantrópicas. Si se incluyen estos datos, se haría doble contabilización en el sector informal. (Beneria, 2006, p.9). 
En los últimos años, investigadores junto con la OIT han trabajado para ampliar el concepto del "Sector informal" incorporando ciertos tipos de empleo informal que no se incluyeron en la anterior definición. Se amplía el enfoque para incluir no sólo las empresas que no están regulados por la ley, sino también las relaciones de empleo que no están legalmente regulados o protegidos. Esta nueva definición de la «Economía informal» tiene en cuenta la naturaleza del empleo y las características de las empresas. Se incluye el empleo no registrado dentro de la agricultura. Atendiendo a lo anterior Martha Chen define de una manera ampliada la informalidad como "el empleo sin trabajo, ni protección social, tanto dentro como fuera de las empresas informales, incluyendo tanto el auto-empleo en las pequeñas empresas no registradas y el empleo asalariado en empleos no registrados" (Chen, 2007, p.2) .

En América Latina a partir de 1975 se detectó su importancia, pero se requería llegar a un consenso acerca de la definición, en consecuencia, muchos esfuerzos han sido dirigidos a esa finalidad. Hoy, después de 40 años, no existe un acuerdo al respecto. Esto demuestra la importancia y la complejidad del fenómeno. Los estudios de informalidad de la OIT en América Latina se basan en las encuestas de hogares y de trabajo elaboradas por los institutos de estadística de cada país.

En Colombia, el Departamento Administrativo Nacional de Estadística -DANEanaliza el comportamiento del trabajo informal a través de la Gran Encuesta Integrada de Hogares. La definición de economía informal del estudio se basa en la desarrollada por el DANE. Esta identifica la naturaleza de los trabajadores informales así: 1. A los empleados y obreros, el patrono y/o socio de unidades productivas que ocupan hasta 5 personas. 2. Los familiares sin remuneración. 3. las personas que laboran sin remuneración en empresas o negocios de otros hogares. 4. Los empleados domésticos. 5. Los por cuenta propia no profesionales. 6. Los patronos o empleadores de unidades productivas de 10 personas. Define a los establecimientos como "unidad económica en donde se 
ejerce una actividad productiva, cualquiera que sea el ritmo de producción (a tiempo completo o parcial, continua o temporal) o el tipo de local usado (taller, en la vía pública, en el hogar, etc.)" (Departamento Administrativo Nacional de Estadística, 2009, p.6). La definición de economía informal de este estudio se basa en la desarrollada por el DANE.

"La definición adoptada por el DANE para la medición del empleo informal, se remite a la resolución 15a de la OIT de 1993 y a las recomendaciones del grupo de DELHI. Estas indican que la aproximación a la medición de informalidad en materia de escala de personal ocupado en las empresas, debe ser de hasta cinco trabajadores excluyendo los independientes que se dedican a su oficio y a los empleados del gobierno" (Departamento Administrativo Nacional de Estadística, 2009).

\subsection{ASPECTOS TEÓRICOS}

Si se considera la pobreza como un problema social y a su vez, se liga la informalidad con la pobreza, es plausible apuntar los orígenes primigenios del estudio de la informalidad en la escuela de Chicago. Nacida en los años 20, la escuela postuló que el proceso de urbanismo es originado del proceso de industrialización. En el siglo XX comenzó la urbanización a gran escala y se presentó un fenómeno proclamado por la escuela, grupos de personas que se aíslan social y económicamente. Se estudia su reproducción y la manera de incorporar estos grupos a la modernidad.

En este punto nació el concepto de dualismo económico que representa dos tipos de comunidades, uno moderno e integrado a la corriente económica y otro aislado y marginado a esta dinámica. Según Consuelo Corredor "la llamada teoría de la marginalidad, que acompañó la sociología en América Latina en los años 60, así 
como la llamada teoría de la informalidad beben en las fuentes de la escuela de Chicago y heredan su metodología" (Corredor,1998,p.9).

La teoría de la marginalidad en América Latina es asociada inicialmente con el concepto de subdesarrollo y una caracteriza del mismo es la existencia de dos sectores, el moderno y el tradicional. La teoría de la marginalidad enseñaba el subdesarrollo como causa del atraso y aislamiento. La receta era simple; Intensificar el capitalismo para desarrollar la economía y esto a su vez integraría los grupos marginales al avance social. En los años 70 los países latinoamericanos avanzaron, sus economías crecieron, sin embargo los grupos marginales no se integraron.

Se percibe que esta teoría no es suficiente para explicar la pobreza. En la década del 70 , en el análisis "se produce un principio de traslape del sector marginal con el informal" (Delfino, 2012, p.28) y se busca explicar la pobreza desde otros enfoques y a principios de los setenta surgen los estudios del empleo informal con la OIT en Kenya y PREALC.

El concepto de informalidad nace con base en una idea de estructura económica dualista, y se manifiesta en un mercado de trabajo segmentado. Por una parte se encuentra un mercado laboral altamente productivo, moderno, y facilitador de los procesos desarrollo social, denominado economía o sector informal, mientras su contraparte, es un mercado laboral atrasado, rezagado del circuito económico, poco capacitado y con relaciones laborales en contra de la dignidad del trabajador.

Y para resolver el problema de la informalidad se busca formalizar a los informales. No se estudia, ni se evalúa a los formales, ni la relación de los formales con los informales o de los informales con la estructura económica en general. Esta concepción dualista y su tratamiento es heredada del enfoque de la 
escuela de Chicago. Este solo visualiza como problema al grupo segregado y busca integrarlos al circuito económico, pero no cuestiona al grupo integrado.

Esta visión de la sociedad se extienda hasta hoy. La ley de los informales busca formalizar a los informales, pero no se establecen leyes antimonopolio que son impedimentos al nacimiento o prosperidad de negocios pequeños.

Según Tokman el primer trabajo de economía informal en América Latina sobre el sector informal lo hizo el brasileño Paul Singer, quien lo denomino "autonómo", le siguieron Aníbal Pinto y Sigmund Slawinsky, con base en la decisión de empresas de mayor productividad y menor productividad (Tokman, 2004).

Como se observa la inclusión del estudio de la economía informal es reciente en el desarrollo de las teorías económicas, y dado que hace parte del mercado de trabajo, se analizará inicialmente los aportes de las escuelas de pensamiento económico al análisis del mercado laboral y después se penetra a la informalidad.

La corriente neoclásica se distingue por el razonamiento abstracto y poco interés en instituciones, cultura e historia de las sociedades. Entre las principales hipótesis se encuentran: los bienes, servicios y los trabajadores son móviles y pueden desplazarse entre sectores de la economía; los trabajadores y empleadores tienen información asimétrica sobre el funcionamiento del mercado y eligen frente entre múltiples alternativas para maximizar su bienestar. Los agentes tienen recursos y la posibilidad de elegir, por tanto escogen entre sustituto o complementarios, entre trabajar o permanecer ociosos. Entre la oferta y la demanda de productos y factores se alcanza el precio de equilibrio, el cual se traduce en el mercado de trabajo en el salario de equilibrio. El salario y el nivel de empleo se determinan a través del sistema de precios y el equilibro entre la oferta y la demanda, de la misma manera para cualquier mercado de productos y 
factores. El empleador y empleado se relacionan con el salario, y no reconocen el trabajo por cuenta propia o informalidad. Entre sus principales representantes se encuentran: C.Menger, Wieser y Von Baje (Neffa, 2007).

Los neomarxistas como Portes, Castells y Benton consideran a los informales como "asalariados encubiertos" y conforman el excedente de mano de obra, disponible para atender los sectores modernos y disminuir los costos salariales. La relación entre formales e informales se hace mediante la subcontratación, y es un regreso al capitalismo clásico (Núñez Castrejón \& Gómez Chiñas, 2008,). El exceso de reglamentación para la formalización y permanencia, conlleva a los agentes a evitar la formalidad.

En los años 80 se concibió la economía informal como un fenómeno favorecido por el Estado, debido a la falta de regulación del mercado laboral en perjuicio de la clase trabajadora. Esto lo perciben Castells y Portes, y es consignado en su definición de economía informal, como “... un proceso de generación de ingreso caracterizado por un hecho central: su no regulación por instituciones sociales en un contexto social y legal donde actividades similares sí lo están", además, según estos autores, el mercado informal crece bajo la complicidad del Estado, la "...informalización no es un proceso que se desarrolla fuera del horizonte estatal, por el contrario, constituye una nueva forma de control caracterizada por la desregulación de un amplio sector de la clase obrera, a menudo con la benevolencia del Estado" (Castells y Portes, 1989, p. 20).

Los estudios de informalidad de la OIT en América Latina se sustentan en las encuestas de hogares y de trabajo elaboradas por los institutos de estadística de cada país. En Colombia la fuente para analizar el comportamiento del trabajo informal es la Gran Encuesta Integrada de Hogares elaborada por el Departamento Administrativo Nacional de Estadística. 
A partir del 2002, la tendencia principal de los estudios es identificar la informalidad como expresión de la pobreza, recalcándose en los planes de desarrollo: Hacia un Estado Comunitario (2002-2006), Un Estado Comunitario: Desarrollo para Todos (2006-2010) y Prosperidad para Todos (2010-2014), siguiendo los lineamientos de los organismos internacionales: Banco Interamericano de Desarrollo -BID-, OIT y PREALC. Bajo ese esquema se han formulado las políticas públicas para atender la informalidad, de tal manera que esta posición oficial y predominante, soslaya la realidad y de ahí su persistencia en un medio, que requiere soluciones de mayor consistencia social.

Otro elemento para el análisis, es el efecto del desplazamiento, considerándose una de las causas de la informalidad; agregándole el componente de género, factor que incide en el grado de incremento en las actividades informales; acerca de esto, bien se refiere la Organización Panamericana de la Salud, "con la situación actual del desplazamiento forzado, disminuye la posibilidad de seguridad alimentaria de las familias, lo que obliga a los hombres y mujeres buscar fuentes de ingreso alternativas" (OPS, 2003, p.1).

En el 2007, en el libro "informalidad: escape y exclusión", el Banco Mundial intentó explicar la causa de la informalidad desde dos categorías; escape y exclusión. En el escape, el trabajador hace un análisis de costo/beneficio y optan por la informalidad porque obtienen beneficios que en algunas ocasiones no son pecuniarios como el manejo del tiempo. Los trabajadores que llegan excluidos a la informalidad, han buscado empleo en la economía formal, pero no han encontrado y se encuentran obligados a emplearse como informales.

Luis Armando Galvis muestra que la informalidad se asocia a las regiones donde se presente. En Colombia la informalidad es mayor en las ciudades que no se encuentran en el trapecio formado por Bogotá, Cali, Medellín y Bucaramanga (Galvis, 2012) 
En el 2014, Valenzuela agrega que además de la economía formal e informal, existe la economía ilegal y hace notar que las normas y controles del Estado para acabar con la informalidad, favorecen las condiciones para desplazarse de la informalidad al crimen, deteriorando las condiciones sociales.

\subsection{LA ECONOMÍA INFORMAL Y SU RELACIÓN CON LA ESCUELA NEOESTRUCTURALISTA}

El estudio de la economía informal encuentra en la teoría aunque reciente, un gran avance para entender el fenómeno. La escuela estructuralista abordó el estudio de la economía informal y asoció en la década del setenta, la informalidad con el desempleo y la pobreza como el punto esencial para entender el problema del empleo y del funcionamiento de los mercados de trabajo en América Latina. Para conocer la importancia de la economía informal como generadora de empleo, es necesario conocer las características y la naturaleza de sus interrelaciones. Se consideró que el crecimiento de la informalidad es acelerado, frente a una poca capacidad de intervención para su reducción.

La teoría estructuralista latinoamericana o cepalina, entre 1950 y 1990 se basó en buscar la industrialización y reformas para reducir la desigualdad, políticas de desarrollo y ajustes macroeconómicos. En este marco y específicamente, dentro de un sentido de desigualdad, se remarca la heterogeneidad estructural ${ }^{2}$. Aníbal Pinto quien es uno de los primeros en manejar el concepto, diferencia dos sectores por su productividad, "enclaves" con complejo exportador, asociados a las economía primario-exportadora de América Latina o banana republics y el "resto", primitivo, cuyo ingreso por habitante es parecido o inferior al de la

\footnotetext{
${ }^{2}$ Diferentes formas productivas y relaciones sociales coexistentes el mismo tiempo y en el mismo lugar e interdependientes entre sí, dentro de un desarrollo periférico.

3 Empresas extranjeras o nacionales que se ubican en países subdesarrollados para explotar recursos.
} 
economía colonial (Pinto, 1970, p.83). Esto sentó bases para asociar la informalidad con los sectores rezagados de baja productividad.

La informalidad desde la óptica de Raúl Prebisch, representante del enfoque estructuralista, es explicada como un fenómeno conflictivo del desarrollo, una cuestión del centro periferia, dado que el mercado en el capitalismo periférico no controla la acumulación de capital, y la distribución del ingreso, de allí surge la exclusión para los estratos inferiores de ingreso. Las grandes empresas tienen su sede principal en el centro, y no reinvierten el excedente en la periferia. La mayor apropiación del excedente por parte de los propietarios de las fuerzas productivas, produce una "ineficacia social", incremento del excedente que no representa mayor productividad, porque no permite maximizar el potencial de acumulación al no formar parte del ingreso de la fuerza de trabajo, para fomentar la mayor producción, dinamizar el crecimiento de la economía y generar empleo, que este a la par del crecimiento de la fuerza de trabajo (Prebisch, 1978).

Expuesto por los estructuralistas, el modelo de desarrollo para los países latinoamericanos proponía mediante la sustitución de importaciones, crear una base productiva capaz de satisfacer la demanda interna y resolver el problema de heterogeneidad en las economías, representada por sectores modernos con tecnología de punta, frente a sectores atrasados que no gozan de adelantos técnicos y ofrece pocas garantías laborales a la mano de obra.

Con la crisis de deuda y bajo crecimiento económico de los ochenta de Latinoamérica, se consideró que el modelo "sustitución de importaciones" producto de la escuela estructuralista se agotó. Lamentable si se tienen en cuenta que antes del mencionado periodo y gracias al modelo hasta la fecha, las economías nacionales transformaron la estructura productiva y lograron niveles satisfactorios de crecimiento. A comienzos de los noventa surgió una renovación de la teoría cepalina que propuso una nueva receta, la transformación productiva 
con equidad, y reinserción al mercado mundial con mayor competitividad. A esta nueva mirada se le denominó neoestructuralismo.

Sin embargo, en los ochenta los países tuvieron que enfrentarse a una desaceleración económica que trajo consigo altos niveles de deuda externa, hiperinflación y disminución del ingreso. Era claro para los teóricos de la economía que era necesario plantear una nueva propuesta que involucre las nuevas tendencias de la economía.

En el horizonte del comercio mundial escollaban cuatro países de Asia. Los cuatro tigres asiáticos Corea del Sur, Singapur, Taiwán y Hong Kong, mostraban resultados económicos sorprendentes frente a su contraparte de América del Sur. Su tasa de crecimiento alcanzaba los dos dígitos y se disminuyó significativamente el desempleo. El milagro económico se originó en una economía dirigida a aumentar la participación de las exportaciones en el mercado mundial, con base en niveles de educación más elevados, mayor productividad y competitividad que impulsó las exportaciones de productos industriales. Esta elevada productividad se sustenta en el factor humano y el capital. Se combinó una tasa de fertilidad creciente con políticas dirigidas a fortalecer la educación, en sus primeros años especialmente y después los niveles superiores.

Como respuesta, en América Latina surgen críticos al modelo estructuralista de sustitución de importaciones, porque no integra productivamente la fuerza de trabajo creciente, en consecuencia el acceso a los bienes de primera necesidad son limitados para la población (Rosales, 1988).

Aparecen nuevas propuestas dirigidas a integrar la economía latinoamericana en el contexto mundial, mediante el aumento del nivel de exportaciones manufactureras. La industria manufacturera es considerada el sector moderno de la economía y es necesaria una transformación laboral que involucre traslado de 
la población de los sectores más atrasados al sector manufacturero. La reinserción al mercado mundial debe estar acompañada de altos niveles de productividad, sustentado en los cambios tecnológicos que viven una transformación acelerada gracias a las nuevas tecnologías de la información. Los sectores con mayores adelantos tecnológicos deben ser los mayores receptores de la mano de obra, para que exista homogeneización en la economía y especialmente en la mano de obra.

Dentro de este contexto surgen dos teóricos a establecer paradigmas en el análisis de la informalidad. El primero resalta los factores estructurales que inciden en la creación y permanencia de la informalidad; algunos representantes son PREALC y Víctor Tokman, y el segundo responsabiliza al Estado dado que sus múltiples normas jurídicas desalientan a los empresarios a formalizarse; el principal representante es De Soto.

Los nuevos acontecimientos económicos dan origen a que la Comisión Económica para América Latina y el Caribe -CEPAL- presté especial atención a los llamados de los teóricos a replantear la forma en que América Latina concibe el crecimiento económico, y de la mano de Fajnzylber en 1991 se publicó el libro. "Transformación productiva con equidad", en donde se concibe como condición para alcanzar el éxito económico una nueva inserción en el mercado mundial, jalonado por la productividad y competitividad. Se considera a la competitividad como fórmula para aumentar la participación regional en el mercado mundial e incrementar el nivel de vida de la población. Así mismo, para alcanzar la competitividad es necesario el progreso tecnológico, mediante una mayor inversión a los departamentos de investigación y desarrollo de las empresas.

Dos factores igualan los sectores, la fuerza de trabajo y el capital. La movilidad del factor trabajo solo es posible con políticas educativas que aumenten la cobertura y la calidad de la educación. Los neoestructuralistas le otorgan a la 
educación el doble poder de influir en la transformación productiva y el crecimiento con equidad. Algunos teóricos como Ffrench-Davis consideraron que para avanzar hacia el desarrollo, es necesario impulsar políticas macroeconómicas que alienten la educación y capacitación laboral, la cual en América Latina se encuentra muy rezagada en el contexto mundial (FfrenchDavis, 1988, p.40). De hecho, la educación se considera uno de los mayores obstáculos para que exista homogenización en el mercado laboral.

La CEPAL con Fajnzylber como impulsador de este nuevo modelo, propuso que la inserción requiere de apertura de la economía con eliminación de aranceles para favorecer la importación e implantar un tipo de cambio estable y alto para fomentar las exportaciones. En efecto en 1991, Colombia se preparó la economía frente a la apertura con un tipo de cambio estable y alto con el propósito de impulsar las exportaciones, pero la productividad, condición importante para ingresar con éxito al mercado mundial, no se desarrolló previamente, por tanto el país no se preparó debidamente para enfrentar la competencia externa que inundaría posteriormente con bienes el mercado nacional. Se resalta que mientras la competitividad es el eje de la integración internacional, que impulsaría a los pueblos de América Latina a un mayor crecimiento económico, no se habla con el mismo interés de los factores sociales que implicarían una mejor distribución del ingreso.

En los planes de desarrollo siguientes en Colombia, se incluyó el término "productividad" como piedra filosofal para aumentar el nivel de competitividad que posibilitaría al país competir triunfalmente en el concierto mundial.

Fajnzylber consideró que la competitividad internacional favorece la equidad del país y por vía de la difusión industrial y políticas públicas, se estimula con asistencia técnica, financiera y capacitación, la asociación social para la producción, coadyuvando a la formalización de empleo (Fajnzylber, 2006). 
Osvaldo Sunkel, uno de los primeros dentro de la nueva visión en hablar explícitamente del "sector informal", entendía a las política públicas como una herramienta fundamental para dirigir los esfuerzos de reformas sociales e innovaciones estructurales con el propósito de inyectar inversión hacia actividades con alta demanda de empleo, y garantizar el flujo de ingresos a los más desprotegidos (Sunkel, 1991).

El pensador neoestructuralista que más ha aportado al análisis del empleo informal es Víctor Tokman. Como director del Programa de empleo para América Latina y el Caribe -PREALC-, adjunto a la OIT, "Tokman en 1987 propuso una política de apoyo al sector informal donde contempla algunas acciones necesarias para su incorporación al sector moderno, entre ellas, hacer más eficaz la intervención del Estado y mejorar por esa vía los ingresos de los grupos más pobres de la población. En sus estudios más actuales, promueve esencialmente las mismas alternativas sobre la integración del sector informal y profundiza en la estrategia de modificación del marco regulador que facilite la incorporación de los informales a la modernidad" (Núñez Castrejón \& Gómez Chiñas, 2008, p.138)

Tokman muestra que existe una fuerte heterogeneidad entre el sector informal y formal, lo que se evidencia en la diferencia entre los ingresos, como reflejo de la cualificación de las personas y las características de la estructura productiva. La heterogeneidad estructural, y abundante mano de obra, conllevan a que la gente pobre acuda a la informalidad como alternativa de sobrevivencia. Las condiciones de pobreza y desempleo se mitigan, a consta de poco desarrollo laboral y aumento de la mala distribución del ingreso (Tokman, 2004).

Después de las voces triunfalistas que presagiaban la inserción exitosa y convergencia hacia los países desarrollados, la CEPAL realizó un balance de la transformación productiva, iniciada en los noventa. Se concluyó que las transformaciones estructurales son pocas; la desigualdad en la distribución del 
ingreso persiste, el crecimiento de la inversión no alcanza para llegar al 5\% del crecimiento económico. La diversificación exportadora no es suficiente para acabar con la independencia de las exportaciones tradicionales y primarias. No existe irrigación de mayor conocimiento a todas las actividades económicas. También señaló que la mano de obra del sector agrícola ha disminuido con respecto al sector industrial y los servicios, lo que se acompaña con aumento del desempleo urbano y la informalidad. Pero no todo es malo, la CEPAL señala que la disciplina fiscal ha disminuido la injerencia de los distorsiones de los mercados externos a las economías latinoamericanas, han mermado los niveles de deuda externa, se ha incrementado la inversión extranjera, la participación de las exportaciones en el mercado mundial y la democracia. (Comisión Económica para América Latina y el Caribe, 2008).

En la tabla 2 se muestra resumido los principales autores del neoestructuralismo y su pensamiento con respecto al empleo informal.

Tabla 2. Autores neoestructurales e informalidad

\begin{tabular}{|c|c|}
\hline Autor & Aporte \\
\hline $\begin{array}{l}\text { Fernando Fajnzylber } \\
\text { Una visión renovadora } \\
\text { del desarrollo de América } \\
\text { Latina (2006) }\end{array}$ & $\begin{array}{l}\text { La competitividad internacional favorece la equidad del } \\
\text { país y por vía de la difusión industrial y políticas públicas, } \\
\text { se estimula con asistencia técnica, financiera y } \\
\text { capacitación, la asociación social para la producción, } \\
\text { coadyuvando a la formalización de empleo. }\end{array}$ \\
\hline $\begin{array}{l}\text { Osvaldo Sunkel } \\
\text { Del desarrollo hacia } \\
\text { adentro al desarrollo } \\
\text { desde dentro (1991) }\end{array}$ & $\begin{array}{l}\text { Entendía a la política pública como una herramienta } \\
\text { fundamental para dirigir los esfuerzos de reformas } \\
\text { sociales e innovaciones estructurales con el propósito de } \\
\text { inyectar inversión hacia actividades con alta demanda de } \\
\text { empleo, y garantizar el flujo de ingresos a los más } \\
\text { desprotegidos. }\end{array}$ \\
\hline $\begin{array}{l}\text { Víctor Tokman } \\
\text { De la informalidad a la } \\
\text { modernidad (2001) }\end{array}$ & $\begin{array}{l}\text { ensador neoestructuralista que más ha aportado al } \\
\text { lisis del empleo informal. La considera resultante de } \\
\text { escentralización, los cambios de la producción y el } \\
\text { ajo a nivel mundial. Muestra que existe una fuerte } \\
\text { rogeneidad entre el sector informal y formal. }\end{array}$ \\
\hline $\begin{array}{l}\text { Ffrench-Davis } \\
\text { Empleo decente }\end{array}$ & $\begin{array}{l}\text { Para avanzar hacia el desarrollo, es necesario impulsar } \\
\text { políticas macroeconómicas que alienten la educación y }\end{array}$ \\
\hline
\end{tabular}




\begin{tabular}{|c|c|}
\hline $\begin{array}{l}\text { estabilidad } \\
\text { macroeconòmica } \\
(2011)\end{array}$ & $\begin{array}{l}\text { capacitación laboral, motivos por los cuales América } \\
\text { Latina se encuentra muy rezagada en el contexto } \\
\text { mundial. }\end{array}$ \\
\hline $\begin{array}{l}\text { Osvaldo Rosales } \\
\text { Comercio internacional y } \\
\text { desarrollo inclusivo: } \\
\text { construyendo sinergias } \\
\text { (2013) }\end{array}$ & $\begin{array}{l}\text { Los bajos salarios y la "precariedad respecto de los } \\
\text { contratos de trabajo y las prestaciones sociales" están } \\
\text { unidos a la informalidad. }\end{array}$ \\
\hline $\begin{array}{l}\text { José Antonio } \\
\text { Ocampo } \\
\text { Luces y sombras de las } \\
\text { reformas estructurales de } \\
\text { lationamerica (2003) }\end{array}$ & $\begin{array}{l}\text { Amplía el tipo de inmigración e indica que la migración } \\
\text { internacional de mano de obra influye en la informalidad. } \\
\text { El afianzamiento de empresas de clase mundial } \\
\text { incrementó el dualismo y coincidió con el aumento de la } \\
\text { informalidad, }\end{array}$ \\
\hline $\begin{array}{l}\text { Nora Lustig } \\
\text { Los grandes problemas } \\
\text { de México: crecimiento } \\
\text { económico y equidad } \\
(2010)\end{array}$ & $\begin{array}{l}\text { informalidad ha crecido, a la par que la participación } \\
\text { las mujeres debido a la disminución de los ingresos de } \\
\text { ros miembros del hogar. }\end{array}$ \\
\hline $\begin{array}{l}\text { José Luis Machinea } \\
\text { Palabras del señor José } \\
\text { Luis Machinea, secretario } \\
\text { ejecutivo de la Cepal en } \\
\text { la inauguración del } \\
\text { trigésimo periodo de } \\
\text { sesiones (2004) }\end{array}$ & $\begin{array}{l}\text { Considera que la informalidad es un espacio donde se } \\
\text { resuelve la necesidad de subsistencia, especialmente la } \\
\text { mujer. Propone políticas de intervención activas para } \\
\text { igualar las reglas del "campo de juegos" entre las } \\
\text { empresas grandes, pequeñas e informales (Machinea, } \\
\text { 2004). }\end{array}$ \\
\hline $\begin{array}{llr}\text { Jorge Katz } & & \\
\text { Tecnologías } & \text { de la } \\
\text { Información } & \text { y } \quad \text { la } \\
\text { comunicación } & & \text { e } \\
\text { industriales } & \text { culturales } \\
\text { (2006) } & & \end{array}$ & $\begin{array}{l}\text { Estima que el mercado informal tiene una "oferta casi } \\
\text { ilimitada de bienes y/o servicios a precios de } \\
\text { subsistencia" (Katz, 2006, p.25) y las barreras de } \\
\text { ingresos son distintas entre los formales e informales y } \\
\text { esto condiciona su modelo de organización. }\end{array}$ \\
\hline $\begin{array}{l}\text { Mario Cimoli } \\
\text { Annalisa Primi } \\
\text { Mauricio Pugno } \\
\text { Un modelo de } \\
\text { bajo:crecimiento: la } \\
\text { informalidad con } \\
\text { restricción estructur }\end{array}$ & $\begin{array}{l}\text { sentan "la persistencia de la informalidad como una } \\
\text { era estructural para el crecimiento" (Cimoli, Primi, \& } \\
\text { no, 2006, p.89) }\end{array}$ \\
\hline
\end{tabular}

Fuente: Elaboración propia

Con base en la crítica al pobre desempeño de las economías latinoamericanas en los noventas y en un contexto de economía abierta, el pensamiento neoestructuralista busca un crecimiento económico y desarrollo mediante el fortalecimiento de la capacidad productiva y la innovación. Este desarrollo debe transformarse en dos objetivos claves en el pensamiento estructuralista y que 
permanecen en el neoestructuralismo, el crecimiento de largo plazo y la justicia social. Para alcanzar ambos se debe manejar con especial atención el mercado laboral y su principal problemática, la informalidad. La informalidad es entendida como una resultante de una economía dual y heterogénea, en donde empresas organizadas y altamente competitivas coexisten con negocios cuya estructura es rezagada en adelantos tecnológicos y administrativos. 


\section{EL EMPLEO INFORMAL Y EL NEOESTRUCTURALISMO}

Según Bielschowsky, la visión neoestructuralista tiene como base los enfoques estructuralista y shumpeteriano ${ }^{4}$. Tres tipos de análisis se resaltan en la nueva visión: la primera son críticas del efecto las reformas sobre los procesos productivos realizadas por Jorge Katz, la segunda son las relaciones entre el crecimiento económico de los países en vías de desarrollo y los cambios en la estructura productiva desarrollado por José Antonio Ocampo, y la última destaca la influencia del comercio exterior sobre el crecimiento sostenido a mediano y largo plazo; de este análisis se destaca el libro Progreso técnico y Cambio estructural de la CEPAL (Bielschowsky, 2009).

El libro Progreso técnico y Cambio estructural de la CEPAL, incluye un capítulo que muestra el análisis de la estructura productiva y heterogeneidad desarrollado por Hubert Escaith. Se presenta un modelo dual que muestra los efectos de la dinámica de la estructura productiva sobre la productividad laboral. Modelo inicialmente desarrollado por Arthur Lewis en 1954 (Caribeño y premio nobel de economía) y según Neffa, el precursor del concepto de empleo o trabajo informal

\footnotetext{
${ }^{4}$ En el sentido amplio de innovación de Shumpeter que incluye nuevas actividades económicas y nuevas maneras de producir las existentes (Bielschowsky).
} 
(Neffa, 2008). El modelo condiciona la superación de la heterogeneidad estructural para alcanzar el desarrollo. En una economía abierta, el sector moderno usa tecnología de frontera y los precios son competitivos internacionalmente.

El ingreso total de la economía se representa con $Y=Y_{1}+Y_{2}$ Ecuación1 en el cual $Y$ es el PIB total, $Y_{1}$ el valor agregado del sector 1 e $Y_{2}$ el valor agregado del sector 2 .

La fuerza de trabajo empleada es $L=L_{1}+L_{2}, L_{1}=L$ a fuerza de trabajo en el sector 1 y $L_{2}=$ la fuerza de trabajo en el sector 2 .

En cualquier momento del tiempo $t=T$, se tiene: $P^{\top}=Y^{\top} / L^{\top}=\left[\left(Y_{1}{ }^{\top} / L_{1}{ }^{\top}\right) \cdot\left(L_{1}{ }^{\top} / L^{\top}\right)\right]+\left[\left(Y_{2}^{\top} / L_{2}{ }^{\top}\right) \cdot\left(L_{2}{ }^{\top} / L^{\top}\right)\right]$ Ecuación 2

La ecuación 2 muestra que la productividad media del trabajador está conformada por la suma de agregado sectorial por empleado ponderado por la participación de cada sector en el empleo total.

Ello puede escribirse así: $\mathrm{P}_{\mathrm{T}}=\mathrm{P}_{1}{ }^{\top} \mathrm{S}_{1}{ }^{\top}+\mathrm{P}_{2}^{\top} \mathrm{S}_{2}^{\top}$ Ecuación 3 donde $P_{i}^{\top}$ es el valor agregado por persona empleada en el sector $i(i=1,2)$ en el instante $t=T$ y $S_{i}^{\top}$ es la participación del sector $i(i=1,2)$ en la población activa total empleada en $\mathrm{t}=\mathrm{T}$.

El modelo supone que los sectores productivos alcancen un mínimo nivel de competitividad: $\left[\mathrm{P}_{1}{ }^{\top} \mathrm{S}_{1}{ }^{\top}+\mathrm{P}_{2}{ }^{\top} \mathrm{S}_{2}{ }^{\top}\right] \geq \mathrm{S}_{\mathrm{m}}{ }^{*}$ Ecuación 4.

En este el conjunto de la economía supera el umbral para la competitividad $\left(S_{m}{ }^{*}\right)$

El gráfico 1 muestra un sector $\mathrm{S} 1$ (tradicional) y un sector S2 (moderno). Se supone que inicialmente la economía se encuentra en el punto $A$ y pasa al punto $B$, por un cambio estructural. Para mantenerse competitiva internacionalmente se 
requiere que la economía se mantenga en un punto donde $\mathrm{P}_{2}{ }^{\top}$ es mayor a $\mathrm{P}_{1}{ }^{\top}$.

Gráfico 1. Productividad y composición en la fuerza de trabajo en un modelo dualista.

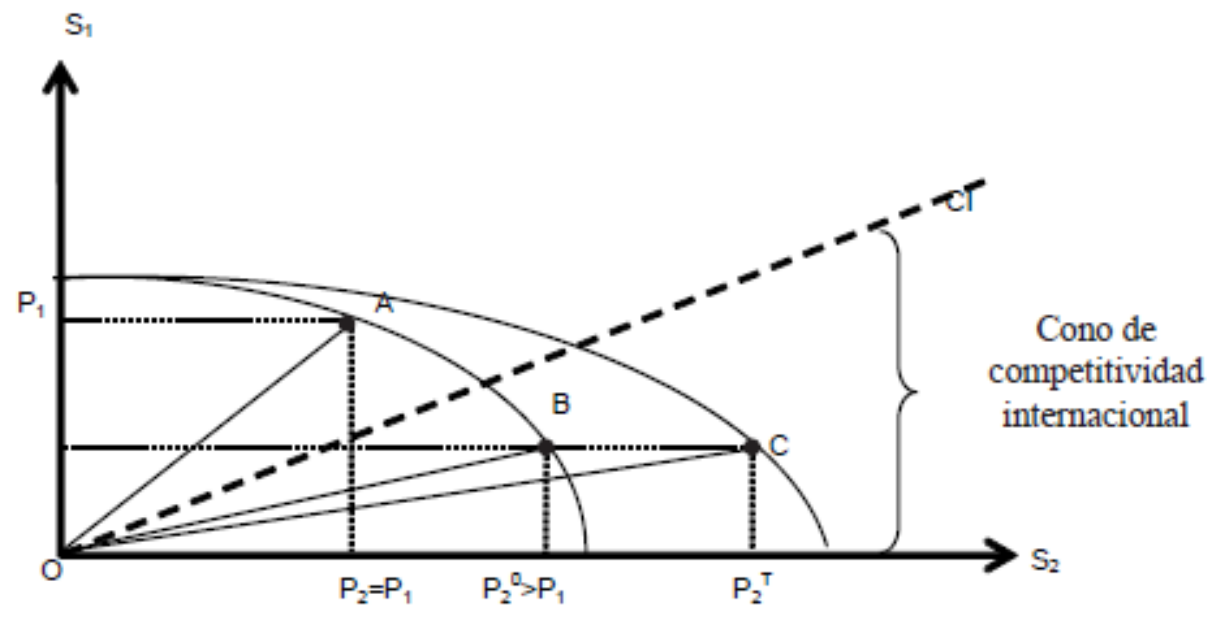

Fuente: Progreso técnico y cambio estructural en América Latina. CEPAL

Partiendo de la ecuación $\mathrm{P}_{\mathrm{T}}=\mathrm{P}_{1}{ }^{\top} \mathrm{S}_{1}{ }^{\top}+\mathrm{P}_{2}{ }^{\top} \mathrm{S}_{2}{ }^{\top}$ Ecuación 5, si se supone que no existe progreso tecnológico en el sector tradicional $\mathrm{P}_{1}{ }^{\top}-\mathrm{P}_{1}{ }^{0}$ $=0$, la variación de $\mathrm{P}^{\mathrm{t}}$ entre $\mathrm{t}=0 \mathrm{yt}=\mathrm{T}$ se descompone obteniendo en el primer término la variación productiva del trabajo como resultado a los cambios en la productividad intrínseca de los $n$ sectores. El segundo término muestra el cambio sectorial en la fuerza de trabajo. Con la anterior fórmula se calculan las variaciones de la productividad total y sus componentes sectoriales en Colombia entre 1960 y 2003 (Tabla 3).

Tabla 3. Valor agregado por empleado en Colombia, 1960 y 2003 (En miles de dólares a precios de 2000)

\begin{tabular}{c|c|c|c|c|c|c|c|c|c|c|c}
\hline & \multicolumn{1}{c}{ Valor agregado por empleado, años seleccionados } & \multicolumn{5}{c}{ Tasa de crecimiento anual } \\
\cline { 2 - 12 } & 1960 & 1970 & 1980 & 1990 & 2000 & 2003 & $\begin{array}{c}1960- \\
2003\end{array}$ & $\begin{array}{c}1960- \\
1970\end{array}$ & $\begin{array}{c}1970- \\
1980\end{array}$ & $\begin{array}{c}1990- \\
1990-\end{array}$ & $\begin{array}{c}1900 \\
2000\end{array}$ \\
\hline Colombia & 3.5 & 4.4 & 5.2 & 5.5 & 6.0 & 5.9 & 1.2 & 2.2 & 1.7 & 0.6 & 0.8 \\
\hline
\end{tabular}

Fuente: Progreso técnico y cambio estructural en América Latina. CEPAL. Con base en el Anuario Estadístico de la Comisión Económica para América Latina y el Caribe. 
El valor agregado por empleado en Colombia aumentó entre 1960 y 2000 cuando pasó la productividad laboral por empleado de 3.500 dólares a 6.000 dólares. En el periodo de 1960-2003, Colombia tiene un crecimiento absoluto del valor agregado de $1.2 \%$ anual. Con las reformas estructurales como la apertura económica que abarató los bienes de capital, se incrementó la inversión y el aparato productivo; se esperaba un aumento en la productividad laboral. No obstante, la tasa de crecimiento del valor agregado de la mano de obra decayó a 0.8 entre 1990 y 2000.

El aumento de la productividad media por trabajador en Colombia entre 1960 y 2003 es de 57 dólares. El efecto de la recomposición estructural en la variación total del producto por empleado explicó apenas el $28 \%$ del cambio promedio en la productividad del trabajo (Tabla 4). En América Latina, 58 dólares es el aumento de la productividad media entre 1960 y 2003, pero a diferencia de Colombia, la recomposición estructural es el principal componente que influye en la productividad laboral (Cepal, 2007).

El modelo de Lewis se consolida cuando la reasignación de la fuerza de trabajo desde el sector agrícola aporta al incremento de la productividad laboral. En Colombia este sector no es moderno, por tanto la pérdida de empleos en el agro se traduce en un incremento del $32 \%$ de la productividad total. Su productividad intrínseca aportó un $17.5 \%$, del incremento total. La manufactura, sector moderno en el modelo de Lewis, aportó un $16 \%$ del aumento de productividad promedio, resultante de un incremento de un 19\% del incremento de su productividad intrínseca. La industria manufacturera no ha generado bastantes puestos de empleo, por tanto se ha reducido su aporte en $3 \%$ al aumento de la productividad laboral. Es insuficiente su contribución al incremento de la productividad, si se tienen en cuenta que este sector debe jalonar el crecimiento económico. 
Tabla 4. Variación anual y descomposición de la productividad laboral, promedio 1960-2003 (Valores en dólares de 2000)

\begin{tabular}{|l|c|c|c|}
\hline \multirow{2}{*}{ Total PIB } & \multicolumn{3}{|c|}{ Colombia } \\
\cline { 2 - 4 } & $\begin{array}{c}\text { Productividad } \\
\text { Total }\end{array}$ & $\begin{array}{c}\text { Productividad } \\
\text { Intrínseca }\end{array}$ & $\begin{array}{c}\text { Productividad } \\
\text { Estructural }\end{array}$ \\
\hline Agricultura & 57 & 40 & 16 \\
\hline Minas y canteras & -8 & 10 & -18 \\
\hline Industria manufacturera & 6 & 5 & 1 \\
\hline Servicios básicos & 9 & 11 & -2 \\
\hline Construcción & 4 & 5 & 0 \\
\hline $\begin{array}{l}\text { Comercio, restaurantes y } \\
\text { hoteles }\end{array}$ & 4 & 2 & 1 \\
\hline $\begin{array}{l}\text { transporte y } \\
\text { comunicaciones }\end{array}$ & 4 & -21 & 25 \\
\hline Servicios financieros & 17 & 2 & 2 \\
\hline Servicios sociales & 17 & 15 & 2 \\
\hline
\end{tabular}

Fuente: Progreso técnico y cambio estructural en América Latina. CEPAL.

Los sectores que más participaron en el aumento de la productividad media son los financieros y servicios sociales con $29 \%$ cada uno y proviene casi totalmente de la productividad intrínseca. Denota un ascenso importante en el aumento del valor agregado por puesto de trabajo, pero ha disminuido su participación en la estructura del empleo. La variación de la productividad intrínseca es positiva y predomina, lo que se traduce en un acercamiento a la frontera productiva, mientras la reasignación de trabajo es poca.

Lewis consideraba que la informalidad es excedente, mano de obra que no es ocupada por el sector moderno. El autor consideraba que cuando crece el sector moderno por inversión de sus ganancias, atrae recursos productivos del sector atrasado al moderno y se contrae el empleo en el sector atrasado, el cual puede ser asimilado a la economía informal, porque las actividades se realizan con

\footnotetext{
${ }^{5}$ La productividad intrínseca es productividad interna relativa a los propios procesos. Esta tiene que ver con el valor agregado por puestos de trabajo. Diferente de la estructural, que muestra las variaciones en cantidad de los puestos de trabajo entre actividades económicas.
} 
escaso capital y poca productividad. A pesar que la industria manufacturera ha crecido, ha perdido productividad estructural, es decir, disminuyó su participación en el empleo frente a otros sectores; por consiguiente la mano de obra no ubicada en la manufactura, se desplaza a sectores atrasados y con más probabilidad de ser informal.

A su vez se cumple el análisis de Raúl Prebisch cuando consideró que la poca capacidad del sector secundario para absorber mano de obra se traduce en una terciarización ${ }^{6}$ de la estructura del empleo (Gutiérrez, 2008). Klein y Tokman señalaron que dada la incapacidad de los sectores modernos de emplear la creciente mano de obra, esta se desplaza al sector informal (Klein \& Tokman, 2000). Precisamente el mayor desplazamiento de la mano de obra en Colombia se presentó hacia el sector comercio, restaurante y hoteles, que mostró un decrecimiento en el valor agregado de la mano de obra.

Cuando se compara a Colombia con otros países, con reciente industrialización como Corea, se observa la necesidad de impulsar la manufactura. Mientras Corea, en los años cincuenta con ingresos inferiores a Colombia, logró un rápido crecimiento en el empleo en la industria manufacturera con un promedio de $8.3 \%$ por año entre 1960 y 1990, catapultándolo como uno de las economías más sólidas del mundo, Colombia presentó un pobre desempeño en el crecimiento del producto y en el empleo de la industria manufacturera (Maldonado, 2010).

La participación del sector industrial con respecto al PIB ha disminuido. Entre 1970 y 1975 fue de 22.6\%, mientras en el 2010 es de 14.3\% (Departamento Administrativo Nacional de Estadísticas, 2011, p.5). Según la Asociación Nacional de Industriales -ANDI- la industria creció en 5.9\% de 2010 a 2011 (ANDI, 2012, p.1), pero el aporte al empleo disminuyó, "en términos de empleo, el $75 \%$ de las

\footnotetext{
6 Implica que la población es más numerosa en el sector terciario (comercio, transporte, comunicaciones, finanzas, turismo, ocio, administración pública y servicios públicos; y disminuye en el sector secundario (artesanía, industria, construcción, minería y obtención de energía).
} 
ramas manufactureras vinculó en el año 2011 menos trabajadores que en 2007 y el 65\% de las mismas ocupó menos empleados que en el año 2008" (La nota digital.com, 2012, p.1). Recientemente la evolución de la manufactura no es favorable. En el último trimestre de 2012 se presentó una caída en la producción industrial. Luis Carlos Villegas, presidente de la Asociación Nacional de Industriales -ANDI- , anunció que entre las causas se encuentra la revaluación del peso y condiciones de baja competitividad. Recomienda la "Agenda de competitividad" y considera establecer tasas de interés competitivas internacionalmente y mejorar la infraestructura de transporte para reducir costos de producción (Lesmes, 2013). Un formula que combina mecanismos monetarios y estructurales.

Los sectores de alta tecnología son incapaces de absorber la creciente mano de obra, por consiguiente esta se ocupa en el sector informal, considerado de baja productividad. Según el DANE, la tasa de informalidad en Colombia es de $49.0 \%$ en el 2013. (DANE, 2014). A lo anterior se suma que la competitividad en Colombia es muy baja. El informe del Foro Económico Mundial realizado en Cartagena en el 2010, señaló que el país ocupó el puesto 68 entre 139 países analizados. La encuesta de percepción realizada por el Foro a líderes mundiales, mostró que la corrupción y la carga tributaria son los principales obstáculos para alcanzar la anhelada competitividad que inserte al país exitosamente en el comercio mundial.

En el informe no se señalan la productividad de la mano de obra. Tampoco hace referencia a las variaciones en la calidad de empleo que implique una mejora en el nivel de vida de las personas. Existe una tendencia en los organismos internacionales a ignorar el bienestar de la población e incluso "la felicidad" y satisfacción laboral como causa de competitividad. Los análisis son pensados en búsqueda de la mayor ganancia posible e ignoran la mano de obra, como el factor más preciado porque es el aporte de seres humanos a la producción. No se 
considera la explotación como factor importante para ampliar el margen de ganancia.

La CEPAL relaciona la mano de obra con la eficiencia productiva. No son los únicos, de hecho en la XII Conferencia de las Naciones Unidas sobre Comercio y Desarrollo se presentó la siguiente información "La Inversión Extranjera Directa orientada a las exportaciones, centrada por lo general en las zonas industriales francas, ha contribuido al crecimiento de muchos países. Este tipo de inversión está destinada a la búsqueda de eficiencia, pero suele depender de la existencia de mano de obra barata y contar con el respaldo de preferencias comerciales" (Organización de las Naciones Unidas, 2008, p.3).

Como se observa, en este caso la búsqueda de eficiencia es interpretada como la capacidad de disminuir costos a través de la mano de obra barata que bien puede interpretarse en alguna medida como informal, porque los empleadores evitan asumir los costos de pensión, salud y riesgos profesionales; pero en ningún momento se toca la ganancia de los capitalistas, que bien podría ser también una manera de reducir costos. "El mercado financiero tiene una tasa de ganancia del $25 \%$ en el 2011, el mercado minero, y construcción y turismo tienen una tasa de ganancia del $20 \%$ y $15 \%$ respectivamente" (Ladino, 2012, p.9). Si se compara el crecimiento de la tasa de ganancia con el sueldo mínimo en $5.8 \%$ en el 2011 , los sueldos cada vez tienen menos participación en la distribución de la producción. El libro denominado "La transformación productiva, 20 años después. Viejos problemas, nuevas oportunidades", originado en el trigésimo segundo periodo de sesiones de la CEPAL en el 2008, señala con respecto al mercado laboral en Colombia los siguientes hechos (CEPAL, 2008):

- La productividad de los factores aumentó cuando las empresas exportaron.

- La inversión extranjera buscó mano de obra barata

- La transferencia de conocimiento tecnológico es débil.

- Colombia se encuentra en una etapa de convergencia que conlleva a mayor 
desarrollo tecnológico con un nivel de infraestructura mediano, pero poca calificación de la mano de obra e innovación. Los mercados de convergencia en Colombia son alimentos, bebidas y electricidad.

- El país ha incursionado con trasnacional o "translatina" en el mercado de gasoducto.

- Entre 2002 y 2004, Colombia tuvo inversión en investigación y desarrollo de $0.17 \%$ del PIB, uno de los porcentajes más pequeños en el mundo.

El país cada vez depende más de actividades con explotación de recursos naturales, en donde en su mayoría están presentes empresas internacionales, con tecnología propia y transfieren muy poco de esta a las economías nacionales. No despegan los sectores intensivos en tecnología.

También señala el libro que en general en América Latina la mayor parte del empleo se ha generado en el comercio, el cual alberga como "refugio" la mano de obra excedente del sector moderno, pero es empleo de baja calidad y en muchos casos es informal o autoempleo. También resalta el estancamiento de la economía latinoamericana frente a la economía asiática. Básicamente se pronostica el mejoramiento en la calidad de vida en China e India en términos de ingresos, pero no menciona el estilo de vida deplorable que tienen los trabajadores chinos quienes trabajan hasta 120 horas extras por mes, sufren de despidos injustificados y salarios muy bajos. En promedio un trabajador Chino recibe menos que un trabajador colombiano y es de los que peores salarios tienen (Ramirez, 2012, p.1). En el tema sectorial, en Asia, el crecimiento de la industria ha mejorado la productividad y la demanda laboral.

El análisis neoestructuralista señala que la mejora tecnológica influye positivamente en la demanda laboral y es factor determinante de la inserción de las economías latinoamericanas al mercado mundial. Según Alex Maldonado "en la década de los noventa, Colombia implementó un nuevo modelo de desarrollo 
económico basado en la internacionalización y de apertura de la economía, y paralelamente inició un programa de estabilización macroeconómica y de reforma estructural $^{7}$, que generó profundos cambios en el comportamiento y la reestructuración productiva de la industria manufacturera. El modelo se implementó ante la necesidad de modernizar la estructura productiva, dinamizar el nuevo proceso de industrialización, restablecer la dinámica del cambio estructural y reactivar el crecimiento estable y sostenible de la economía" (Maldonado, 2010).

Se esperaba que la mayor internacionalización trajera consigo cambios positivos para la industrialización. Los resultados no coincidieron con las expectativas. "La agricultura y la industria sufrieron los rigores de la competencia internacional y la ausencia de políticas sectoriales y macroeconómicas consistentes. La participación de estos sectores se redujo ostensiblemente durante la década de los noventa, mientras que el sector minero y no transable se expandían rápidamente. La participación de los sectores agrícola e industrial en el empleo total no es predominante, mientras el sector servicios absorbe cerca del $60 \%$ de la fuerza de trabajo colombiana" (Centro de Investigaciones para el Desarrollo, 2003, p. 45).

Similar comportamiento presenta el departamento del Meta. Se destaca que las actividades agropecuarias descendieron mientras la minería creció de manera consistente. La transformación de la estructura de forma comparativa se observa en la tabla 5.

\footnotetext{
7 "Las reformas estructurales a lo largo de la década de los noventas comprendieron las siguientes políticas: liberalización de importaciones, liberalización del mercado cambiario y adopción del sistema de bandas, liberalización de la cuenta de capitales, independencia del Banco de la República, descentralización fiscal, administrativa y política, flexibilización laboral, reforma al sistema de seguridad social en pensiones y salud, sucesivas reformas tributarias, reforma al sistema educativo, y reducción del tamaño y redefinición de las funciones del Estado". (Maldonado, 2010)
} 
Tabla 5. Composición sectorial y crecimiento del PIB en Meta.

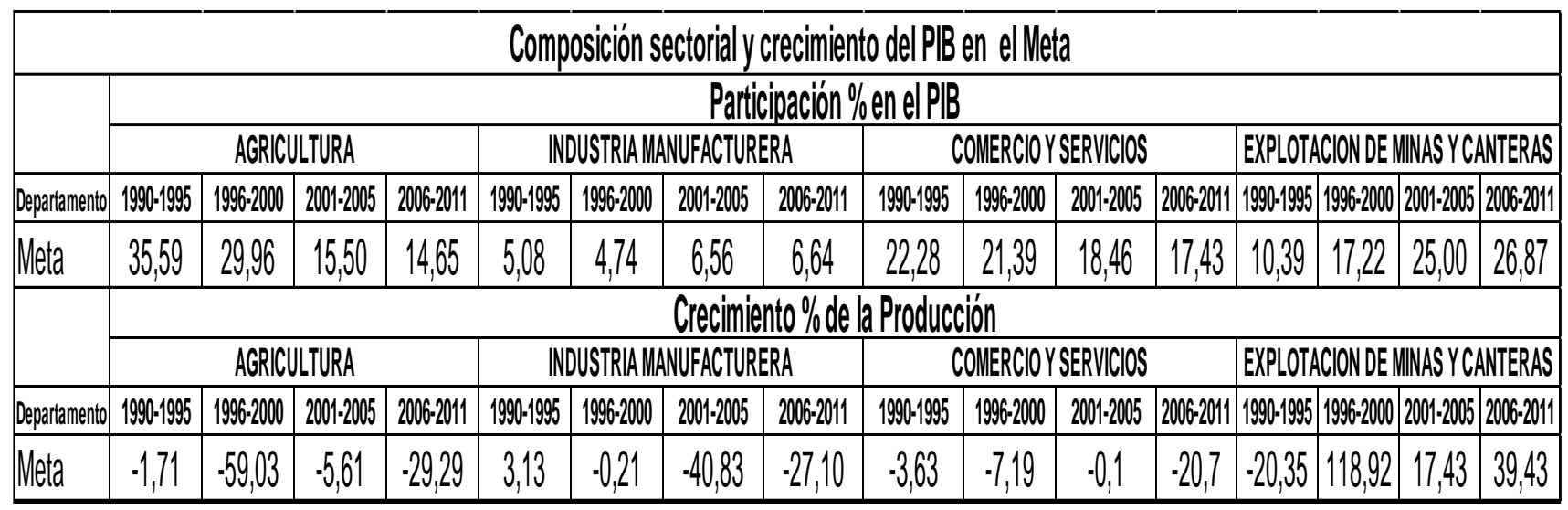

Fuente: Cálculos propios con base en Cuentas departamentales del DANE.

La composición sectorial muestra que la agricultura ha disminuido su participación desde 1990 en $20 \%$. Es más notoria la caída en la producción, la cual se aceleró en el último quinquenio de los noventa. La participación de la industria manufacturera ha sido estable, no así mismo los niveles de producción cuya disminución es significativa en el presente siglo.

El sector comercio y servicios muestra una caída leve en su participación en el departamento y disminución importante de la producción, particularmente a partir del 2006. El comportamiento de la participación en el PIB de los sectores en mención se debe en conjunto al crecimiento de la explotación de minas y canteras, cuyo crecimiento se ha acelerado en los últimos años; al contrario en Villavicencio la explotación de minas y canteras ha disminuido y acelerado la caída de producción a partir del 2009.

Retomando el esquema analítico de Hubert Escaith, la ecuación $P^{\top}=Y^{\top} / L^{\top}=[(Y$ $\left.\left.{ }_{1}^{\top} / L_{1}{ }^{\top}\right) \cdot\left(L_{1}{ }^{\top} / L^{\top}\right)\right]+\left[\left(Y_{2}^{\top} / L_{2}{ }^{\top}\right) \cdot\left(L_{2}{ }^{\top} / L^{\top}\right)\right]$ Ecuación 6

se calcula los cambios en la productividad Intrínseca ${ }^{8}$ de los $n$ sectores y el cambio sectorial en la fuerza de trabajo en la ciudad de Villavicencio. Se pretende verificar desde la recomposición estructural de la fuerza de trabajo, la condición 
para alcanzar el desarrollo según la teoría estructuralista, es decir, pasar de una economía agrícola a una estructura económica diversificada en varios sectores, en donde sobresale el sector moderno que es tipificado por la industria manufacturera, circunstancia que según la teoría neoestructuralista en un contexto de apertura económica, es necesaria en la reconversión para la competitividad internacional.

Tomando el valor agregado del departamento del Meta y la población ocupada en Villavicencio entre 2000 y 2012, se calcula la descomposición de la productividad laboral. La recomposición de la fuerza de trabajo explicó el $40 \%$ del cambio promedio en la productividad del trabajo ${ }^{9}$ (Tabla 6).

Tabla

6. Descomposición

de

la

productividad

laboral promedio

\begin{tabular}{|l|c|c|c|}
\hline \multicolumn{4}{|c|}{$\begin{array}{c}\text { DESCOMPOSICIÓN DE LA PRODUCTIVIDAD LABORAL } \\
\text { PROMEDIO 2000-2012. En pesos }\end{array}$} \\
\hline & $\begin{array}{c}\text { Productividad } \\
\text { Intrínseca }\end{array}$ & $\begin{array}{c}\text { Productividad } \\
\text { estructural }\end{array}$ & $\begin{array}{c}\text { Productividad } \\
\text { total }\end{array}$ \\
\hline Agropecuario & $1.153 .317,2$ & $-1.076 .755,0$ & $76.562,2$ \\
\hline Minas y canteras & $495.539,2$ & $-105.493,3$ & $390.045,8$ \\
\hline Industria manufacturera & $192.199,8$ & $-201.986,6$ & $-9.786,8$ \\
\hline Electricidad, agua y gas & $551.503,8$ & $-468.295,7$ & $83.208,0$ \\
\hline Construcción & $1.881 .119,5$ & $1.403 .592,3$ & $3.284 .711,8$ \\
\hline $\begin{array}{l}\text { Comercio, restaurante y } \\
\text { hoteles }\end{array}$ & $-974.043,8$ & $85.405,5$ & $-888.638,3$ \\
\hline Transporte y comunicaciones & $514.494,6$ & $884.586,5$ & $1.399 .081,0$ \\
\hline Servicios financieros & $-1.430 .200,5$ & $1.866 .374,3$ & $436.173,8$ \\
\hline Servicios del gobierno & $437.184,9$ & $-509.031,2$ & $-71.846,3$ \\
\hline Total PIB & $2.821 .114,6$ & $1.878 .396,7$ & $4.699 .511,3$ \\
\hline
\end{tabular}

Fuente: Cálculos propios con base en Cuentas departamentales del DANE.

${ }^{9}$ La productividad del trabajo es el valor agregado por empleado en pesos. 
El mayor crecimiento del valor agregado por empleado se encuentra en la construcción con $\$ 1.881 .119,5$. La industria manufacturera creció en promedio $\$ 192.199,8$. En productividad estructural por cada trabajador que ha expulsado el sector agropecuario ha perdido $\$ 1.76 .755$. En la tabla 7 se muestra la participación de la productividad laboral de cada sector en productividad total.

Tabla 7. Participación de la productividad laboral en Villavicencio

\begin{tabular}{|l|c|c|c|}
\hline \multicolumn{4}{|c|}{$\begin{array}{c}\text { PARTICIPACIÓN DE LA PRODUCTIVIDAD LABORAL DE CADA } \\
\text { SECTOR EN PRODUCTIVIDAD TOTAL. Promedio 2000-2012 }\end{array}$} \\
\hline & $\begin{array}{c}\text { Productividad } \\
\text { Intrínseca }\end{array}$ & $\begin{array}{c}\text { Productividad } \\
\text { estructural }\end{array}$ & $\begin{array}{c}\text { Productividad } \\
\text { total }\end{array}$ \\
\hline Agropecuario & $24,54 \%$ & $-22,91 \%$ & $1,63 \%$ \\
\hline Minas y canteras & $10,54 \%$ & $-2,24 \%$ & $8,30 \%$ \\
\hline Industria manufacturera & $4,09 \%$ & $-4,30 \%$ & $-0,21 \%$ \\
\hline Electricidad, agua y gas & $11,74 \%$ & $-9,96 \%$ & $1,77 \%$ \\
\hline Construcción & $40,03 \%$ & $29,87 \%$ & $69,89 \%$ \\
\hline $\begin{array}{l}\text { Comercio, restaurante y } \\
\text { hoteles }\end{array}$ & $-20,73 \%$ & $1,82 \%$ & $-18,91 \%$ \\
\hline $\begin{array}{l}\text { Transporte y } \\
\text { comunicaciones }\end{array}$ & $10,95 \%$ & $18,82 \%$ & $29,77 \%$ \\
\hline Servicios financieros & $-30,43 \%$ & $39,71 \%$ & $9,28 \%$ \\
\hline Servicios del gobierno & $9,30 \%$ & $-10,83 \%$ & $-1,53 \%$ \\
\hline Total PIB & $60,03 \%$ & $39,97 \%$ & $100,00 \%$ \\
\hline
\end{tabular}

Fuente: Cálculos propios con base en Cuentas departamentales del DANE.

El modelo de Lewis se fortalece en el caso de Villavicencio. El sector agropecuario aportó a la productividad laboral un 22,9\% por la reubicación de la fuerza laboral e implica una reasignación de la fuerza de trabajo a sectores más productivos, mientras su productividad laboral se incrementó y aporta un $24.5 \%$. La industria manufacturera, considerado el sector moderno, aumenta su productividad intrínseca en $4.09 \%$, pero merma la productividad total en $0.21 \%$, proveniente de una caída de su productividad estructural en $4.3 \%$, e indica que lejos de atraer los empleos necesarios para jalonar la economía, está expulsando 
mano de obra. En el modelo de Lewis no existe desempleo, por tanto la mano de obra expulsada en Villavicencio del sector moderno, se ocupa en el sector informal. El fácil desplazamiento de la mano de obra de un sector a otro facilita el traslado hacia la informalidad.

Cimoli señala que "La progresiva erosión de la capacidad de absorber empleo que ha mostrado el sector formal manufacturero ha aumentado el desempleo y ha nutrido al sector informal urbano, que ha ido absorbiendo la fuerza de trabajo residual" (Cimoli, Primi, \& Pugno, 2006, p.92). Y la posibilidad de jalonar desarrollo se reduce, "....afectando adversamente las capacidades tecnológicas endógenas, reduciendo los encadenamientos internos y la capacidad de absorción de fuerza de trabajo del sector formal manufacturero y disminuyendo así la capacidad del mismo sector de actuar como vector del desarrollo de toda la economía" (p.92).

Agrega el autor. "En los Estados Unidos, los sectores intensivos en tecnología representan el $60 \%$ del valor agregado industrial, y muestran una alta productividad en comparación con los otros sectores de la economía. Eso no ocurre en América Latina, donde los sectores más productivos y que más contribuyen a la generación del valor agregado manufacturero total son los intensivos en recursos naturales" (Cimoli, et al, 2005, p.17). En Villavicencio, el $35 \%$ del valor agregado por empleado es aportado por la agricultura y minería. La industria manufacturera participa con un pobre $4.1 \%$ en el valor agregado por trabajador.

La construcción es la actividad económica que más aporta al crecimiento de la productividad total con un $70 \%$, debido principalmente al incremento de su productividad intrínseca, es decir, es la actividad que tiene mayor incremento de valor agregado por trabajador y es la segunda, después de los servicios 
financieros, que aporta más a la recomposición estructural. La mayor productividad estructural se encuentra en los servicios financieros con $40 \%$, es decir, ha incrementado significativamente su participación en el empleo local, pero pierde en productividad intrínseca con 30\%. También aporta significativamente comercio, transporte y comunicaciones con $20,4 \%$, es decir, los servicios atraen una importante cantidad de mano de obra.

Disminuyó la participación laboral de la agricultura, minas y canteras, la industria manufacturera, electricidad, gas y agua y servicios del gobierno. Pese a la caída de la participación del empleo público en el empleo total, es el segundo generador de empleo, después del comercio. Villavicencio y Pasto presentan los valores más altos de empleados públicos por habitante y altas tasas de informalidad (García Cruz, 2009). Aumentó la participación laboral del comercio y servicios, y presenta una productividad estructural que contribuye con el $60 \%$ de la productividad total, pero a su vez le resta a la misma productividad total un $40 \%$, como consecuencia de la caída en la productividad intrínseca. Esta actividad combina una fuerte atracción de mano de obra, pero generan poco valor agregado del mismo. El comercio y servicios multiplican el empleo de mala calidad o empleo informal.

Los datos de la informalidad en Villavicencio se obtienen de la Gran Encuesta Integrada de Hogares -GEIH- del DANE en el 2012 y Encuesta Nacional de Hogares en el 2000. La actividad con mayor número de informales en Villavicencio en el 2012 es el comercio y servicios con 84\%. En el 2000, el comercio y servicios aportaron el $67 \%$ de los informales. Ha crecido su participación en los informales, a la vez que ha disminuido el valor agregado del empleo en el sector. Se asocia el crecimiento de la informalidad con la disminución de la productividad laboral. El oficio más frecuente de los informales son vendedores y empleados de comercio, le sigue comerciantes y propietarios de comercio al por mayor y al por menor. Las actividades de comercio y servicios 
suman un $60,35 \%$ de productividad laboral y de productividad intrínseca se pierde $40,21 \%$, en total solo aportan a la productividad total de $20,14 \%$ (Tabla 8 ).

Tabla 8. Comercio y servicios y la productividad laboral

\begin{tabular}{|c|c|c|c|}
\hline & $\begin{array}{c}\text { Productividad } \\
\text { Intrinseca }\end{array}$ & $\begin{array}{c}\text { Productividad } \\
\text { estructural }\end{array}$ & $\begin{array}{c}\text { Productividad } \\
\text { total }\end{array}$ \\
\hline $\begin{array}{c}\text { Comercio,restaurante } \\
\text { y hoteles }\end{array}$ & $-20,73 \%$ & $1,82 \%$ & $-18,91 \%$ \\
\hline $\begin{array}{c}\text { Transporte y } \\
\text { comunicaciones }\end{array}$ & $10,95 \%$ & $18,82 \%$ & $29,77 \%$ \\
\hline Servicios financieros & $30,43 \%$ & $39,71 \%$ & $9,28 \%$ \\
\hline Servicios del gobierno & $9,30 \%$ & $-10,83 \%$ & $-1,53 \%$ \\
\hline Total & $-40,21 \%$ & $60,35 \%$ & $20,14 \%$ \\
\hline
\end{tabular}

Fuente: Cálculos propios

La industria manufacturera aportó el 10\% de los informales en el 2012 y en 2002 el $14 \%$, actividad que ha aumentado su productividad intrínseca y en concordancia es proveedora de empleos de buena calidad, por tanto es predecible que disminuya el número de informales que ejerzan esta actividad. Una mayor productividad intrínseca se relaciona con disminución en los empleos informales. Esto se puede verificar especialmente con la actividad de mayor productividad intrínseca en el periodo, la construcción, que en el 2012 participó con el $1.6 \%$ de los informales y en el 2002 con $5,25 \%$, es la mayor disminución de participación en la informalidad. Se presentan diferencias en las productividades laborales en las actividades económicas. Falló el intento de homogenizar la economía. 


\subsection{COMPARACIÓN DE LOS ENFOQUES DE LA ECONOMÍA INFORMAL DEL DANE, NEOESTRUCTURALISMO Y VICTOR TOKMAN}

Víctor Tokman, el neoestructuralista quién más aporta al análisis de la informalidad se destaca entre los suyos por su profusa producción en el tema y su rechazo como miembro del enfoque neoestructural (Tokman, 2004). Sin embargo, sus colegas lo asumen como neoestructural. En el Seminario "Políticas de empleo en Chile y América Latina" en honor a Víctor Tokman, realizado por la Organización Internacional del Trabajo, se señala su aporte al enfoque neoestructural. Para Tokman "los trabajadores informales no son un residuo o grupo marginal de la sociedad, sino un estrato que se desenvuelve en condiciones precarias, pero relacionado con otros sectores y que, con apoyo y políticas específicas, dispone de un potencial cierto de desarrollo" (p.15), a diferencia de la OIT que señala a los trabajadores como marginales, Tokman les confiere una posición funcional y de articulación en la economía.

Tokman coincide con los estructuralistas al considerar que el empleo está sujeto a la estructura económica. También presenta algunas divergencias con el neoestructuralismo, las cuales enriquecen el análisis de la informalidad. Teniendo en cuenta lo anterior, se compara la informalidad en Villavicencio (tomado de la Gran Encuesta Integrada de Hogares -GEIH- del DANE, 2012) con el pensamiento de Tokman y otros neoestructuralistas.

Para Tokman una fuente creciente de empleo informal, es la disminución del sector público, generador de empleo formal, que ha expulsado trabajadores, y no encuentran empleo formal en el sector privado, por tanto se ven forzados a trabajar de manera informal (Tokman, 2004). Los servicios del gobierno presentan pérdida estructural del $11 \%$. La pérdida de empleo en un sector generador de empleo formal como es el sector público, dentro de un mercado laboral dominado por la informalidad, confluye a engrosar el empleo informal. La 
Gran Encuesta Integrada de Hogares -GEIH- pregunta a los informales ¿en su empleo anterior usted era...?, en las respuestas, después de empleado de empresa particular y trabajador por cuenta propia, quienes más se trasladaron de un anterior empleo al actual, estaban en el sector público.

Según Tokman, la economía informal es creciente, "es difícil pensar que su incidencia en el empleo (economía informal) pueda retroceder al rango pre crisis de los años ochenta, en que abarcaba al $30 \%$. En la medida que no surjan respuestas nuevas desde el ángulo del empleo -y es difícil que existan-, seguirá presente una alta proporción de personas que trabajan por cuenta propia, en especial en una cultura que ha revalorizado el trabajo independiente. Asimismo, este fenómeno se encuentra asociado con las tendencia recientes a la disminución de las horas de trabajo y a la búsqueda de formas de ocupación más autónomas, que ya no sólo están presentes en los países más desarrollados, sino también en los de la región." (p.109).

Efectivamente la informalidad en Villavicencio ha permanecido por encima del pomedio. En el 2001 (el DANE incluyó por primera vez el módulo de informalidad) la tasa de informalidad fue de $71.7 \%$. Según Bielschowsky, en la etapa del pensamiento neoestructural, se afirma que la absorción de mano de obra por parte de los sectores con mayor productividad es insuficiente, mientras que el sector informal está atrayendo más mano de obra, lo que acentúa la heterogeneidad en la economía (Bielschowsky, 2009).

Al igual que lo señalado por Tokman y en general de los neoestructuralista, quienes sostienen que la mayoría de los informales son trabajadores independientes o cuenta propia, por ejemplo Ffrench-Davis muestra que en una encuesta de la OIT en cinco países de la región, entre estos Colombia, entre 2007 y 2009, mientras los empleos informales decrecieron, los cuenta propia informales incrementaron su participación en la fuerza laboral (Ffrench-Davis, 
2011), la mayor proporción de empleados informales en Villavicencio se encuentra entre trabajadores por cuenta propia con $65.4 \%$ y le sigue obreros 0 empleados de empresa particular con 15.2\% (tabla A.1) (en Colombia en el 2013, los empleados informales son 20.6\%). Este dato es similar a la informalidad en Colombia, en donde el trabajador por cuenta propia es $60 \%$ de los informales. La mayoría, el $28.7 \%$, trabaja en sitio local fijo, oficina o fábrica, le sigue en su vivienda $21.7 \%$. Tokman señala que el empleo por cuenta propia origina la reducción de horas de trabajo. En Villavicencio, en donde la mayoría de los informales trabajan por cuenta propia, el $63.4 \%$ trabaja hasta 48 horas semanales que es el horario máximo semanal por ley. El 36.6\% trabaja más de 48 horas semanales. El $22.8 \%$ trabaja hasta 24 horas semanales. En general se presenta la reducción de horas anunciada por Tokman. La informalidad se asocia al subempleo. En Villavicencio no se respalda tal asociación, en razón que el 83\% no quiere trabajar más horas, es decir, existe complacencia con la jornada laboral.

Tokman expresa que buena parte del origen de la informalidad se encuentra en la inmigración de mano de obra que proviene del campo a las ciudades, y no se ubica laboralmente (Tokman V. E., 2004). Ocampo amplía el tipo de inmigración e indica que la migración internacional de mano de obra influye en la informalidad (Ocampo J. , 2001, p. 3) . La ciudad aporta el $60.8 \%$ de los informales, migrantes de poblaciones del Meta y Bogotá el 40.2\%. "La población migrante está conformada en gran parte por desplazados, cuyas condiciones laborales no son aptas para las necesidades de la ciudad; esto reduce significativamente las oportunidades de empleo formal" (León Camargo \& Caicedo Mora, 2011, p.92). El mayor aporte a la informalidad proviene de la ciudad, pero es notoria la inserción de la población migrante al mercado informal, cuyas actividades en el sector comercio y servicios no exigen mayores competencias de los empleados.

Tokman advierte que las brechas de género presentadas en el sector formal, se 
reproducen en el sector informal, en tanto las mujeres desempeñan los puestos de trabajo más vulnerables (Tokman V. E., 2004). En Villavicencio, el 51.4\% de los informales son mujeres y el $48.6 \%$ son hombres. La mayor participación femenina puede encontrar su explicación en situaciones como la descrita por Nora Lustig. La autora estima que en México la informalidad ha crecido, a la par que la participación de las mujeres debido a la disminución de los ingresos de otros miembros del hogar (Lustig, 2010).

En Villavicencio, el $88.9 \%$ de la población informal se encuentra afiliada a salud, el $58.4 \%$ se encuentra en el régimen contributivo (EPS), el $34.4 \%$ es subsidiado, los otros se encuentran en otros regímenes. Algunos teóricos explican que la asistencia no contributiva en salud para los trabajadores alientan la informalidad (Perry et al, 2007, p.9). No es el caso de Villavicencio, en la ciudad la mayoría de informales están en régimen contributivo. El $37.1 \%$ de los informales dicen que el patrón paga todo a parte de la cotización y el $57.1 \%$ de informales la pagan toda. Al $42 \%$ le descuentan $\$ 25.000$ pesos mensuales o menos.

Mientras en salud, la mayoría de la población informal se encuentra afiliada, en pensión el $88.9 \%$ no cotiza y el $99 \%$ no está haciendo nada para tener recursos en la vejez. Es una carga onerosa a futuro para el Estado, porque deberá cubrir los gastos en salud y sostenimiento que esta población acarreará en la ancianidad.

La consideración anterior apoya el pensamiento de Tokman, cuando afirma que los empleados informales, definidos desde la OIT o desde cualquier óptica analítica, tienen varias características comunes: "no están reconocidos ni protegidos por la ley, su nivel de vulnerabilidad es elevado y carecen de seguridad (del mercado laboral, del empleo, ocupacional, en el trabajo, de ingresos y de representación)" (Tokman, 2004, p.217). En este punto muchos coinciden con Tokman. Para Osvaldo Rosales, los bajos salarios y la "precariedad 
respecto de los contratos de trabajo y las prestaciones sociales" están unidos a la informalidad (Rosales, 2013, p.136).

El $85.8 \%$ tiene contrato verbal, y el $14.1 \%$ tiene contrato escrito. El $67 \%$ es indefinido y el $32.8 \%$ a término fijo. A pesar de considerarse la mayoría en contrato indefinido, el $37.3 \%$ tiene 12 meses o menos de permanencia en el trabajo. La inestabilidad es palpable. Esto contradice la percepción que tiene el obrero de su trabajo, el $55.3 \%$ considera que es estable.

Con relación a las prestaciones sociales, la situación es lamentable. No recibió el $85.5 \%$ prima de servicios, el $91.9 \%$ prima de navidad y cesantías, y el $82.9 \%$ vacaciones con sueldo. No está afiliado a una caja de compensación familiar el 96.3\%. El 98.6\% no recibe ingresos por horas extras. El 95.4\% no cobró prima de vacaciones y el $98 \%$ viáticos. Además del salario en dinero, el $39.5 \%$ obtuvo alimentos como parte de pago de su trabajo; el 58\% estima que equivale a $\$ 120.000$ mensuales o menos. El $2 \%$ recibió vivienda como parte del pago. E $82.4 \%$ no tiene auxilio de transporte. El $96 \%$ no tiene subsidio familiar. El 99\% no tiene subsidio de educación y alimentación. El 99\% no recibió bonificaciones. El panorama es claro, los empleados informales no gozan de beneficios sociales.

El salario mínimo mensual legal en el 2012 fue de \$634.500. El 87\% recibió menos del salario mínimo legal. El $99 \%$ recibió máximo $\$ 1.000 .000$. A pesar de las condiciones desfavorables, el $63.6 \%$ de los informales está satisfecho con el pago que recibe en el trabajo, con los beneficios y prestaciones el $43.4 \%$ y con la jornada laboral el $43.4 \%$. El $89.9 \%$ dice que es compatible el horario con sus deberes familiares. El $55 \%$ no ha hecho diligencias para cambiar de trabajo. E $55.3 \%$ considera su trabajo estable. En general los empleados informales están conformes con su empleo. La apreciación positiva de los empleados informales hacia su trabajo, se debe tal vez en parte a la capacidad de absorción de mano de obra, de hecho los periodos de desempleo de los informales son bajos. El 60\% 
esperó menos de un mes entre un empleo y otro. Otra explicación de la satisfacción, se encuentra en la incapacidad de los empleados de reconocer las condiciones deplorables que se encuentran como empleados. En esta falta de percepción de su propia problemática se alberga en buena parte la perpetuidad de las condiciones injustas de trato laboral a la masa informal. Mientras la población no se sensibilice frente a su condición de empleado informal, no estará en capacidad de organizarse para exigir sus derechos. Las cifras así lo demuestran, el $99.3 \%$ de los informales no están afiliados a una asociación gremial o sindical.

En un esfuerzo por disminuir los niveles de empleo informal, el gobierno nacional creó la Ley 1429 del 2010 "por la cual se expide la ley de formalización y generación de empleo". En un estudio realizado con el apoyo del Observatorio del Mercado del Trabajo del Departamento del Meta, Mauricio Céspedes y David Patiño, "demuestra que la norma resulta inocua en el departamento del Meta y muestra falta de compromiso del Estado y de sectores gremiales y empresariales en su difusión, por el alto grado de desconocimiento de ella" (Gutierrez Quiroga, 2012, p.1).

En la ciudad, el $53.3 \%$ de los negocios informales están registrados en las Cámaras de Comercio, alcaldías, Rut y registro mercantil. El 92\% realizó renovación del registro en el 2012. El registro de los negocios informales es el resultado de los esfuerzos del gobierno para formalizar empresas. El costo de crear una empresa se redujo en un 50\%. El promedio de demora los trámites de creación de una empresa formal pasó de 42 a 14 días y el número de trámites descendió de 11 a 9 trámites (Ministerio de Comercio, Industria y Turismo, 2011); pero el $46.3 \%$ no lleva contabilidad y "La fuente de financiación de los trabajadores informales procede en el $54 \%$ de préstamos personales, $29 \%$ de recursos propios y $17 \%$ de los bancos, cooperativas o entidades financieras" (León Camargo \& Caicedo Mora, 2011, p.93). 
La mayoría de los negocios están registrados, pero en los demás aspectos asumen las características informales que los identifican. Esta posición se asume calculadamente, porque en un análisis de costo beneficio, es preferible tener registro para existir como negocio, y a su vez no llevar contabilidad, porque esta actividad tiene un costo que el comerciante no está dispuesto a asumir en términos de tiempo y dinero. Una visión inmediatista de la rentabilidad del negocio, implica evitar inversiones que a mediano y largo plazo traen ganancias sustanciosas, por consiguiente los negocios están circunscritos a ganancias minúsculas. El $89.7 \%$ registra una ganancia mensual igual o menor a 1.000 .000 de pesos. Con ganancias tan exiguas, es difícil considerar que exista acumulación de capital.

Con relación a la actividad económica, en Villavicencio, el mayor número de informales se encuentra en comercio y servicios. Tokman indica que la terciarización en América Latina se ha acentuado, aumentando el nivel de empleo formal e informal en el sector comercio y servicios. También asocia el crecimiento de los servicios con la informalidad, la desprotección laboral y baja productividad “... la informalidad se concentra en los servicios y resulta en desprotección. Los servicios se concentran a su vez en actividades de baja productividad..." (Tokman V., 2003, p.17). También para Di Filippo, el sector servicios atrae la mayor cantidad de empleo informal (Di Filippo \& Franco, 2000, p.40).

Con respecto a la ansiada competitividad para competir exitosamente en el mercado, Cimoli agregó un marco analítico en donde la coexistencia de la formalidad con la informalidad, le confiere a la informalidad "características de la estructura productiva que actúan como barreras y limitan el crecimiento liderado por las exportaciones y, en un círculo vicioso, contribuye con sus debilidades estructurales a reducir el crecimiento" (Cimoli, et al, 2006, p.101). El coeficiente de internacionalización ${ }^{10}$ del departamento es de 0.5. El más alto lo tiene el

10 Relación entre importación y exportaciones con el PIB. Tomado de Escalafón de la 
departamento de Cundinamarca con 59.3. En Meta el nivel de exportaciones no tradicionales ha permanecido bajo, excepto en el 2008. Las exportaciones se basan en recursos primarios; el petróleo y derivados aportó el $99.6 \%$ de las exportaciones totales en el 2011, mientras los productos no tradicionales ha disminuido su nivel de exportación y participación hasta llegar al ínfimo 0,4\% del total de las exportaciones del Meta.

La deseada competitividad internacional y propósito del pensamiento neoestructuralista, es un anhelo del gobierno nacional y departamental, pero difícil de lograr según las evidencias históricas recientes. Según el informe de escalafón de competitividad de los departamentos en Colombia 2009, el departamento del Meta en el 2000 y 2004 se encontraba en el nivel alto, y entre 2006 y 2009 disminuyó a nivel medio alto. Se perdió competitividad. "Los obstáculos del departamento están en la calidad de sus colegios, la esperanza de vida, y también en individuos con habilidades globales" (Ramirez J. \& Parra-Peña S., 2010, p.38). La afirmación claramente despeja la duda con respecto a la calidad de la educación en la ciudad. Entre los informales, el $71.9 \%$ tienen educación formal de bachiller, universitario $10.8 \%$ y postgrado el $2.7 \%$. La población informal cuenta con capacitación, por ende el problema del empleo informal no radica en su falta de cualificación. Se deduce, que personas con títulos académicos están realizando labores de baja complejidad. Es un indicio que la calidad de la educación es deficiente o que el sector formal no es capaz de absorber gente calificada. Dependiendo de cuál sea la respuesta, debe dirigirse la política de educación que atenúe la problemática informal.

En el estudio de competividad departamental elaborado por la Cepal, se muestra que entre los seis factores para medir la competitividad, en el departamento del Meta, el factor peor clasificado es ciencia y tecnología, ubicado como colero inferior (Ramirez J. \& Parra-Peña S., 2010).

competitividad de los departamentos en Colombia, 2009. 
Para los neoestructuralista, la educación es un factor decisivo en la superación la heterogeneidad. Fajzylber considera que la informalidad es parte de estrategias de sobrevivencia frente a la recesión, y es resultante de la "disminución del frágil apoyo público precedente" y una política para reducirla es por medio de la capacitación, "apoyar e inducir en las asociaciones el desarrollo de organismos de asistencia técnica, financiera y de capacitación" (Fajnzylber, 2006). Tokman asocia la informalidad con bajos niveles de educación y considera que para superarla se necesita crear condiciones para crear pequeñas y medianas empresas mediante programas de formación y educación, "de modo que se desarrolle conciencia sobre la importancia de las buenas condiciones de trabajo para incrementar la productividad" (Tokman, 2001, p. 176 ). Ante el nivel de vulnerabilidad y en medio de la crisis económica en 1999, Ocampo aconsejó para minimizar los impactos en los niveles de empleo y el bienestar del trabajador, un seguro de desempleo fiscalmente sostenible, para cubrir la protección social del trabajador (Ocampo J. A., 1999, p.2). Colombia no cuenta con seguro de desempleo. En caso de no tener empleo, el $49.6 \%$ de los informales acuden a familiares para obtener recursos para los gastos, el $13.9 \%$ no tienen recursos y apenas cuentan con el ahorro personal 9.5\%. La poca cultura del ahorro, sumado a la inexistencia del seguro de desempleo, señala que el trabajador colombiano formal e informal se encuentra desamparado, frente al desempleo. En suma, la sociedad no es solidaria con los desempleados.

La tabla 9 resume las posiciones de los distintos enfoques y los resultados de Villavicencio. Se muestran las características que comparte la ciudad con el enfoque neoestructuralista. Dada su importancia en el análisis informal, Tokman se toma aparte. En la columna de Villavicencio, señala los datos de informalidad de la ciudad que SI y NO comparte con el enfoque. 
Tabla 9. Cuadro comparativo de enfoques

\begin{tabular}{|l|c|c|c|c|c|c|c|c|c|c|c|}
\hline Enfoque & $\begin{array}{l}\text { Ca. } \\
\text { A }\end{array}$ & $\begin{array}{l}\text { Ca. } \\
\text { B }\end{array}$ & $\begin{array}{l}\text { Ca. } \\
\text { C }\end{array}$ & $\begin{array}{l}\text { Ca. } \\
\text { D }\end{array}$ & $\begin{array}{l}\text { Ca. } \\
\text { E }\end{array}$ & $\begin{array}{l}\text { Ca. } \\
\text { F }\end{array}$ & $\begin{array}{l}\text { Ca. } \\
\text { G }\end{array}$ & $\begin{array}{l}\text { Ca. } \\
\text { H }\end{array}$ & $\begin{array}{l}\text { Ca. } \\
\text { I }\end{array}$ & $\begin{array}{l}\text { Ca. } \\
\text { J }\end{array}$ & $\begin{array}{l}\text { Ca. } \\
\text { K }\end{array}$ \\
\hline Villavicencio & $\mathrm{No}$ & $\mathrm{Si}$ & $\mathrm{Si}$ & $\mathrm{Si}$ & $\mathrm{No}^{*}$ & $\mathrm{No}$ & $\mathrm{No}$ & $\mathrm{Si}$ & $\mathrm{Si}$ & $\mathrm{Si}$ \\
\hline Neoestructuralismo & $\mathrm{Si}$ & $\mathrm{Si}$ & $\mathrm{Si}$ & $\mathrm{Si}$ & $\mathrm{Si}$ & $\mathrm{Si}$ & $\mathrm{Si}$ & $\mathrm{Si}$ & $\mathrm{Si}$ & $\mathrm{Si}$ & $\mathrm{Si}$ \\
\hline Víctor Tokman & $\mathrm{No}$ & $\mathrm{Si}$ & $\mathrm{Si}$ & $\mathrm{Si}$ & $\mathrm{Si}$ & $\mathrm{Si}$ & $\mathrm{Si}$ & $\mathrm{Si}$ & $\mathrm{Si}$ & $\mathrm{Si}$ & $\mathrm{Si}$ \\
\hline
\end{tabular}

Fuente: Elaboración propia. La información de Villavicencio, corresponden a bases de datos del DANE, año 2012.

$\mathrm{Si}=$ Villavicencio comparte el enfoque. No = Villavicencio no comparte el enfoque.

n.c. $=$ no menciona esta característica.

* Tomado de León \& Caicedo. La economía informal en Villavicencio .Revista Finanzas y Política Pública. Universidad Católica.

Característica A. Los empleados informales no cotizan para salud Característica B: Los empleados informales no cotizan para pensión Característica C: Los negocios informales no están registrados.

Característica D: La mayoría de los informales trabajan por cuenta propia.

Característica E: Los negocios informales no llevan contabilidad.

Característica F: La mayoría de la población informal son inmigrantes.

Característica G: Brechas de género.

Característica H: Bajos niveles de educación.

Característica I: Crecimiento de la economía informal.

Característica J: La informalidad favorece la heterogeneidad.

Característica K: La informalidad aumenta con el comercio y servicios

Desde el enfoque laboral, aunque la situación de Villavicencio no se ajusta plenamente a la visión neoestructuralista, en tanto que difieren en las características A, F, G y H; en su mayoría comparten su punto de vista. 


\section{UN MODELO PROBIT PARA LOS DETERMINANTES DE LA INFORMALIDAD EN VILLAVICENCIO}

\subsection{CARACTERIZACIÓN DE LA ECONOMÍA INFORMAL EN VILLAVICENCIO}

El municipio de Villavicencio capital del departamento del Meta, es el centro político y económico del departamento del Meta y la región de la Orinoquia, y se encuentra a 90 kilómetros al suroriente de Bogotá. La ciudad cuenta con una población de 450.000 habitantes, participa con el $50 \%$ de la población del departamento del Meta y se encuentra a 90 kilómetros al suroriente de Bogotá. Dado esta importante participación de la población, algunos datos que no se encuentran para la ciudad de Villavicencio, son reemplazados con datos del departamento del Meta.

El crecimiento del Producto Interno Bruto -PIB- se sustenta en regalías del petróleo, (Hernández, 2004, p.37), sin embargo el aumento en los ingresos corrientes, no está acompañado de políticas que contengan un impacto significativo en el desarrollo de la ciudad. Se evidencia en la poca dotación de redes de infraestructura urbana como vías y servicios públicos que no está aparejada con el crecimiento acelerado en construcción de vivienda y comercio y servicio. En el 2005, la ciudad tiene una cobertura de acueducto total de $89.5 \%$ y alcantarillado total de 90.1\% (Departamento Nacional de Estadística, 2005). El agua es tratada pero no es potable. Este crecimiento desordenado se empeora 
con el aumento de la población nativa y migrante. La escasez de vivienda, ocasiona el surgimiento de barrios periféricos habitados por personas que construyen sus propias viviendas con carencia de servicios públicos, dentro de una perspectiva de informalidad.

La explotación de minas y canteras contribuyó en el 2009 al $46.7 \%$ de la producción total del departamento del Meta, seguido del sector servicios con $30.1 \%$, el $9.4 \%$ es agricultura, ganadería, caza, pesca y silvicultura; el sector comercio con $6.2 \%$ y la industria solo aporta el $4.2 \%$. A pesar de la participación significativa de la explotación de minas y canteras en el departamento, la generación de empleo de este sector es muy poca, apenas del 1\% en el 2009 (Departamento Nacional de Estadística, 2010).

La poca vocación empresarial impide el montaje de empresas enormes que demanden grandes cantidades de empleo. En el 2005, de las 20.889 empresas matriculadas en el departamento del Meta, 20.329 son microempresas. 446 son pequeñas empresas, 95 son medianas empresas, y únicamente 2 son grandes empresas (Cámara de Comercio de Villavicencio, 2011). Según Cordepaz, los megaproyectos (la construcción de 315 hectáreas para estrato 5 y 6 del Meta, centros comerciales como Unicentro y Llanocentro planta de Biodiesel y parque agroecológico Merecure) en su momento no generaron suficiente empleo.

De otra parte, actividades que demandan abundante mano de obra como la agricultura, caza y pesca, y la construcción, presentan un decrecimiento debido, en parte, al aumento presentado desde finales del 2008, en los precios de algunos insumos como fertilizantes y agroquímicos; a la devaluación, al aumento de los precios internacionales del petróleo y al desplazamiento de los cultivadores hacía otros departamentos como Casanare por razones de seguridad, fortaleciendo de esta manera las prácticas de subcontratación y el trabajo a destajo (Banco de la República, 2009). 
Merecen referencia especial las ventas callejeras o ambulantes en la ciudad. Estas absorben trabajadores que desean ingresar al mercado formal, pero que por diversas razones no pueden hacerlo, ya sea porque sus destrezas y habilidades son escasas en un mercado altamente competitivo como es el laboral, o porque estos encuentran su campo de acción en el sector agrícola y no son requeridas en la ciudad. Algunos por enfermedad, pocos estudios o escaso presupuesto para montar un negocio se ven incluidos dentro de la informalidad; también recoge en su mayoría trabajadores más jóvenes o viejos, los primeros ya sea por la necesidad económica que se les puede presentar o como una actividad complementaria a sus estudios; los más viejos o los que quedan abandonados por el sistema, conformados por jubilados con destrezas particulares buscan compensar su pensión, y los que salen de las empresas desplazados por relevo generacional o porque han sido despedidos por las reestructuraciones y les queda imposible conseguir un nuevo empleo (León Camargo \& Caicedo Mora, 2011).

En el informe de los Conversatorios sobre el desarrollo en Villavicencio, coordinado por CORDEPAZ se señala como "las causas principales del desempleo en la ciudad es la concentración de la propiedad que se manifiesta en un incipiente mercado de tierras, el favorecimiento en la asignación de contratos, la concentración de los ingresos financieros, la poca participación de los pequeños productores en la contratación, el bajo perfil profesional, la alta aversión al riesgo por parte de los empresarios, la visión de desarrollo con énfasis en lo pecuario y el acceso diferencial a los bienes meritorios que busca resolverse con la asignación de subsidios que profundiza la exclusión laboral de los más pobres, pues no hay distribución de ingresos que mejoren sus condiciones y su situación" (Corporación Desarrollo para la paz del Piedemonte Oriental, 2004, p.12). 
Según el Ministerio de la Protección Social (Ministerio de la Protección Social, 2010) existen tres consecuencias negativas de la informalidad: 1. Los informales están en una trampa de improductividad. 2. El sector informal frena la expansión de la economía formal, y 3 . La informalidad amenaza la sostenibilidad del sistema de seguridad social. El tercer punto hace palpable el costo de cobertura en salud por la escasa afiliación de los informales a Empresas Promotoras de Salud -EPS. Según León y Caicedo, solamente el $18 \%$ de los informales en Villavicencio se encuentran afiliados a una EPS (León Camargo \& Caicedo Mora, 2011), por tanto el Estado debe asumir los costos en salud de los informales, quienes se encuentran en su mayoría en el Régimen Subsidiado. Por cada usuario activo en Fosyga y que sea atendido por una EPS el Estado le gira en Unidad de Medida por Capitación -UPC-, que en el departamento del Meta corresponde a un promedio de $\$ 550.641,60$ pesos anuales por usuario (Secretaría de Salud, 2011).

En la ciudad de Villavicencio, los Gobiernos Municipales no han prestado mucha atención a la problemática de la informalidad. Los Planes de Desarrollo previos a 2008 apenas mencionaban la informalidad entendida como expresión del desempleo. A mediados de los noventa, en el intento de construir el centro comercial San Andresito por parte de la Empresa de Desarrollo Urbano de Villavicencio -EDUV- y trasladar a los vendedores ambulantes del centro implicó que los vendedores ambulantes perdieran su puesto de trabajo y por tanto su medio de subsistencia, por lo cual, algunos vendedores interpusieron acción de tutela por la presunta violación al derecho al trabajo. La Corte Constitucional favoreció a los demandantes mediante la denominada confianza legítima que tiene su sustento en el principio general de la buena fe. Sin embargo, El Estado se manifestó con medidas de corte operativo como el decreto 001 de 1999, el cual promulga la restricción del espacio público. En enero de 2003, la reglamentación se endurece mediante el incremento de multas pero no así la aplicación. 
El Plan de Desarrollo Municipal periodo 2008-2011 "Villavicencio ciudad decente de Colombia" enfrentó el tema de la informalidad con la recuperación del espacio público "de la informalidad a la formalidad". El interés del Gobierno Municipal fue la generación, construcción, recuperación, mantenimiento del espacio público y amueblamiento urbano permitiendo que tanto hombres y mujeres que lo ocupan lleven sus actividades de la informalidad a la formalidad de tal forma que los Villavicenses gocen de un espacio agradable mejorando su calidad de vida. Estas políticas no han disminuido el empleo informal. A finales del 2011 el desempleo en Villavicencio es de $11.65 \%$. Mientras el desempleo no cede, en diciembre de 2011 , del total de mano de obra ocupada, el $61.2 \%$ es informal. La informalidad disminuyó en 5.8\% con respecto al 2010 (Departamento Administrativo Nacional de Estadística, 2011).

En la medida que persista esta problemática, el municipio estará afrontando múltiples situaciones adversas al desarrollo de la ciudad y a nivel institucional, por cuanto la extensión del fenómeno será permanente.

La informalidad presenta condiciones que impiden el crecimiento y desarrollo de la ciudad. La Redacción de negocios del periódico El Tiempo señaló que el crecimiento económico no llega a las personas menos calificadas, es decir que el crecimiento del Producto Interno Bruto -PIB- margina a las personas con bajo nivel de educación. Precisamente la informalidad alberga a mayor número de personas poco calificadas ya que no fomenta la capacitación profesional, por tanto su persistencia impide lograr objetivos de equidad, mediante el acceso a empleos de mayor calidad gracias a altos niveles de educación.

A lo anterior se suma que el país entra en una nueva fase de comercio internacional en donde entrará en vigencia del Tratado de Libre Comercio de Colombia con Estados Unidos. Con los elevados niveles de informalidad, el país y Villavicencio se encuentran en desventaja, dado que el empleo informal limita los 
beneficios del comercio para los países en desarrollo. La existencia de una economía informal importante puede, a) hacer disminuir el grado de diversificación de las exportaciones; b) limitar el tamaño de las empresas $y$, por consiguiente, el incremento de la productividad; c) actuar como una especie de trampa de la pobreza, que impide la reasignación de los puestos de trabajo en la economía formal, porque frente a cambios estructurales en ocasiones se requiere mayor cantidad de mano de obra en el sector formal con un nivel de calificación que no tienen quienes permanecen demasiado tiempo en el sector informal. (Organización Mundial del Comercio, 2009)

El municipio no llegará a establecer la Planeación de Desarrollo local que requiere la ciudad, si no dispone de una visión real de las necesidades y oportunidades del funcionamiento de las diferentes actividades económicas y en este caso de la economía informal y si insiste en políticas que remedian temporalmente la situación para alguno informales, pero no están dirigidas a revertir las causas. El Plan de Desarrollo Municipal "Gobierno de la Ciudad" del periodo 2012-2015, contempla dentro del programa "Villavicencio emprendedora" el subprograma "de la informalidad a la formalidad", cuya meta es la "capacitación, fortalecimiento, asesoría y estratificación de impuestos para identificación y desarrollo de fami, micro, pequeña y mediana empresa, para legalizar 15 Mipymes".

La visión de los informales de la Alcaldía de Villavicencio se circunscribe principalmente a los vendedores ambulantes, por tanto se buscan la reubicación de ellos en el centro, con la estrategia de recuperación del espacio público que tiene como meta dos acciones relacionadas con los informales, la primera es "ofrecer apoyo logístico a la Secretaria de Control Físico y asistencia técnica a 200 vendedores informales del centro de la ciudad para su reubicación", y la segunda es "pasar de la informalidad a la formalidad a 200 vendedores y trabajadores informales de acuerdo a las políticas de generación de empleo, 
fomento micro empresarial y sustitución de vehículos de tracción animal". (Alcaldía de Villavicencio, 2012, p.55). Las acciones tendientes a revertir la informalidad son pocas y pobres, por tanto, no se vislumbra a corto plazo una solución a esta problemática.

En consecuencia, es preciso estudiar ¿Qué factores inciden en las altas tasas de la informalidad en Villavicencio?. La visión actual que se tiene de la Informalidad en Villavicencio no permite entender la realidad del fenómeno, su complejidad, las relaciones con otros sectores, sus características propias, etc., por tanto las políticas de formalización que de esta visión se derivan fracasan. La repuesta a la misma, ofrecerá un panorama integral y a fondo del fenómeno de la informalidad en Villavicencio.

Los estudios de la economía informal en Villavicencio describen las condiciones económicas y sociales en que se desenvuelven sus participantes. En el año 2002, Castro y Galvis realizaron en la ciudad de Villavicencio un estudio de 784 encuestados, la mayoría fueron hombres, pertenecientes a los estratos 1 y 2 , con edades entre los 25 y 54 años, quienes viven en arriendo, carecen de seguridad social (Solo Sisben), trabajan todos los días alrededor de 10 horas, venden sus productos de manera ambulante como independientes, no cuentan con los elementos de protección y manifiestan dolores en todo el cuerpo y estrés por su entorno laboral. Los autores concluyeron que: "el sector informal es una población vulnerable; en general los trabajadores tienen un empleo mal remunerado, a pesar de largas jornadas de trabajo en condiciones mediocres y no reglamentadas, conllevando a malas condiciones de vida" (Castro Torres \& López Galvis, 2002, p.15). La problemática local se estudió desde el punto de vista epidemiológico, sin embargo arrojó resultados que señalan características asociadas a la desprotección estatal y el bajo nivel de vida.

Beltrán y Gómez caracterizaron a los empleados informales, "por ser una población joven que se ubica en los estratos medios, son jefes y esposos, 
casados y responsables directos del hogar, con bajos niveles de educación, laboran 51,43 horas a la semana y perciben mensualmente ingresos promedio de $\$ 304.387$, cifra inferior al salario mínimo mensual legal vigente, para el año de estudio" (Beltrán Díaz \& Gómez Ramos, 2005, p.32). Acertadamente Beltrán y Gómez advierten que usualmente se suele confundir empleados informales con vendedores ambulantes. Toman como fuente de información, la Encuesta Continua de Hogares, del DANE, en el 2003, que analiza solo desde su característica ocupacional, además, se limita a tomar un solo año, por tanto no es posible conocer la evolución de la economía informal.

En el mismo año, Torres señaló que los informales se dedican principalmente a las ventas y la mayoría de los vendedores son ambulantes, oriundos de la ciudad, se dedican por completo a su actividad, no reciben ayuda estatal, tienen una percepción negativa del sector público, bajo nivel educativo, recurren al crédito gota a gota, poco acceso al crédito bancario, dicen no conocer la forma de constitución de una empresa, saben de los impuestos que deben pagar, consideran que estarían dispuestos a pagar, siempre y cuando se ajuste a sus capacidades y les gustaría formalizarse. A este tipo de estudios se les critica que son encuestas de percepción que en buena proporción depende de la apreciación del encuestado, además el limitado espacio geográfico (centro de la ciudad) y el escaso periodo de tiempo en que fue aplicada la encuesta (15 y 20 de enero de 2007), no permite señalar con certeza los resultados (Torres, 2007).

El Ministerio de la Protección Social (Hernández, 2010), presentó un estudio de causalidad del empleo informal en el espacio público del centro de Villavicencio. Indica que la mayoría se encuentran entre mujeres entre 26 y 45 años; y tienen menos de cinco años en su oficio actual.

Los factores económicos, sociales y culturales de la informalidad fueron analizados por Méndez y Cubillos que caracterizaron a la economía informal en 
Villavicencio durante el periodo 2002-2009. Se identificaron los principales problemas que atañen a la economía informal en la capital del Meta, a través de un análisis descriptivo de cada factor. Sus resultados muestran que en el año 2008 se presentó una tasa de informalidad del orden del $68 \%$, con una disminución cerca al 5\% respecto al año 2002, mayor a la tasa de informalidad media nacional de 57\%. Señalan al Estado como responsable en gran medida de la informalidad en la ciudad (Méndez \& Cubillos, 2010).

Un avance en el conocimiento de la informalidad fue realizado por Díaz y Ortiz al mostrar la relación entre economía formal e informal en Villavicencio, en el periodo 2002 - 2009, partiendo desde cuatro puntos de vista que son: la demanda de bienes y servicios, la demanda y oferta de trabajo, los derechos de propiedad, y por último las relaciones en los ciclos económicos. Realizaron un estudio descriptivo y concluyeron que existe una alta probabilidad de que en muchos de los casos, en los negocios formales se presente la informalidad bien sea porque emplean mano de obra a destajo, o porque sus insumos y materias primas son provenientes de establecimientos informales. En periodos de recesión económica, se presenta una relación dada por la transición de personas de una economía hacia la otra, ya que cuando el sector formal despide empleados, estos acuden la mayoría de veces a refugiarse en la informalidad, como una opción viable en dichos periodos de decrecimiento.

El Observatorio de Empleo en el Departamento del Meta, en encuesta realizada a los vendedores ambulantes de la zona centro de Villavicencio, muestra las causas para ejercer la informalidad. El 56,6\% dice que él no encontrar empleo formal, lo excluyó del empleo formal (Gutiérrez et al, 2012).

Los resultados de la Gran Encuesta Integrada de Hogares entre los años 2008 y 2012, muestra información sobre la situación económica de los informales. A 
continuación se presentaran datos de informales que luego serán contrastados en el modelo probit.

En el 2008 la mayoría de la población está entre 26 a 60 años con $44.5 \%$ y en el 2012 hasta los 25 años se encuentra el gran grueso de la población con 47.3\%. En educación en el 2008 quienes han estudiado 5 o menos años son $45.7 \%$, el $35.6 \%$ entre 6 y 11 años y de 12 a 21 años es el 18.7\%. En el 2012, el 43.0\% tiene 5 o menos años de educación, el 43.3\% tiene de 6 a 11 años de educación y el 13.7\% tiene de 12 a 21 años de educación. Los informales en el 2008 principalmente son casados o viven en pareja, mientras en el 2012 cambia la participación de los informales con su situación conyugal y principalmente no son casados ni viven en pareja. Los informales no tienen mucha antigüedad en el 2008 al igual que en el 2012, y principalmente se encuentran en comercio y servicios en el 2008 y 2012. En el 2008 la posición ocupacional es mayormente trabajador por cuenta propia y en el 2012 se repite la mayor participación de los informales en trabajador por cuenta propia.

Los informales cotizan a salud en el 2008 y 2012, pero una minoría apenas cotiza a pensión. Según la ley 1361, familia numerosa es aquella que tiene más de tres hijos, si le sumamos los padres, una familia numerosa es de mínimo 6 personas. El $17.61 \%$ de los informales están catalogados como familia numerosa en el 2008, y en el 2012, el 21,46\%, por tanto ha crecido en el periodo el número de integrantes en la familias que tienen trabajadores informales. Las mujeres en el 2008 y 2012 participan más que los hombres en la informalidad. Los informales en su mayoría no son jefes de hogar. 


\subsection{ESTIMACIÓN DE UN MODELO PROBIT PARA LOS DETERMINANTES DE LA INFORMALIDAD EN VILLAVICENCIO EN LOS AÑOS 2008 Y 2012}

Para conocer el impacto que tienen diferentes factores en la economía informal de Villavicencio, se utiliza un modelo probit ${ }^{11}$. Este tipo de modelo sirve para conocer el comportamiento de una variable de respuesta binaria frente otras variables binarias o no. En este caso se quiere conocer la respuesta de la informalidad frente a variables demográficas y estructurales. El objetivo del modelo es conocer la incidencia de las variables estructurales en la informalidad de Villavicencio. Estas variables son estructurales porque corresponden a componentes de la estructura económica, representado por los sectores económicos y posición ocupacional. El modelo es neoestructural porque atiende a variables analizadas en un contexto reciente en donde los teóricos intentan mostrar que el crecimiento y desarrollo requiere buscar la convergencia de las distintas ramas de actividad en la economía y disminuir el nivel de heterogeneidad dada por la economía formal en coexistencia de la economía informal.

La regresión probit es un modelo de regresión no lineal con una variable dependiente binaria, la cual representa la probabilidad de que $Y=1$. Tiene ventajas sobre el Modelo de probabilidad Lineal -MPL-, porque las probabilidades siempre están entre 0 y 1 (Enchautegui, 2008), a diferencia de MPL que pueden tener probabilidades menores a cero o mayores que uno (tabla A.2) ${ }^{12}$.

\footnotetext{
${ }^{11}$ En el modelo probit la autocorrelación es poco probable que exista porque es un modelo de corte transversal. No se manejan los elementos de normalidad en los errores, estos se distribuyen de manera probabilística.

${ }^{12}$ La tabla 2 del anexo muestra el valor de probabilidad mínimo y máximo de ser informal entre todas las personas encuestadas. El valor probit se mantiene entre 0 y 1 , mientras el modelo lineal sale del rango 0 y 1 , además las probabilidades no pueden ser negativas.
} 
Se justifica el modelo probit porque cuando se utiliza una variable de respuesta binaria (la variable informal es binaria) se evita que los residuos violen los supuestos de homocedasticidad y normalidad de los mínimos cuadrados ordinarios -MCO-, situación presentada en modelos de probabilidad lineal y conlleva a errores en las pruebas de hipótesis y errores estándar válidos. Dado que la variable dependiente es binaria y los resultados se presentan en probabilidades, se esperan que estas sean positivas, sin embargo en modelos de MCO no todas las probabilidades son positivas, razón principal por la cual el modelo lineal no sirve en este caso para predecir el comportamiento de los informales.

Otro modelo de variable dependiente limitada es el logit. En modelos de mercados laborales y por evidencia empírica el modelo probit es mejor que el logit, (Posada \& Arango, 2002), (Charry, 2003), (Ortiz, Uribe , \& García, 2007), (Alvis, 2010), (Figueroa, 2010). Además en modelos de máxima verosimilitud los criterios de selección de akaike y schwartz, indican que el mejor modelo es el más positivo y en este caso los modelos probit de los años 2008 y 2012, son mejores que los modelos logic (Tabla A.3).

El modelo a trabajar es el siguiente:

Inf $=\beta_{0}+$ años aprobados de educación + edad + casado + antigüedad + rama de actividad + posición ocupacional + salud + pensión + familia + género + jefe de hogar + Ui. Ecuación 7

Para el análisis de la respuesta binaria se utilizó la Gran Encuesta Integrada de Hogares -GEIH-, del DANE, datos de corte transversal, años 2008 y 2012. Las variables se explican en la tabla A.4.

El modello a trabajar es un modelo probit poblacional con varios regresores de la forma $\operatorname{Pr}\left(Y=1 X_{1}, X_{2}, \ldots, X_{k}\right)=\Phi\left(\beta_{0}+\beta_{1} X_{1}+\beta_{2} X_{2}+\ldots+\beta_{k} X_{k}\right)$. La variable dependiente $Y$ es binaria, $\Phi$ es la función de distribución normal estándar acumulada, y $X_{1}$ y 
$\mathrm{X}_{2}$, etc., son regresores. El modelo se interpreta mejor calculando las probabilidades esperadas y el efecto de un cambio en un regresor.

La probabilidad esperada de que $Y=1$, con valores de $X 1, X 2, \ldots, X k$, se calcula con el z-valor, $z=\beta 0+\beta 1 X 1+\beta 2 X 2+\ldots+\beta k X k$, Ecuación 8

buscando luego este valor de $z$ en la tabla de distribución normal. El $\beta 1$ es el cambio en el z-valor derivado de un cambio unitario en $\mathrm{X} 1$, manteniendo constantes $\mathrm{X} 2, \ldots \mathrm{Xk}$.

Los coeficientes en el modelo probit no se pueden interpretar de la misma manera que los modelos de probabilidad lineal -MPL-. Se requiere hallar los efectos marginales del modelo probit.

Con este modelo se tiene estimaciones en el rango 0,1 y se ajusta a los requerimientos de los modelos probabilísticos (Rosales Álvarez, Perdomo Calvo, Morales Torrado, \& Urrego Mondragón, 2010, p.109).

Se estima un modelo probit porque nos permite respuestas binarias para variables cualitativas como informal y cotizante para salud (tabla A.4). Los efectos probit no se pueden medir directamente ya que se calculan según la siguiente estructura:

$\frac{\partial P(Y=1 \mid X)}{\partial X_{i j}}=\frac{\partial E(Y \mid X)}{\partial X_{i j}}=\frac{\partial F(X \beta)}{\partial X_{i j}}=f(X \beta) \beta_{i} \quad$ Ecuación 9

Esto muestra el cambio en el logaritmo de las probabilidades como resultado de cambios en las variables independientes, dejando las otras variables constantes (tabla A.5). En este modelo el efecto marginal es variable y decreciente (Wooldridge J. M., 2010), por tanto para conseguir un efecto marginal constante, se busca calcularlo con respecto al promedio de las variables, es decir efectos marginales medios, a partir de la media muestral de la variable. La interpretación 
del modelo probit no se da en términos marginales; apenas se puede interpretar los signos. En un modelo de $\mathrm{MCO}$, el efecto marginal es el mismo para cada observación (en particular, el efecto marginal es el coeficiente de la variable ficticia). Sin embargo, en un modelo no lineal - incluyendo Probit - el efecto marginal está condicionado a las $X$ de la observación particular; y dado que se requiere conocer el impacto marginal de las variables independientes sobre la dependiente, se deben transformar las variables. En la tabla 10 se muestra los efectos marginales sobre la informalidad en los años 2008 y 2012.

Se aplicará un modelo Probit con determinantes sobre la informalidad con variables de la demanda y la oferta laboral. Luis Armando Galvis (Galvis, 2012, p. 28) indicó que existe una brecha entre la demanda y oferta laboral, causada por una oferta laboral de baja calificación y trabajadores del sector formal calificados y expulsados hacia el sector informal, frente a una demanda laboral formada por empresas del sector moderno que no son capaces de absorber la suficiente mano de obra y empresas de baja productividad que atraen mano de obra bajo condiciones deficientes. Se suma la política de disminución del tamaño del Estado, el cuál expulsa mano de obra formal (Tokman V. E., 2004).

Según Galvis y adaptado a este modelo de parte de la oferta laboral se encuentra el crecimiento de la población, la mayor participación de las mujeres, y el aumento de la participación de los miembros del hogar (Tabla 10). En el lado de la demanda se presenta escaso desarrollo estructural y la disminución del tamaño del Estado.

Tabla 10. Factores asociados a la informalidad en el enfoque neoestructural

\begin{tabular}{|lc|l|}
\hline \multicolumn{1}{|c|}{ DEMANDA } & \multicolumn{2}{|c|}{ OFERTA } \\
\hline $\begin{array}{l}\text { Escaso desarrollo estructural (baja } \\
\text { diversificación económica). }\end{array}$ & $\begin{array}{l}\text { Una disminución de la tasa de } \\
\text { mortalidad, y una tasa de natalidad } \\
\text { constante. }\end{array}$ \\
\hline Intensidad en bienes primarios con & \begin{tabular}{l} 
La mayor participación de las mujeres \\
\hline
\end{tabular}
\end{tabular}




\begin{tabular}{|l|l|}
\hline tecnologías intensivas en capital. & en el mercado laboral. \\
\hline Poca inversión. & $\begin{array}{l}\text { La creciente introducción en el mercado } \\
\text { laboral de miembros diferentes al jefe } \\
\text { de hogar. }\end{array}$ \\
\hline $\begin{array}{l}\text { La disminución del tamaño del Estado, } \\
\text { el cual tiene empleo formal. }\end{array}$ & La migración de tipo rural-urbano. \\
\hline Poca cuantía de las exportaciones. & Bajo nivel de educación. \\
\hline $\begin{array}{l}\text { Deficientes políticas del Estado para la } \\
\text { equidad social. }\end{array}$ & \\
\hline
\end{tabular}

Fuente: Elaboración propia con base en Galvis (2012)

Los resultados del modelo probit señalarán que variables de demanda y oferta influyen en la informalidad.

\subsection{RESULTADOS DEL MODELO}

Los datos utilizados para el análisis de regresión son los de GEIH los periodos 2008 y 2012 para la ciudad de Villavicencio. La estimación del modelo se presenta en la Tabla 12 destacando los coeficientes que son altamente significativos, es decir, los que tienen 3 estrellas, porque el nivel de significancia es menor, es decir de $1 \%$.

La prueba de Wald (el estadístico $\rho$ es igual a cero) se rechaza, por tanto existe evidencia estadística que el modelo está ajustado (Tabla A.6 del anexo). "El estadístico de Wald, después de una simple transformación, es esencialmente el estadístico F " (Wooldridge, 2009). Los coeficientes del modelo en general son significativos. También la prueba de hipótesis muestra la validez del modelo (Tabla A.7 del anexo).

Otra prueba de bondad de ajuste del modelo es la matriz de clasificación. En el 2008, la sensibilidad nos dice que existe una probabilidad de predecir correctamente el $90.29 \%$ quienes son informales. La especificidad indica que existe una probabilidad de predecir correctamente que el $78.39 \%$ no son 
informales. El modelo clasifica correctamente el $85.88 \%$ de las observaciones. En el 2012 el modelo clasifica correctamente el $\mathbf{8 7 . 3 7 \%}$. Ambos modelos están bien ajustados (Tabla A.8).

La curva ROC (Receiver Operating Characteristic) también expone la bondad del ajuste. El área bajo la curva ROC debe ser mayor a 0.7 para considerar que el modelo es bueno. Su interpretación es parecida a la curva de Lorenz. Entre más se aleje de la diagonal es mejor, porque se puede separar en el análisis los empleados formales de los informales. El área bajo la curva ROC en el 2008 es de 0.8723 y en el 2012 es de 0.9208 .

Las variables más relevantes que influyen sobre la informalidad y las cuales tienen mayor nivel de significancia se presentan con tres asteriscos. En el 2008 son: años aprobados en educación, comercio, restaurante y hoteles, transporte, número de personas en la familia y jefe de hogar. En el 2012 son: Antigüedad en años en el empleo, construcción, comercio, restaurante y hoteles, transporte, número de personas en la familia y jefe de hogar. Variables estructurales que influyen en la informalidad, en donde sobresalen los componentes de rama de actividad y estructura familiar.

Según el modelo, para los años 2008 y 2012, un año aprobado en educación disminuye la probabilidad de ser informal, en $0.7 \%$ y $0.3 \%$ respectivamente, y refuerza la afirmación de la tabla 8 , que indica que la educación en Villavicencio no se relaciona significativamente con la informalidad. Además de cuestiones relacionadas con la educación e informalidad en Villavicencio mencionadas en el capítulo anterior, se puede mencionar la incapacidad del mercado laboral formal de absorber mano de obra capacitada.

Está creciendo la oferta laboral capacitada, de hecho en Villavicencio existen más de 17 instituciones universitarias, mientras que de parte de la demanda, la 
dinámica es muy incipiente. Las empresas grandes (generadoras de mayor volumen de empleo formal) en el departamento del Meta son 8 y corresponde apenas a $\mathbf{0 . 0 3 \%}$ del total de las empresas (Cámara de Comercio de Villavicencio, 2014, p.8). En Risaralda, departamento con similar población, las empresas grandes participan con el $0.1 \%$ del total de empresas (Osorio Duque, 2011) y en Bogotá y Antioquia con $0.4 \%$ (Cámara de Comercio de Bucaramanga, 2012). La heterogeneidad se puede visualizar desde diferentes aspectos. Machinea visualiza la heterogeneidad desde el tamaño de la empresa y resalta "tres velocidades". Las empresas informales (pequeñas y sin regulación estatal) las empresas y medianas, y las empresas grandes. La mayor velocidad se encuentra en las grandes, altamente competitivas (Machinea, 2004).

La edad influye poco en la condición de informalidad, y a medida que se tienen un año más de edad en el 2008 la probabilidad para llegar a la informalidad disminuye en $0.1 \%$, y en el 2012 esta influencia cae a $0.05 \%$, es decir, población de todas las edades tienen en la informalidad igualdad de posibilidades para laborar.

El casado aumenta la probabilidad de ser informal en el 2008 con 5.9\%; muestra que las personas casadas buscan emplearse aunque signifique empleos de baja calidad. En el 2012 disminuyó a 0.7\%, para esta fecha la condición de casado no se relaciona significativamente con la informalidad.

Por cada año de antigüedad en el empleo en el 2008 se disminuye la probabilidad de ser informal en $0.2 \%$ y en el 2012 de $0.4 \%$, debido a que los empleados formales tienen más antigüedad que los informales. El efecto de la antigüedad sobre la informalidad no es importante.

Con variables estructurales como rama de actividad se puede afirmar que para la industria manufacturera en el 2008 la probabilidad de ser informal frente a 
quienes trabajan en la agricultura disminuyó en $87.6 \%$. Se redujo este dato en el 2012, es decir, la probabilidad de ser informal frente a quienes trabajan en la agricultura mermó a $32.01 \%$, porque con el tiempo las personas empleadas en la agricultura se han ido formalizando ${ }^{13}$.

\begin{tabular}{|c|c|c|}
\hline \multicolumn{3}{|c|}{$\begin{array}{c}\text { Tabla 11. Modelo Probit de informalidad para Villavicencio } 2008 \text { y } 2012 \\
\text { (Efectos marginales) }\end{array}$} \\
\hline & $\operatorname{Pr}(2008)$ & $\operatorname{Pr}(2012)$ \\
\hline Años aprobados de educación & $-0.0074^{\star \star \star}$ & $-0.0028^{\star *}$ \\
\hline Edad & $-0.0011^{*}$ & -0.0005 \\
\hline Casado & $0.0587^{\star}$ & 0.0075 \\
\hline Antigüedad en años en el empleo & $-0.0017^{*}$ & $-0.0043^{\star \star \star}$ \\
\hline \multicolumn{3}{|l|}{ Rama de actividad (Base agricultura) } \\
\hline Industria manufacturera & $-0.876^{\star *}$ & -0.3201 \\
\hline Electricidad, gas y agua & $-1.433^{\star *}$ & 0.0000 \\
\hline Construcción & -0.7622 & $-0.9316^{\star \star \star}$ \\
\hline Comercio, restaurante y hoteles & $1.8084^{\star * \star}$ & $1.2830^{\star \star *}$ \\
\hline Transporte & $1.7534^{\star \star \star}$ & $0.5218^{* * *}$ \\
\hline Comunicaciones & -0.5514 & -0.1053 \\
\hline Establecimientos financieros & -0.5368 & $-0.3506^{* *}$ \\
\hline \multicolumn{3}{|l|}{$\begin{array}{l}\text { Posición ocupacional en el empleo (Base obrero o } \\
\text { empleado de empresa particular) }\end{array}$} \\
\hline Obrero o empleado del gobierno & 0.0000 & -1.5276 \\
\hline Empleado doméstico & -0.4712 & 0.0000 \\
\hline Trabajador por cuenta propia & 0.1387 & 1.7770 \\
\hline Patrón o empleador & -0.0029 & 2.6362 \\
\hline Trabajador familiar sin remuneración & $0.6161^{* *}$ & 2.0867 \\
\hline Cotizante de salud & $-0.125^{\star \star}$ & -0.3961 \\
\hline Cotizante de pensión & $-0.9672^{\star *}$ & $-0.3599^{\star}$ \\
\hline Nro. de personas en la familia & $0.1554^{\star \star \star}$ & $0.2753^{\star \star *}$ \\
\hline Género & $0.2990^{*}$ & -0.0135 \\
\hline \multirow[t]{2}{*}{ jefe de hogar } & $0.1318^{\star * \star}$ & $-0.0595^{\star \star \star}$ \\
\hline & \multicolumn{2}{|c|}{$p<0.1^{* \star} p<0.05 \quad{ }^{* \star *} p<0.01$} \\
\hline
\end{tabular}

Fuente: Elaboración propia con base en la GEIH año 2008 y GEIH año 2012 del DANE. $\operatorname{Pr}=$ Probabilidad

${ }^{13}$ Según cálculos propios con base a la GEIH años 2008 y 2012. 
Si se incrementa la población de quienes trabajan en electricidad, gas y agua en uno por ciento en el 2008, la probabilidad de que un empleado sea informal con respecto a quienes trabajan en la agricultura disminuye en $143.3 \%$. Esta gran diferencia se da en orden a que las empresas que corresponden a esta rama son empresas grandes y vigiladas por el Estado, por consiguiente el empleo es formal. En el 2012 la injerencia de trabajar en electricidad, gas y agua es nula con respecto a la agricultura. Estos indicadores se dan a raíz que la agricultura se ha ido formalizando, mientras la participación de la electricidad, agua y luz en el empleo ha ido disminuyendo ${ }^{14}$.

La construcción presentó en el 2008 una probabilidad menor de ser informal frente a quienes trabajaron en la agricultura de $76.22 \%$. Se acentuó este dato en el 2012, es decir, la probabilidad de ser informal en la construcción frente a quienes trabajaron en la agricultura disminuyó en 93.16\%, dado que el crecimiento en la construcción está a cargo de empresas que manejan grandes presupuestos y sus empleados son formales. Esta actividad genera un alto valor agregado como se muestra en la tabla 7.

Cuando el comercio, restaurante y hoteles, en el 2008 incrementa su población de quienes trabajan en uno por ciento, la probabilidad de que un empleado sea informal con respecto a quienes trabajan en la agricultura aumenta en $180.84 \%$. En el 2012 este dato es de 128.3\%. Se reafirma lo dicho, el comercio restaurante y hoteles aporta en buena parte a la informalidad. El transporte incide de forma parecida sobre la informalidad, aunque disminuyó su participación en el 2012 sobre la informalidad, dado que los que trabajan en el transporte se han venido formalizando en razón a que son empresas donde el control de Estado es más riguroso y esto incluye la contratación laboral. Katz le confiere a la informalidad mediante las pocas o nulas barreras a la entrada, el eje central para su existencia. Las actividades del comercio y servicio presentan las características

\footnotetext{
${ }^{14}$ La tabla 6 muestra la pérdida de participación estructural de la electricidad, gas y agua en el empleo
} 
propias para facilitar el ingreso de mano de obra laboral a la informalidad e identificadas por el autor: la oferta casi ilimitada de bienes y/o servicios a precios de subsistencia y los ahorros personales o familiares que pueden financiar negocios de baja inversión en un entorno donde no existen leyes para defender la competencia y derechos de propiedad (Katz, 2006).

Las comunicaciones y los establecimientos financieros en el 2008 y 2012 aportan de manera negativa a la informalidad. A medida que se incrementa la población laboral en $1 \%$ en las comunicaciones, disminuye la probabilidad de ser informal con respecto a la agricultura en 55.14\% y $10.53 \%$ en los años 2008 y 2012 respectivamente. Similar efecto tienen los servicios financieros sobre la informalidad. Ambas actividades, especialmente los establecimientos financieros son negocios regulados por el gobierno, y son de gran tamaño, por tanto las condiciones de contratación laboral facilitan la formalidad.

En el 2008, participar en la industria manufacturera, disminuyó la posibilidad de ser informal con respecto a quien trabaja en la agricultura en 87.6\%; en el 2012 es de $32.01 \%$. No es suficiente el aporte que hace la manufactura a la formalización. Según Cimoli la apertura económica ha acentuado el uso intensivo en los recursos naturales y junto con la privatización y el avance tecnológico en la producción, "procesos que han transformado las dinámicas del sector formal" se han afectado adversamente las capacidades tecnológicas endógenas de absorción de fuerza de trabajo del sector formal manufacturero (Cimoli, Primi, \& Pugno, 2006, p. 92).

Los establecimientos financieros tienen un efecto negativo sobre la informalidad, como es de esperarse, porque son negocios modernos y vigilados por el gobierno. Lo anterior es conforme a la dualidad existente en la economía de la ciudad, a saber, actividades económicas modernas y empleos formales, frente a otras con atraso tecnológico y relaciones laborales de mala calidad. 
Para el análisis de la posición ocupacional se tiene al obrero o empleado de empresa particular como base y se relaciona con el obrero o empleado del gobierno, empleado doméstico, trabajador por cuenta propia, patrón o empleador y trabajador familiar sin remuneración.

Si se incrementa la población quienes trabajan como empleado del gobierno en uno por ciento, la probabilidad de que un empleado sea informal con respecto a quienes trabajan como obrero o empleado de empresa particular es de $0 \%$ en el 2008 y en el 2012 disminuye la probabilidad en 152.76\%. Es una variación importante de la influencia del empleo del sector público sobre la informalidad. Indica que el gobierno es un empleador formal. De hecho la menor probabilidad de ser informal se encuentra como empleado del gobierno.

La posición ocupacional en el 2008 indica que el empleado doméstico disminuye significativamente la probabilidad de ser informal, al igual que el trabajador por cuenta propia, mientras el patrón o empleador también tiene una relación negativa pero no significativa con la informalidad. En este año el factor más determinante en la informalidad es trabajar como familiar sin remuneración. Esto muestra que las unidades informales están conformadas en buena parte por familiares quienes no reciben sueldos, a cambio de cubrir gastos de mantenimiento y educación.

En el 2012 el empleado doméstico no influye en la informalidad, mientras el trabajador por cuenta propia cambia su relación con la informalidad al constituirse en un factor decisivo sobre esta, al igual que el patrón o empleador, que se convierte en el determinante más importante para ser informal, desplazando a los familiares sin remuneración, el cual le sigue en influencia. Esto corrobora que los informales en Villavicencio en general no son empleados, y trabajan por cuenta propia. 
El trabajador por cuenta propia en el 2008 aumentó su posibilidad de ser informal con respecto a los trabajadores de una empresa particular en $13.87 \%$, mientras en el 2012 el trabajador por cuenta propia incrementa su probabilidad de ser informal con respecto a los trabajadores de una empresa particular en $17.7 \%$. Este dato similar a la posición ocupacional de patrón o empleador recalca que muchos de los informales en Villavicencio son independientes y optan por establecer negocio propio de uno o más empleados.

Con el aumento en $1 \%$ de los empleados domésticos, disminuyó la probabilidad de ser informal con respecto a los empleados de empresa particular en $47.2 \%$ en el 2008 y en el 2012 aumentó la probabilidad a 1.0\%. Cifras un poco inciertas en el 2008 dado que los empleados domésticos generalmente son de tipo informal, sin embargo las cifras pasan a positiva en el 2012 y se ajusta a lo esperado para este tipo de empleo.

El trabajador familiar sin remuneración incrementa su probabilidad de ser informal con respecto al empleado de empresa particular en $61.61 \%$ en 2008 y la aumenta en el 2012 en 208.67\%. Esto se da porque generalmente los familiares trabajan en calidad de informal para ayudar a la familia y sostenerse a sí mismos, sin más compromisos que sus lazos familiares.

Los cotizantes en salud disminuyen su probabilidad de ser informal en $12.5 \%$ en el 2008 y de $39.6 \%$ en 2012; muestra en este periodo que cada vez más los cotizantes en salud trabajan en el sector formal. A su vez los cotizantes en pensión disminuyen su probabilidad de ser informal en $96.7 \%$ en el 2008 y en el 2012 en $35.9 \%$. Estas cifras asocian a los cotizantes en pensión con trabajo formal. 
En el 2008, la probabilidad de ser informal por formar parte de una familia numerosa fue de $15.54 \%$ y aumenta esta probabilidad en el 2012 a $27.53 \%$. Indica que las familias numerosas aportan a la informalidad, posiblemente porque este tipo de familia se encuentra mayoritariamente en barrios de nivel medio bajo y bajo y sus integrantes no encuentran fácilmente empleos de buena calidad y optan por lo informal. Además se infiere que a mayor cantidad de miembros, se dificulta el sustento familiar, en razón a un pobre ingreso del jefe de la familia insuficiente para cubrirlo.

La condición de género influye decisivamente en el comportamiento de los informales en el 2008, dado que los hombres aumenta la probabilidad de ser informal en 29.9\%. Esta relación es inversa en el 2012, en tanto los hombres disminuyen su posibilidad de ser informal en $1.4 \%$. El enfoque neoestructural recalca que las mujeres ocupan puestos de mayor vulnerabilidad o informales y aunque la brecha de género no es importante en el 2012, es importante observar que la tendencia cambia a favor del hombre, dado que disminuye su participación en la informalidad. Es preocupante porque indica una mayoritaria participación de la mujer, en empleos de baja calidad.

Las variables significativas y la tendencia de las variables como determinantes sobre la informalidad entre 2008 y 2012 son las siguientes:

Tabla 12. Significancia de las variables a un nivel del $1 \%$ y tendencia de las variables como determinantes sobre la informalidad

\begin{tabular}{|c|c|c|c|}
\hline Variables & 2008 & 2012 & Tendencia \\
\hline Educación & Significativa & & Decreciente \\
\hline Edad & & & Disminuve \\
\hline Casado & & & Disminuve \\
\hline Antigüedad & & $S$ & Aumenta \\
\hline$\frac{\text { Rama de actividad }}{\text { Construcción }}$ & & & \\
\hline
\end{tabular}




\begin{tabular}{|l|l|l|l|}
\hline $\begin{array}{l}\text { Comercio, restaurante yotes } \\
\text { Transporte }\end{array}$ & $\begin{array}{l}\text { Significativa } \\
\text { Significativa }\end{array}$ & $\begin{array}{l}\text { Significativa } \\
\text { Significativa } \\
\text { Significativa }\end{array}$ & $\begin{array}{c}\text { Aumenta } \\
\text { Disminuye } \\
\text { Disminuye }\end{array}$ \\
\hline $\begin{array}{l}\text { Posición ocupacional } \\
\text { Trabajador por cuenta propia }\end{array}$ & & & Aumenta \\
\hline $\begin{array}{l}\text { Salud } \\
\text { Pensión }\end{array}$ & & & Aumenta \\
\hline $\begin{array}{l}\text { Número de personas en la } \\
\text { Familia }\end{array}$ & Significativa & Significativa & Aumenta \\
\hline Género & & & Disminuye \\
\hline Jefe de Hogar & Significativa & Significativa & Disminuye \\
\hline
\end{tabular}

Fuente: Elaboración propia con base en el modelo probit

Los jefes de hogar en el 2008 aumentan la probabilidad de ser informal en 13.2\% en el 2008, y la disminuyen en el 2012 en 5.6\%. Aunque ser jefe de hogar incrementa la probabilidad de ser informal, dado que la imposibilidad de encontrar empleo en la formalidad, y la urgencia de sostener el hogar, obliga a los jefes de hogar a emplearse en cualquier tipo de empleo, en el periodo su impacto sobre la informalidad disminuyó, en consideración a que son una población con más educación y experiencia laboral.

En general, los resultados del modelo probit son similares a la Gran Encuesta Integrada de Hogares. No existe mucha diferencia en los resultados entre ambas metodologías y se puede afirmar que el modelo probit explica satisfactoriamente el comportamiento de los informales. La siguiente tabla muestra los resultados de la GEIH del 2012 y resultados del modelo probit en la misma fecha.

Tabla 13. Comparativo de la GEIH con el modelo probit en el año 2012

\begin{tabular}{|l|l|l|ll|}
\hline \multicolumn{1}{|c|}{ Variables } & \multicolumn{1}{|c|}{ GEIH } & \multicolumn{2}{c|}{ Modelo Probit } & \multicolumn{2}{c|}{ Comparación } \\
\hline Educación & $\begin{array}{l}\text { Con más años de } \\
\text { educación, se es menos } \\
\text { informal. Mientras el }\end{array}$ & $\begin{array}{l}\text { A medida que se estudia } \\
\text { más la probabilidad de } \\
\text { ser informal disminuye, }\end{array}$ & $\begin{array}{l}\text { La diferencia de de } \\
\text { influyente en án la }\end{array}$ \\
\hline
\end{tabular}




\begin{tabular}{|c|c|c|c|}
\hline & $\begin{array}{l}43.0 \% \text { de los informales } \\
\text { tiene } 5 \text { o menos años } \\
\text { de educación, el } 43.3 \% \\
\text { tiene de } 6 \text { a } 11 \text { años de } \\
\text { educación, el } 13.7 \% \\
\text { tiene de } 12 \text { a } 21 \text { años } \\
\text { de educación. }\end{array}$ & $\begin{array}{l}\text { aunque muy poco, en } \\
\text { apenas } 0.28 \%\end{array}$ & $\begin{array}{lr}\text { GEIH cuando } & \text { se } \\
\text { pasa a niveles de } 11 \\
\text { años o } & \text { más, } \\
\text { mientras } & \text { entre } \\
\text { primaria } & \text { y } \\
\text { bachillerato } & \text { no } \\
\text { existe } & \text { gran } \\
\text { diferencia. } & \text { El } \\
\text { modelo romparte } \\
\text { aunque } & \text { no } \\
\text { totalmente } & \text { el } \\
\text { resultado del } & \text { GEIH. }\end{array}$ \\
\hline Edad & $\begin{array}{l}\text { Hasta los } 25 \text { años se } \\
\text { encuentra el gran } \\
\text { grueso de la población } \\
\text { con } 47.3 \% \text {. }\end{array}$ & $\begin{array}{l}\text { A medida que se tienen } \\
\text { un año más de edad la } \\
\text { probabilidad para llegar a } \\
\text { la informalidad disminuye } \\
\text { en } 0.05 \%\end{array}$ & $\begin{array}{l}\text { Los resultados de la } \\
\text { GEIH indican que el } \\
\text { gran grueso de la } \\
\text { población en la } \\
\text { informalidad es } \\
\text { joven. Lo mismo } \\
\text { señala el modelo } \\
\text { probit. }\end{array}$ \\
\hline Casado & $\begin{array}{llr}\text { La mayoría de } & \text { los } \\
\text { informales no } & \text { son } \\
\text { casados ni viven } & \text { en } \\
\text { pareja } & & \\
\end{array}$ & $\begin{array}{lrr}\text { Si es casado, la } & \text { la } \\
\text { probabilidad de } & \text { ser } \\
\text { informal aumenta } & \text { en } \\
0.75 \% & & \end{array}$ & $\begin{array}{l}\text { No coinciden los } \\
\text { resultados de la } \\
\text { GEIH con el modelo. }\end{array}$ \\
\hline Antigüedad & $\begin{array}{l}\text { Los informales no } \\
\text { tienen } \\
\text { antigüedad }\end{array}$ & $\begin{array}{lrr}\text { Por cada año } & \text { de } \\
\text { antigüedad en el empleo } \\
\text { se disminuye } \\
\text { probabilidad la } \\
\text { informal en } 0.4 \% & \text { ser } \\
\end{array}$ & $\begin{array}{lr}\text { Coinciden los } \\
\text { resultados de la } \\
\text { GEIH con el modelo. }\end{array}$ \\
\hline $\begin{array}{ll}\text { Rama } & \text { de } \\
\text { actividad } & \\
\text { Construcción } & \\
\text { Comercio, } & \\
\text { restaurante y } \\
\text { hoteles } \\
\text { Transporte }\end{array}$ & $\begin{array}{l}\text { El } 3.6 \% \text { de los } \\
\text { informales trabaja en la } \\
\text { construcción, en } \\
\text { comercio, restaurante y } \\
\text { hoteles el } 36.7 \% \text { y el } \\
\text { transporte el } 12 \% \text {. En } \\
\text { total el } 52 \% .\end{array}$ & $\begin{array}{l}\text { En el modelo probit, la } \\
\text { Construcción } \\
\text { Comercio, restaurante y } \\
\text { hoteles } \\
\text { Transporte son las ramas } \\
\text { que tienen mayor } \\
\text { probabilidad de emplear } \\
\text { informales }\end{array}$ & $\begin{array}{lr}\text { Coinciden los } & \text { los } \\
\text { resultados de la } \\
\text { GEIH con el modelo. }\end{array}$ \\
\hline $\begin{array}{l}\text { Posición } \\
\text { ocupacional } \\
\text { Trabajador por } \\
\text { cuenta propia }\end{array}$ & $\begin{array}{l}\text { El } 50.9 \% \text { es trabajador } \\
\text { por cuenta propia }\end{array}$ & $\begin{array}{l}\text { El trabajador por cuenta } \\
\text { propia aumenta su } \\
\text { posibilidad de ser } \\
\text { informal con respecto a } \\
\text { los trabajadores de una } \\
\text { empresa particular en } \\
17.7 \% \text {. }\end{array}$ & $\begin{array}{l}\text { Coinciden los } \\
\text { resultados de la } \\
\text { GEIH con el modelo }\end{array}$ \\
\hline Salud & $\begin{array}{l}\text { El } 99 \% \text { es cotizante } \\
\text { para salud }\end{array}$ & 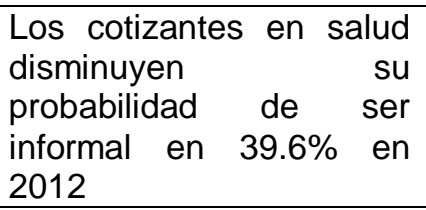 & $\begin{array}{l}\text { No coinciden los } \\
\text { resultados de la } \\
\text { GEIH con el modelo }\end{array}$ \\
\hline Pensión & $\begin{array}{l}\text { El } 26.3 \% \text { está afiliado y } \\
\text { el } 73.7 \% \text { no está } \\
\text { afiliado. }\end{array}$ & \begin{tabular}{l}
\multicolumn{3}{l}{ Los cotizantes en pensión } \\
disminuyen \\
probabilidad de su \\
informal en $35.9 \%$.
\end{tabular} & $\begin{array}{lr}\text { Coinciden los } \\
\text { resultados de la } \\
\text { GEIH con el modelo }\end{array}$ \\
\hline
\end{tabular}




\begin{tabular}{|l|l|l|l|}
\hline $\begin{array}{l}\text { Número de } \\
\text { personas en la } \\
\text { Familia }\end{array}$ & $\begin{array}{l}\text { El } 61.5 \% \text { de los } \\
\text { informales no son } \\
\text { familias numerosas }\end{array}$ & $\begin{array}{l}\text { La probabilidad de ser } \\
\text { informal por formar parte } \\
\text { de una familia numerosa } \\
\text { fue de } 27.53 \% .\end{array}$ & $\begin{array}{l}\text { No coinciden los } \\
\text { resultados de la } \\
\text { GElH con el modelo }\end{array}$ \\
\hline Género & $\begin{array}{l}\text { El } 51.4 \% \text { son mujeres y } \\
\text { el } 48.6 \% \text { son hombres }\end{array}$ & $\begin{array}{l}\text { Los hombres aumenta la } \\
\text { probabilidad de ser } \\
\text { informal en 1.4\%. }\end{array}$ & $\begin{array}{l}\text { Coinciden los } \\
\text { resultados de la } \\
\text { GElH con el modelo }\end{array}$ \\
\hline Jefe de Hogar & $\begin{array}{l}\text { El } 46.4 \% \text { son jefes de } \\
\text { hogar. }\end{array}$ & $\begin{array}{l}\text { Los jefes de hogar } \\
\text { aumentan la probabilidad } \\
\text { de ser informal en 5.6\%. }\end{array}$ & $\begin{array}{l}\text { Coinciden los } \\
\text { resultados de la } \\
\text { GElH con el modelo }\end{array}$ \\
\hline
\end{tabular}

Fuente: Elaboración propia con base en el modelo probit y la GEIH.

Los resultados de la GEIH y el modelo probit indica que la superioridad al promedio nacional de la informalidad en la ciudad de Villavicencio es explicada desde el enfoque neoestructural, como un fenómeno cuyo origen está asociado a la estructura de la economía. En este sentido, en la ciudad existen sectores ampliamente atrayentes de empleo, pero ofrecen pocas garantías a quienes lo asumen. Específicamente el comercio y servicios, es el sector que atrae, más de la mitad del empleo, pero aporta a una disminución en la productividad laboral.

La caída en la productividad se asocia a la presencia de empleos de mala calidad, con contratos verbales que no incluyen prestaciones sociales y garantías laborales que por ley debe tener un trabajador. Este tipo de empleos se potencializa en el comercio y servicios, cuya propia naturaleza abriga el medio óptimo para multiplicar la informalidad. Pequeños negocios dirigidos por trabajadores por cuenta propia, de menos de cinco empleados y trabajadores familiares sin remuneración, hacen expedita la proliferación de personas que hayan en la informalidad un medio de acceder a empleo y resolver su situación económica, aunque no de la mejor manera posible.

Cimoli considera que la informalidad se origina por la baja demanda laboral en el sector formal y el sector informal recibe la oferta residual (Cimoli, Primi, \& Pugno, 2006). El modelo probit muestra que no solamente la informalidad se origina por la baja demanda laboral, también muestra que un factor de la oferta laboral, la creciente mano de obra a raíz de familias numerosas, es apoyo a la informalidad. 
Las recomendaciones y esfuerzos por disminuir las cifras de informalidad pasan por modernizar a las empresas formales y formalizar a las informales. En la tabla 14 se muestra un comparativo entre el enfoque neoestructural, la ley 1429 de 2010 (ley de formalización y generación de empleo) y el Plan de Desarrollo Municipal, así como una incipiente propuesta para afrontar el fenómeno.

Tabla 14. Comparativo para afrontar el fenómeno de la informalidad

\begin{tabular}{|c|c|c|c|}
\hline $\begin{array}{lr}\text { Propuesta } & \\
\text { Neoestructural } & \text { para } \\
\text { Incrementar } & \text { la } \\
\text { formalización } & \end{array}$ & $\begin{array}{l}\text { Ley } 1429 \text { de } 29 \text { de } \\
\text { diciembre de } 2010 \\
\text { (ley de formalización } \\
\text { y generación de } \\
\text { empleo) }\end{array}$ & $\begin{array}{l}\text { Plan de desarrollo } \\
\text { del municipio de } \\
\text { Villavicencio 2012- } \\
2015\end{array}$ & $\begin{array}{l}\text { Propuesta } \\
\text { afrontar } \\
\text { informalidad }\end{array}$ \\
\hline 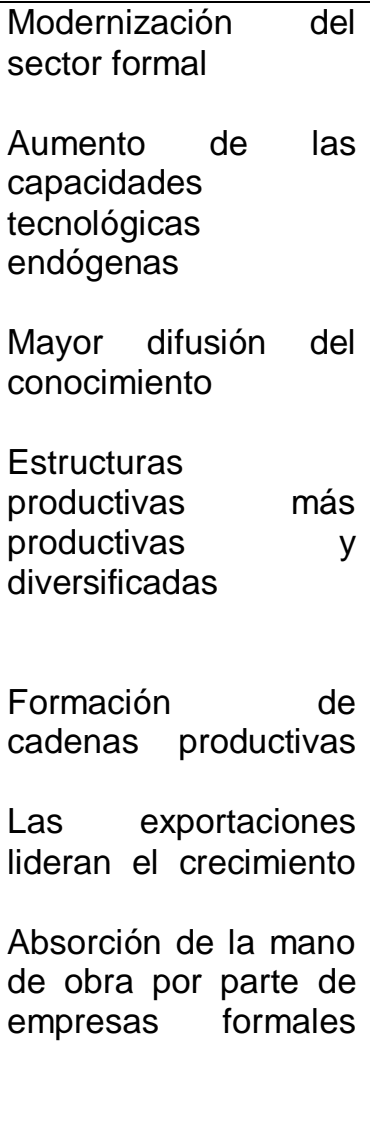 & $\begin{array}{lr}\text { Busca formalizar } \\
\text { empleos y empresas } \\
\text { informales, y } \\
\text { aumento de empleos } \\
\text { formales. Mediante: } \\
\text { eliminación r de } \\
\text { algunos trámites } \\
\text { laborales } \\
\text { comerciales, } \\
\text { beneficios a pequeñas } \\
\text { empresas ran con } \\
\text { descuentos en los } \\
\text { parafiscales * y tarifa } \\
\text { preferencial en el } \\
\text { impuesto de renta a } \\
\text { las pequeñas } \\
\text { empresas que se } \\
\text { formalicen. }\end{array}$ & 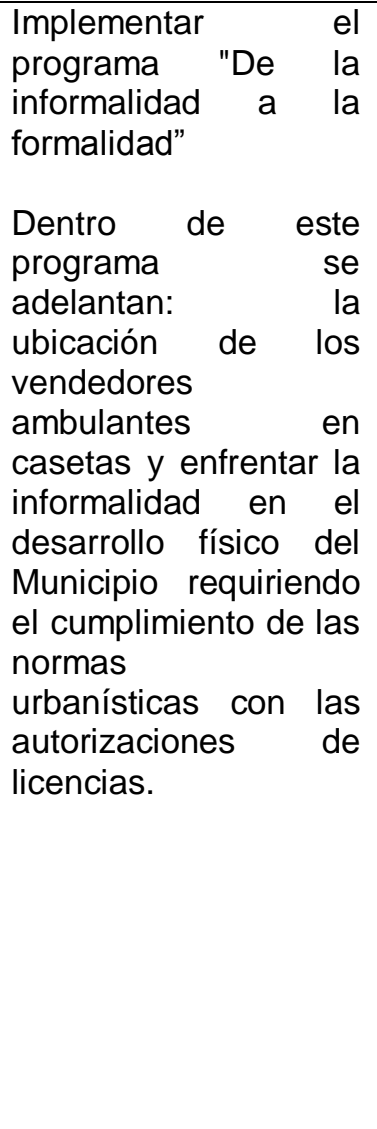 & $\begin{array}{l}\text { Combina la propuesta } \\
\text { neoestructural de } \\
\text { modernización del } \\
\text { sector formal con la } \\
\text { ley de formalización } \\
\text { de empleos y } \\
\text { empresas informales, } \\
\text { para acelerar desde } \\
\text { ambas estrategias la } \\
\text { formalización del } \\
\text { empleo las } \\
\text { empresas informales. } \\
\text { Es difícil dentro de } \\
\text { esta propuesta } \\
\text { encontrar puntos } \\
\text { comunes en el Plan } \\
\text { de Desarrollo del } \\
\text { Municipio de } \\
\text { Villavicencio, pues se } \\
\text { limita a la } \\
\text { recuperación del } \\
\text { espacio público con el } \\
\text { propósito de "velar por } \\
\text { el cumplimiento de la } \\
\text { normatividad" } \\
\text { (Contraloría Municipal } \\
\text { de Villavicencio, 2013) }\end{array}$ \\
\hline
\end{tabular}

Fuente: Elaboración propia con base en Ley 1429 de 29 de diciembre de 2010 y Plan de Desarrollo del municipio de Villavicencio 2012-2015

Una nueva propuesta para agilizar los procesos de formalización incluye mezclar 
la propuesta neoestructural y la ley de formalización. Lo anterior debe complementarse con políticas integrales que no solo involucren la transformación de la empresa, también el cambio del individuo como sujeto que se concibe a si mismo con derechos y responsabilidades, los cuales debe asumir con pasión y conciencia ciudadana. 


\section{Conclusiones}

Villavicencio es el principal centro político y económico del departamento del Meta y la región de la Orinoquia. En esta se congrega poblaciones de todos los rincones del país y origina una confluencia de características de dos regiones, la Andina y la Llanera y da paso a un mestizaje social, creando su propia cultura, e informalidad que se unta de formalidad. La mayoría de sus características las explica el neoestructuralismo. A la vez que se debe tener presente que la informalidad está insertada en todo tipo de economías, llámense capitalistas o comunistas, desarrolladas o subdesarrolladas, el fenómeno merece un tratamiento discriminado por lugar geográfico, para hallar sus propias particularidades regionales.

La escuela de pensamiento neoestructuralista, ha continuado el pensamiento de la escuela estructuralista, pero adaptado en un contexto de internacionalización, por tanto formula insertar las economías latinoamericanas en el comercio internacional con el propósito de alcanzar una convergencia de los países latinoamericanos hacia los más desarrollados mediante trasferencia de conocimiento y tecnología, para potenciar las capacidades tecnológicas endógenas. Pero la persistencia de dos sectores uno formal y otro informal que concentra la mitad de la mano de obra es una restricción al crecimiento.

De los primeros que hablaron de dualidad, Carl Lewis, teórico del desarrollo elaboró un modelo dualista que requiere transformación productiva y superación 
de la heterogeneidad para alcanzar el desarrollo. Este modelo es base para análisis dual del neoestructuralismo, que explica la cohabitación de empresas con grandes desarrollos tecnológicos y altamente competitivas con empresas rezagadas en su dinámica empresarial. La ciudad de Villavicencio muestra esta heterogeneidad en donde la participación de las empresas grandes, generadoras de investigación, desarrollo y empleo informal presenta una participación mínima en un universo ampliamente dominado por empresas pequeñas e informales.

Como parte de su propuesta de desarrollo, los neoestructuralista proponen penetrar al mercado internacional mediante la captación del sector manufacturero a los otros sectores hacia la modernidad, ya que es por excelencia, el sector con más desarrollo tecnológico. Por el contrario, Villavicencio desplaza mano de obra de la manufactura a otros sectores que están rezagados, especialmente comercio y servicios. Es decir, se verifica que la ciudad se ha terciarizado y su mano de obra ha perdido valor agregado. Esta atracción del comercio y servicios de mano de obra, con actividades rezagadas de la productividad, aporta significativamente a la informalidad en la ciudad. En buena parte se debe a las mínimas barreras a la entrada y a la poca participación de otras ramas de actividad en la ciudad. Si se extiende el análisis al contexto actual de globalización, se observa que la economía no está evolucionando a favor de penetrar de las empresas locales al mercado internacional. Desde la demanda, la baja diversificación económica y la incapacidad del sector moderno de absorber la creciente oferta laboral, refuerza la segmentación en el mercado laboral.

La mayoría de puntos propuestos por el enfoque neoestructuralista, concuerdan con la situación en Villavicencio: los empleados informales no cotizan para pensión, los negocios informales no están registrados y no llevan contabilidad, existe crecimiento de la informalidad, son trabajadores por cuenta propia, se favorece la heterogeneidad y aumenta la informalidad con el comercio y servicios. No coincide la informalidad en Villavicencio con el punto de vista de los 
neoestructuralistas cuando afirman que: la mayoría de la informalidad son inmigrantes, existen brechas de género y se presentan bajos niveles de educación.

Se utiliza un modelo probit para mostrar la incidencia de las variables estructurales en la informalidad de Villavicencio. Este modelo permite utilizar variables de respuesta binaria como informalidad y minimiza problemas de autocorrelación y homocedasticidad. Las pruebas de validez del modelo y bondad de ajuste son favorables, por tanto es válido utilizarlo para explicar la influencia de variables explicativas sobre la informalidad.

Los principales determinantes sobre la informalidad son: comercio y servicios, transporte, número de personas en el hogar y jefe de hogar. Se resalta la actividad comercio y servicios como importante factor para la existencia de la informalidad. La ciudad se visualiza como un centro de actividades comerciales cuyo aporte a la informalidad es representativo, porque pululan negocios con empelados informales quienes encuentran en este medio un modo de subsistencia.

Las recomendaciones para superar la problemática, desde el enfoque neoestructural, no es legalizar lo informal, como actualmente se está realizando con "la ley de la formalización"; es modernizar las empresas formales, para aumentar la producción y la productividad, y favorecer la creación de mano de obra formal. Las reformas dirigen la producción hacia bienes sofisticados de alto valor agregado y a la vez, intensivos en mano de obra y capital. "El cambio estructural implica reorientar la especialización del sector formal hacia etapas o industrias con mayor contenido de conocimiento y más diversificadas" (Cimoli, Primi, \& Pugno, 2006, p.99). De esta forma, la mano de obra se traslada de los sectores informales al formal y se elimina la heterogeneidad existente por la presencia de la economía informal e informal. 
Sin embargo una mezcla entre mejorar los resultados del sector formal y formalizar lo informales es una estrategia combinada que tiene más efecto en ciudades como Villavicencio, atestada de negocios informales. Buscar un círculo virtuoso en donde confluyen la formalización de los informales y la modernización de los formales, acelera el proceso de formalización, ya que surgen sinergias entre las empresas recién formalizadas y las formales, más grandes y tecnificadas que consolidarían el proceso.

Por tanto las políticas para aumentar la actividad formal no solamente debe estar destinadas a empresas de tipo manufacturera, también debe involucrar todo tipo de empresas, incluyendo comercio, servicios y agricultura. La producción de bienes y servicios de alto valor agregado, en actividades generadoras de empleo en comercio y servicios como las finanzas, ingeniería, consultoría y construcción, el turismo y telecomunicaciones, exportables y de gran impacto en la economía de la ciudad, dado su carácter terciario, apoyarían en gran medida la formalización.

Además deben incrementarse los esfuerzos en torno a la agroindustria, para el aprovechamiento de productos agropecuarios en especial lácteos, soya, carne, cuero, embriones congelados de peces y frutas en función de ofrecer productos de larga vida, cuya expiración es de meses o años. Lo anterior se logra con programas sólidos de emprendimiento y financiación que garantice el acceso a los recursos. La formalización y el desarrollo son resultados de las mismas políticas de apoyo a la transformación de la estructura productiva y acrecentar las condiciones que facilitan este cambio.

Con relación a la educación como instrumento para disminuir los niveles de informalidad es menester adelantar dos acciones: la primera incrementar la calidad académica por medio de estrategias cuyas finalidades sean formar al individuo como ciudadanos con principios, valores y con interés por el 
conocimiento; y habilidades para enfrentar y afrontar el cambio. Esto implica cambiar la mentalidad del profesional y tecnólogo, quien se concibe así mismo como empleado, e inculcarle en su formación que es posible verse y ser empresario.

Los profesionales y tecnólogos como líderes del cambio deben ser reclutados por el gobierno y entidades privadas para adelantar programas de capacitación en emprendimiento y educación financiera; además de ser gentes multiplicadores para cambiar la percepción frente al funcionamiento del mercado, es decir, propender por deshabituar a las personas de considerar las actividades informales como el único medio de subsistencia.

Esta investigación hace parte de la línea de investigación denominada desarrollo humano, puesto que plantea desde diversas dimensiones como la laboral, profesional, cultural y política, la posición de la mayoría de los trabajadores de la ciudad de Villavicencio, la informalidad. Definirse como empleado en nuestra sociedad, trae consigo la noción de crecimiento personal y de progreso. crecimiento personal requiere entre otros, desarrollar las fortalezas profesionales y laborales, además de la capacidad de decidir que se quiere hacer con la vida. Dentro de la informalidad no existen estas condiciones. Un empleado informal se encuentra laborando en negocios pequeños, sin organización y sin propósitos claros. En este espacio, el desarrollo de sus ideas y capacidades están enormemente limitados en un entorno, donde lo único importante es lograr la venta del día y sobrevivir.

El sujeto pierde de vista la capacidad de influir en su estilo de vida. Simplemente se ajusta a su entorno, en donde las relaciones laborales son inciertas. Los empleados devengan exiguo ingresos, y no están amparados por la legislación laboral. En este panorama, el autoestima no se desarrolla y no se alcanza el logro o reconocimiento social. Es una situación generalizada y verificable en el paisaje 
urbano de Villavicencio. Las calles y las edificaciones se encuentran plagadas de negocios informales y personas quienes trabajan por cuenta propia. La infraestructura propia para el crecimiento económico se encuentra atrofiada. Aumentan en la ciudad construcciones hibridas entre viviendas y modificaciones leves para convertirlas en negocios y las calles están ocupadas por vendedores ambulantes quienes toman el espacio público como propio. La ciudad se encuentra sumergida en un letargo complaciente, que oculta esta dura realidad. 


\section{ANEXOS}

Tabla A.1: Información estadística de la informalidad en Villavicencio

\begin{tabular}{|c|l|c|}
\hline Nro. & PREGUNTAS \\
\hline 1 & Sexo & OP \\
\hline
\end{tabular}

\begin{tabular}{|c|c|}
\hline 2 & Edad \\
\hline 3 & ¿Sabe leer y escribir? \\
\hline 4 & ¿Estudia actualmente? \\
\hline
\end{tabular}

¿Cuàl es el nivel educativo? OPCIONES DE RESPUESTA

\begin{tabular}{|c|c|}
\hline $\mathbf{2 0 0 2}$ & $\mathbf{2 0 0 8}$ \\
\hline \multicolumn{3}{|c|}{ (Porcentajes) } \\
\hline 45.8 & 47.7 \\
\hline
\end{tabular}

Hombre

Mujer

Hasta los 25 años

De 26 a 60 años

De 6186 años

$\mathrm{Si}$

No

No

\section{Ninguno}

Primaria completa

Secundaria completa

Universitaria completa

Postgrado

6 Horas a la semana de trabajo

Hasta 24 horas

De 25 a 48 horas

Más de 48 horas

¿Cuál es la razón por la que trabaja normalmente

Es lo único que ha conseguido pero quiere

trabajar más horas

Es la jornada que se ajusta a sus necesidades

8 ¿En que horario realizó su trabajo principal?

En horario $u$ horarios fijos

Por tunos rotatorios

9 Además de las horas que trabaja actualmente,

Si

9 ¿quiere trabajar más horas?

No

Vendedores, empleados de comercio y

trabajadores asimilados

10 Ocupación

Personal de servidumbre

Obreros de la construcción

Comerciantes propietarios (comercio al por

mayor y al por menor)

Trabajó en su oficio (plomero, taxista,

11 Formas de trabajo

doméstica por dias, vendedor ambulante, etc.)

¿Tiene un negocio de industria, comercio,

servicios o una afin?

¿Trabajo vendiendo por catálogo?

Obrero o empleado de empresa particular

Trabajador por cuenta propia

12 ¿En este trabajo es? Empleado doméstico

13 ¿Tiene contrato de trabajo?

14 ¿El contrato es verbal o escrito?

15 El contrato de trabajo es a término

16 ¿La empresa que lo contrató es la misma donde presta los servicios?

Si la empresa que lo contrató no es la misma donde

17 presta sus servicios, entonces la empresa que lo contrató es:

18 ¿Está conforme con el tipo de contrato que tiene?

19 ¿Por su contrato actual recibe prima de navidad?

20 ¿Por su contrato actual recibe derechos de

cesantías?

21 ¿Por su contrato actual recibe vacaciones con sueldo

$\mathrm{Si}$

No

Verbal

Escrito

A término fijo

A término indefinido

$\mathrm{Si}$

No

Otra

Empresa de servicios temporales

Cooperativa de trabajo asociado

$\mathrm{Si}$

No

$\mathrm{Si}$

No

No

\begin{tabular}{l|lll}
21 & ¿Por su contrato actual recibe vacaciones con sueldo & Si \\
\cline { 3 - 4 } & & & No \\
& &
\end{tabular}

22 ¿Porqué medio principal consiguió el empleo actual?

No

Pidiendo ayuda a familiares, amigos o colegas

Visitando, enviando o llevando hojas de vidas a empresas o empleadores

Puso o consultó avisos clasificados

De\$ 0 a $\$ 600.000$

23 ¿Cuanto ganó el mes pasado en el empleo?

De $\$ 610.000$ a $\$ 1.000 .000$

De $\$ 1.100 .000$ en adelante

24 ¿El mes pasado recibió ingresos por horas extras?

$\mathrm{Si}$

25 ¿Además del salario, recibió alimentos como parte de

¿Además del dinero, recibió pago en especie?

26 (electrodomesticos, ropa, etc.)

27 ¿Tiene auxilio de transporte?

28 ¿Tiene subsidio familiar?

\begin{tabular}{l|l|l}
\hline 54.2 & 52.3 & 48.6 \\
\hline 57.2 & 43.1 & 47.3
\end{tabular}

47.3

\begin{tabular}{l|l|l}
37.5 & 44.5 & 41.8 \\
\hline
\end{tabular}

\begin{tabular}{|l|l|l}
\hline 5.3 & 12.4 & 10.9 \\
\hline 78.7 & 89.9 & 89.9 \\
\hline
\end{tabular}

\begin{tabular}{|l|l|l}
\hline 8.7 & 89.9 & 89.9 \\
\hline 9.6 & 10.1 & 10.1 \\
\hline
\end{tabular}

\begin{tabular}{l|l|l}
\hline 24.4 & 29.5 & 30.5 \\
\hline
\end{tabular}

\begin{tabular}{c|c|c}
63.9 & 70.5 & 69.5 \\
12,9 & 8.3 & 7.1
\end{tabular}

55,7 n.d. $\quad$ n.d.

\begin{tabular}{c|c|c}
\hline 30,8 & 65.2 & 71.9 \\
\hline 0,6 & 13.7 & 10.8 \\
\hline
\end{tabular}

\begin{tabular}{l|l|l} 
n.d. & 5.4 & 2.7 \\
\hline
\end{tabular}

\begin{tabular}{l|l|l}
12.6 & 21.8 & 22.8 \\
\hline 35.3 & 42.9 & 40.6
\end{tabular}

\begin{tabular}{l|l|l}
\hline 52.1 & 35.3 & 36.6 \\
\hline
\end{tabular}

\begin{tabular}{l|l|l} 
n.d. & 54.1 & 36.2
\end{tabular}

\begin{tabular}{l|l|l} 
n.d. & 45.3 & 62.4
\end{tabular}

\begin{tabular}{l|l|l} 
n.d. & 56.2 & 73.1 \\
\hline
\end{tabular}

\begin{tabular}{|l|l|l} 
n.d. & 43.8 & 26.9 \\
\hline
\end{tabular}

\begin{tabular}{|l|l|l} 
n.d. & 13.7 & 17.0 \\
\hline
\end{tabular}

\begin{tabular}{l|l|l} 
n.d. & 86.3 & 83.0 \\
\hline
\end{tabular}

\begin{tabular}{l|l|l}
\hline & 15.8 & 14.4 \\
\hline
\end{tabular}

\begin{tabular}{c|c|c}
10.4 & 12.7 & 8.4 \\
\hline 4.9 & 3.9 & 6.4
\end{tabular}

\begin{tabular}{l|l|l}
2.8 & 9.3 & 12.5 \\
\hline
\end{tabular}

\begin{tabular}{l|l|l} 
n.d. & 43.7 & 65.9
\end{tabular}

\begin{tabular}{l|l|l} 
n.d. & 37.3 & 19.5
\end{tabular}

\begin{tabular}{c|c|c} 
n.d. & 4.1 & 4.7 \\
\hline
\end{tabular}

\begin{tabular}{l|l|l}
\hline 46.8 & 12.4 & 15.2 \\
\hline 36.4 & 71.4 & 65.4
\end{tabular}

\begin{tabular}{l|l|l}
\hline 36.4 & 71.4 & 65.4 \\
\hline
\end{tabular}

\begin{tabular}{l|c|c}
36.4 & 71.4 & 65.4 \\
\hline 7.1 & 8.3 & 6.7 \\
\hline
\end{tabular}

\begin{tabular}{l|l|l}
7.1 & 8.3 & 6.7 \\
\hline 23.1 & 88.8 & 26.2 \\
\hline
\end{tabular}

\begin{tabular}{|c|c|c}
\hline n.d. & 88.8 & 73.8 \\
\hline & 32.8 & 85.8 \\
\hline
\end{tabular}

\begin{tabular}{l|l|l} 
n.d. & 67.2 & 14.1 \\
\hline
\end{tabular}

\begin{tabular}{l|l|l}
\hline 11.7 & 69.2 & 32.8 \\
\hline 19.3 & 30.8 & 67.0
\end{tabular}

\begin{tabular}{l|l|l}
11.7 & 69.2 & 32.8 \\
\hline 19.3 & 30.8 & 67.0 \\
\hline 4
\end{tabular}

\begin{tabular}{|c|c|c|}
\hline 49.0 & 98.3 & 98.7 \\
\hline 8.0 & 1.7 & 1.3 \\
\hline
\end{tabular}

\begin{tabular}{|r|r|r}
\hline 8.0 & 1.7 & 1.3 \\
n.d. & n.d. & 58.9
\end{tabular}

\begin{tabular}{c|c|c} 
n.d & n.d. & 28.6 \\
\hline
\end{tabular}

\begin{tabular}{c|c|c} 
n.d. & n.d. & 10.7
\end{tabular}

\begin{tabular}{l|l|l} 
n.d. & 72.4 & 74.7 \\
\hline
\end{tabular}

\begin{tabular}{l|l|l} 
n.d. & 27.6 & 25.3 \\
\hline
\end{tabular}

\begin{tabular}{c|c|c} 
n.d. & 5.2 & 9.7 \\
\hline
\end{tabular}

\begin{tabular}{c|c|c} 
n.d. & 94.8 & 90.3 \\
\hline
\end{tabular}

\begin{tabular}{l|l|l} 
n.d. & 55.2 & 17.3 \\
\hline
\end{tabular}

\begin{tabular}{|c|c|c|} 
n.d. & 44.8 & 82.7 \\
\hline n.d. & 60.3 & 17.1
\end{tabular}

\begin{tabular}{|c|c|c|}
\hline n.d. & 60.3 & 17.1 \\
\hline n.d. & 39.7 & 82.9 \\
\hline
\end{tabular}

\begin{tabular}{l|l|l}
\hline 44.7 & 95.4 & 92.6 \\
\hline
\end{tabular}

\begin{tabular}{l|l|l}
7.9 & 2.8 & 5.1
\end{tabular}

\begin{tabular}{l|l|l} 
n.d. & 0.9 & 0.5
\end{tabular}

\begin{tabular}{l|l|l}
\hline 93.8 & 86.0 & 84.0 \\
\hline 5.4 & 9.3 & 13.4
\end{tabular}

\begin{tabular}{|c|c|c|}
\hline 5.4 & 9.3 & 13.4 \\
\hline 0.8 & 4.7 & 2.6 \\
\hline
\end{tabular}

\begin{tabular}{l|l|l} 
n.d. & 2.8 & 1.3
\end{tabular}

\begin{tabular}{c|c|c} 
n.d. & 97.2 & 98.6 \\
\hline
\end{tabular}

\begin{tabular}{l|l|l}
14.5 & 40.7 & 39.5 \\
\hline 43.3 & 59.3 & 60.4
\end{tabular}

\begin{tabular}{c|c|c}
\hline 43.3 & 59.3 & 60.4 \\
\hline n.d. & 0.9 & 0.6
\end{tabular}

\begin{tabular}{c|c|c} 
n.d. & 0.9 & 0.6 \\
n.d. & 99.1 & 99.3 \\
\hline n.d. & 19.4 & 17.3
\end{tabular}

\begin{tabular}{c|c|c} 
n.d. & 19.4 & 17.3 \\
\hline
\end{tabular}

\begin{tabular}{c|c|c} 
n.d. & 9.3 & 4.0 \\
\hline n.d. & 90.7 & 96.0
\end{tabular} 
Tabla A.1: (Continuación)

\begin{tabular}{|c|c|c|c|c|c|}
\hline \multirow{2}{*}{29} & \multirow{2}{*}{ ¿Tiene prima de vacaciones? } & $\mathrm{Si}$ & n.d. & 0.9 & 4.6 \\
\hline & & No & n.d. & 99.1 & 95.4 \\
\hline \multirow{2}{*}{30} & \multirow{2}{*}{ ¿Tiene prima de navidad? } & Si & n.d. & 1.9 & 8.1 \\
\hline & & No & n.d. & 98.1 & 91.9 \\
\hline \multirow{2}{*}{31} & \multirow{2}{*}{ ¿Tiene prima de servicios? } & Si & n.d. & 25.9 & 14.5 \\
\hline & & No & n.d. & 74.1 & 85.5 \\
\hline \multirow{2}{*}{32} & \multirow{2}{*}{$\begin{array}{l}\text { Afiliados como cotizantes o beneficiario a alguna } \\
\text { entidad de salud }\end{array}$} & Si & 65.2 & 85.3 & 88.9 \\
\hline & & No & 33.8 & 14.7 & 25.5 \\
\hline & & Contributivo & 58.2 & 63.1 & 58.4 \\
\hline 33 & Afiliación al régimen contributivo o subsidiado & Subsidiado & 7.0 & 31.1 & 34.4 \\
\hline & & Otros. Fuerzas armadas, Ecopetrol, & n.d & 5.9 & 7.0 \\
\hline & & Paga una parte y la otra la empresa o patrón & 36.1 & 24.3 & 23.9 \\
\hline 34 & Paga mensualmente por la afiliación a salud & No paga. Es beneficiario & 11.4 & 55.4 & 57.8 \\
\hline & & Paga la totalidad la empresa o patrón & n.d. & 15.1 & 12.5 \\
\hline & ¿En los últimos meses dejó de asistir al médico o no & $\mathrm{Si}$ & n.d & 3.9 & 89.9 \\
\hline 35 & $\begin{array}{l}\text { se hospitalizó, porque no tenía conque pagar una EPS } \\
\text { o ARS? }\end{array}$ & No & n.d & 96.1 & 10.1 \\
\hline & & $\mathrm{Si}$ & 33.5 & 19.3 & 8.1 \\
\hline 36 & Afiliación a un fondo de pensiones & No & 61.2 & 78.2 & 88.9 \\
\hline & 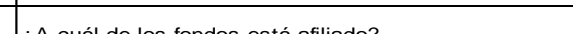 & Fondo Privado & n.d. & 58.8 & 56.6 \\
\hline 37 & ¿A cuál de los fondos está afiliado? & ISS, Cajanal & n.d. & 38.0 & 30.2 \\
\hline & & Paga una parte y la otra la empresa o patrón & 28.6 & 41.0 & 37.1 \\
\hline 38 & Paga mensualmente por la afiliación a pensión & Paga la totalidad de su afiliación & 3.4 & 46.0 & 57.1 \\
\hline & & $\mathrm{Si}$ & n.d. & 9.8 & 3.6 \\
\hline 39 & ¿Está afiliado a una caja de compensación familiar? & No & n.d. & 90.2 & 96.3 \\
\hline & & Hasta 1 año & 44.1 & 30.7 & 37.3 \\
\hline 40 & Tiempo que lleva trabajando de manera continua en la & De 1 a 5 años & 30.0 & 30.5 & 28.8 \\
\hline & & De 5 años en adelante & 25.9 & 38.8 & 34.5 \\
\hline 41 & & De 0 a 11 meses & n.d. & 23.9 & 23.2 \\
\hline 41 & ¿Cuanto tiempo trabajó en los últimos 12 meses? & 12 meses & n.d. & 76.1 & 76.8 \\
\hline 42 & L Cunntas nersonas on total tiene la emnresa? & Trabaja solo & 49.8 & 67.8 & 59.7 \\
\hline 42 & ¿Cuantas personas en total tiene la empresa? & De 2 a 5 personas & 50.2 & 32.2 & 40.3 \\
\hline & & Local fijo (oficina, fábrica, etc.) & 30.2 & 29.9 & 28.7 \\
\hline & & En su vivienda & 25.6 & 22.2 & 21.7 \\
\hline 43 & ¿Donde realiza principalmente su trabajo? & $\begin{array}{l}\text { Sitio al descubierto en la calle (ambulante y } \\
\text { estacionario) }\end{array}$ & 11.9 & 14.1 & 9.9 \\
\hline & & En otras vivendas & 10.4 & 13.2 & 16.0 \\
\hline 44 & ¿Cuantos meses estuvo sin empleo entre el trabajo & Hasta 12 meses & 85.3 & 82.2 & 86.3 \\
\hline 44 & anterior y el actual? & De 13 meses en adelante & 14.7 & 17.8 & 13.7 \\
\hline & & Trabajando & n.d. & 49.0 & 48.3 \\
\hline 45 & $\begin{array}{l}\text { ¿En que ocupó la mayor parte del tiempo la semana } \\
\text { pasada }\end{array}$ & Estudiando & n.d. & 21.6 & 17.1 \\
\hline & & Oficios del hogar & n.d. & 19.7 & 21.3 \\
\hline 46 & ¿Trabajó la semana pasada en un negocio familiar por & $\mathrm{Si}$ & n.d. & 2.1 & 3.1 \\
\hline 40 & una hora o más sin que le pagarán? & No & n.d. & 97.9 & 96.9 \\
\hline 47 & ¿Hizo en las últimas 4 semanas alguna diligencia & Si & n.d. & 12.8 & 34.5 \\
\hline 47 & para conseguir un trabajo o instalar un negocio? & No & n.d. & 87.2 & 65.5 \\
\hline & ¿Está afiliado por una empresa o individualmente a & $\mathrm{Si}$ & n.d. & 13.3 & 5.9 \\
\hline 48 & una aseguradora de riesgos profesionales (ARP)? & No & n.d. & 86.7 & 94.0 \\
\hline & ¿Además de la ocupación principal, tenía la semana & Si & n.d. & 2.9 & 6.6 \\
\hline 49 & pasada otro trabajo o negocio? & No & n.d. & 97.1 & 93.4 \\
\hline & - Desea cambiar el trahain oue tiene actualmente? & Si & n.d. & 28.6 & 36.4 \\
\hline 50 & ¿ ¿usea camolar en trabajo que nene actuamente? & No & n.d. & 71.4 & 63.6 \\
\hline & LNo le austa su trabain actual? & $\mathrm{Si}$ & n.d. & 11.5 & 23.5 \\
\hline 51 & ¿No le gusta su trabajo actual? & No & n.d. & 88.5 & 76.5 \\
\hline & & Insatisfecho & n.d. & 51.2 & 52.0 \\
\hline 52 & ¿Con los beneficios y prestaciones que recibe? & Satisfecho & n.d. & 33.8 & 43.4 \\
\hline & L Con suiornada lagoral actual? & Satisfecho & n.d. & 72.6 & 43.3 \\
\hline 53 & ¿Con su jornada laboral actual? & Insatisfecho & n.d. & 18.0 & 52.0 \\
\hline & & Ocasional & n.d. & 38.6 & 13.6 \\
\hline 54 & Este trabajo es: & Permanente & n.d. & 61.4 & 85.4 \\
\hline & Diligenció en las últimas 4 semanas para conseguir un & $\mathrm{Si}$ & n.d. & 0.2 & 39.0 \\
\hline 55 & empleo o montar un negocio & No & n.d. & 99.8 & 61.0 \\
\hline & L Como considera oue es su empleo o trabain actual? & Estable & n.d. & 51.5 & 55.3 \\
\hline 56 & ¿Como considera que es su empleo o trabajo actual? & Inestable & n.d. & 39 & 39.9 \\
\hline & Compatibilidad del trabajo con compromisos y & Compatible & n.d. & 87.3 & 89.9 \\
\hline 57 & deberes familiares & Incompatible & n.d. & 6.0 & 7.4 \\
\hline 58 & ¿Desea conseguir un trabajo remunerado o instalar un & Si & n.d. & 14.6 & 25.0 \\
\hline 58 & negocio? & No & n.d. & 85.4 & 75.0 \\
\hline & & Ayudas de hijos o familiares & n.d. & 53.7 & 49.6 \\
\hline 59 & $\begin{array}{l}\text { ¿en caso de no tener trabajo, de donde obtendria los } \\
\text { recursos principalmente? }\end{array}$ & No tendría recursos & n.d. & 22.0 & 13.9 \\
\hline & & Ahorros personales & n.d. & 6.8 & 9.5 \\
\hline 60 & Está afiliado o hace parte de una asociación sindical o & Si & n.d. & 0.2 & 0.7 \\
\hline 60 & gremial & No & n.d. & 99.8 & 99.3 \\
\hline 61 & Ha registrado el negocio ante alguna entidad (Cámara & Si & 1.2 & 29.9 & 53.3 \\
\hline & de Comercio, Alcaldías, Rut) & No & 38.8 & 70.1 & 46.7 \\
\hline & & De $\$ 0$ a $\$ 1.000 .000$ & 75.0 & 17.8 & 89.7 \\
\hline 62 & empleador: ¿Cuál fué la ganancia neta en la actividad, & De \$1.120.000 a \$5.000.000 & 22.8 & 49.5 & 10.0 \\
\hline & & De $\$ 5.000 .000$ en adelante & 2.2 & 32.7 & 0.3 \\
\hline
\end{tabular}


Tabla A.1: (continuación)

\begin{tabular}{|c|c|c|c|c|c|}
\hline \multirow{4}{*}{63} & \multirow{4}{*}{$\begin{array}{l}\text { Actividad de la empresa donde trabaja. Según código } \\
\text { a dos digitos de la CllU revisión } 3 \text { adaptada para } \\
\text { Colombia }\end{array}$} & $\begin{array}{l}\text { Comercio al por menor, excepto el comercio de } \\
\text { vehículos automotores y motocicletas; }\end{array}$ & 18.8 & 23.6 & n.d. \\
\hline & & $\begin{array}{l}\text { Actividades de hogares privados como } \\
\text { empleadores de personal doméstico }\end{array}$ & 6.8 & 8.5 & n.d. \\
\hline & & $\begin{array}{l}\text { Otras actividades empresariales (jurìdica, } \\
\text { contable, asesoría empresarial, ingeniería) }\end{array}$ & 4.1 & 8.1 & n.d. \\
\hline & & $\begin{array}{l}\begin{array}{l}\text { Transporte por vía terrestre; transporte por } \\
\text { tuberías }\end{array} \\
\end{array}$ & 4.9 & 6.5 & n.d. \\
\hline \multirow{4}{*}{64} & \multirow{4}{*}{$\begin{array}{l}\text { Rama de actividad de la empresa donde trabaja. } \\
\text { Según código a cuatro digitos de la ClIU revisión } 3 \\
\text { adaptada para Colombia }\end{array}$} & Transporte no regular individual de pasajeros & n.d. & 3.7 & 5.2 \\
\hline & & $\begin{array}{l}\text { Comercio al por menor, en establecimientos no } \\
\text { especializados, con surtido compuesto } \\
\text { principalmente de alimentos (Viveres en } \\
\text { general), bebidas y tabaco }\end{array}$ & n.d. & 3.9 & 4.8 \\
\hline & & $\begin{array}{l}\text { Construcción de edificaciones para uso } \\
\text { residencial }\end{array}$ & n.d. & 2.9 & 5.0 \\
\hline & & $\begin{array}{l}\text { Otros tipos de expendio de alimentos } \\
\text { preparados }\end{array}$ & n.d. & 1.9 & 4.0 \\
\hline \multirow{2}{*}{65} & \multirow{2}{*}{$\begin{array}{l}\text { El negocio o actividad lleva contabilidad o libro de } \\
\text { registro }\end{array}$} & $\mathrm{Si}$ & 1.2 & n.d. & 3.9 \\
\hline & & No & 38.8 & n.d. & 46.3 \\
\hline 66 & Tasa de informalidad & & 73.6 & 66.4 & 62.0 \\
\hline
\end{tabular}

Fuente: Cálculos propios con base en la Encuesta Continua de Hogares del DANE año 2002 y Gran Encuesta integrada de Hogares para años 2008 y 2012. n.d.=No existen datos. En algunas opciones de respuesta la suma no es de $100 \%$ porque se escoge las respuestas con mayor frecuencia. Las opciones de SI y NO, no siempre suma $100 \%$, porque existen valores perdidos en las encuestas. 
Tabla A.2: Valores mínimos y máximos de probabilidad de modelos lineal y probit de los años 2008 y 2012

\begin{tabular}{|c|c|c|c|c|}
\hline \multirow{2}{*}{ Año } & \multicolumn{3}{|c|}{2008} & \multicolumn{2}{c|}{2012} \\
\cline { 2 - 5 } & \multicolumn{3}{|c|}{ Valor de probabilidad } \\
\hline Mónimo & Máximo & Mínimo & Máximo \\
\hline Modelo Lineal & -0.5548 & 1.1805 & -0.1988 & 1.5117 \\
\hline
\end{tabular}

Fuente: Elaboración propia con base en la GEIH año 2008 y GEIH año 2012 del DANE

Tabla A.3: Selección de modelos mediante criterio de Akaike y Schwartz

\begin{tabular}{|c|c|c|c|c|}
\hline Año & \multicolumn{2}{|c|}{2008} & \multicolumn{2}{c|}{2012} \\
\hline Modelo & Probit & Logic & Probit & Logic \\
\hline $\begin{array}{c}\text { Criterio de } \\
\text { ajuste }\end{array}$ & & & & \\
\hline Akaike & 1266.09 & 1265.46 & 1308.12 & 1288.79 \\
\hline Schwartz & 1324.62 & 1323.98 & 1377.57 & 1353.25 \\
\hline
\end{tabular}

Fuente: Elaboración propia con base en la GEIH año 2008 y GEIH año 2012 del DANE 


\begin{tabular}{|c|c|}
\hline & Tabla A.4 \\
\hline \multicolumn{2}{|c|}{ Variables utilizadas en el modelo probit años 2008 y 2012} \\
\hline Variables & Definición \\
\hline Dependientes & $\begin{array}{l}\text { Se sigue la definición de informalidad del } \\
\text { DANE }\end{array}$ \\
\hline \multirow{2}{*}{ Informal } & $1=$ Informal \\
\hline & $0=$ Formal \\
\hline \multicolumn{2}{|l|}{ Independientes } \\
\hline \multirow{2}{*}{$\begin{array}{l}\text { Años aprobados de educación } \\
\text { Edad }\end{array}$} & $\begin{array}{l}\text { Es el número de años aprobados en } \\
\text { educación formal }\end{array}$ \\
\hline & Es la edad de la persona \\
\hline \multirow[t]{2}{*}{ Casado } & 1= Casado o en unión libre \\
\hline & $0=$ Otro caso \\
\hline $\begin{array}{l}\text { Antigüedad en años en el empleo } \\
\text { actual }\end{array}$ & Número de años que lleva en el empleo \\
\hline \multirow{9}{*}{ Rama de actividad } & 1=Agricultura \\
\hline & $2=$ Industria manufacturera \\
\hline & $3=$ Electricidad, gas y agua \\
\hline & 4=Construcción \\
\hline & $5=$ Comercio, restaurante y hoteles \\
\hline & $6=$ Transporte \\
\hline & $7=$ Comunicaciones \\
\hline & $8=$ Establecimientos financieros \\
\hline & 9=Servicios \\
\hline \multirow{6}{*}{$\begin{array}{l}\text { Posición ocupacional en el } \\
\text { empleo }\end{array}$} & 1= Obrero o empleado de empresa particular \\
\hline & 2=Obrero o empleado del gobierno \\
\hline & 3=Empleado doméstico \\
\hline & $4=$ Trabajador por cuenta propia \\
\hline & 5= Patrón o empleador \\
\hline & $6=$ Trabajador familiar sin remuneración \\
\hline \multirow{2}{*}{ Cotizante para salud } & 1=Si afiliado \\
\hline & $0=$ No afiliado \\
\hline \multirow{2}{*}{ Cotizante para pensión } & $1=$ Si afiliado \\
\hline & $0=$ No afiliado \\
\hline Nro. de personas en familia & $\begin{array}{l}\text { Se refiere al número de integrantes en la } \\
\text { familia }\end{array}$ \\
\hline \multirow{2}{*}{ Género } & 1=Hombre \\
\hline & $0=$ Mujer \\
\hline \multirow{2}{*}{ Jefe de Hogar } & $1=$ Jefe de Hogar \\
\hline & $0=$ Otro caso \\
\hline
\end{tabular}

Fuente: Elaboración propia con base la GEIH año 2008 y GEIH año 2012 del DANE. 


\begin{tabular}{|c|c|c|}
\hline \multicolumn{3}{|c|}{$\begin{array}{l}\text { Tabla A.5: Modelo Probit de informalidad para Villavicencio años } \\
2008 \text { y } 2012\end{array}$} \\
\hline & $\operatorname{Pr}(2008)$ & $\operatorname{Pr}(2012)$ \\
\hline Años aprobados de educación & $-0.1929^{\star \star}$ & -0.0144 \\
\hline Edad & -0.0029 & -0.0003 \\
\hline Casado & $0.1527^{\star \star}$ & 0.3744 \\
\hline Antigüedad en años en el empleo & -0.0044 & $-0.0216^{\star \star *}$ \\
\hline \multicolumn{3}{|l|}{ Rama de actividad (Base agricultura) } \\
\hline Industria manufacturera & $-0.8760^{\star *}$ & -1.5276 \\
\hline Electricidad, gas y agua & $-1.4330^{* *}$ & 0.0000 \\
\hline Construcción & -0.7622 & $0.9316^{* * *}$ \\
\hline Comercio, restaurante y hoteles & $1.3084^{\star \star \star}$ & $1.2829^{\star \star \star}$ \\
\hline Transporte & $1.7534^{\star \star \star}$ & $0.5217^{\star \star \star}$ \\
\hline Comunicaciones & -0.5514 & -0.1053 \\
\hline Establecimientos financieros & -0.5368 & $-0.3806^{* *}$ \\
\hline \multicolumn{3}{|c|}{$\begin{array}{l}\text { Posición ocupacional en el empleo (Base } \\
\text { obrero o empleado de empresa } \\
\text { particular) }\end{array}$} \\
\hline Obrero o empleado del gobierno & 0.0000 & $-1.5276^{* * *}$ \\
\hline Empleado doméstico & -0.4712 & 0.0000 \\
\hline Trabajador por cuenta propia & -0.1387 & $1.7770^{\star \star \star}$ \\
\hline Patrón o empleador & -0.0029 & $2.6362^{* * *}$ \\
\hline Trabajador familiar sin remuneración & $0.6161^{\star *}$ & $2.0867^{* * *}$ \\
\hline Cotizante de salud & $-0.3259^{* *}$ & $-0.234^{*}$ \\
\hline Cotizante de pensión & 0.2519 & 1.7961 \\
\hline Nro. de personas en la familia & $0.7171^{* * *}$ & $0.0773^{\star * *}$ \\
\hline Género & 0.7797 & -0.0671 \\
\hline jefe de hogar & $0.3513^{* * *}$ & $-0.2913^{* * *}$ \\
\hline
\end{tabular}

Fuente: Elaboración propia con base en la ENH año 2008 y GEIH año 2012 del DANE 
Tabla A.6: Ajuste del Modelo

\begin{tabular}{|l|c|c|}
\hline Años & $\mathbf{2 0 0 8}$ & $\mathbf{2 0 1 2}$ \\
\hline Nro. de observaciones & 970 & 2589 \\
\hline LR chi2(11) & 60.24 & 1618.49 \\
\hline Prob>chi2 & 0.0000 & 0.0000 \\
\hline & - & - \\
Log likelihood & 621.0447 & 643.0601 \\
\hline Pseudo R2 & 0.0463 & 0.5572 \\
\hline Capacidad de predicción & $85.58 \%$ & $92.16 \%$ \\
\hline Test de Wald & & \\
\hline chi2(11) & 57.70 & 943.50 \\
\hline Prob>chi2 & 0.0000 & 0.0000 \\
\hline
\end{tabular}

Fuente: Elaboración propia con base en la GEIH año 2008 y GEIH año 2012 del DANE

Tabla A.7: Pruebas de hipótesis para contrastar la validez de probit 2008 y 2012.

\section{Prueba de hipótesis para contrastar la validez del modelo probit 2008}

Ho: no existe correlación entre los errores del sistema de ecuaciones.

Ha: existe correlación entre los errores del sistema de ecuaciones.

Chi-squared $=60.24$

P-value, Chi-Squared $=0.0000$

Como la probabilidad es menor al $5 \%$, muestra que se aprueba la hipótesis nula Prueba de hipótesis para contrastar la validez del modelo probit 2012 Ho: no existe correlación entre los errores del sistema de ecuaciones. Ha: existe correlación entre los errores del sistema de ecuaciones.

Chi-squared $=1618.49$

P-value, Chi-Squared $=0.0000$

Como la probabilidad es menor al $5 \%$, muestra que se aprueba la hipótesis nula

Fuente: Elaboración propia con base en la GEIH año 2008 y GEIH año 2012 del DANE 
Tabla A.8. Matriz de clasificación

\begin{tabular}{|c|c|c|}
\hline \multicolumn{3}{|l|}{ Año 2008} \\
\hline Sensitivity & $\operatorname{Pr}(+\mid D)$ & $90.29 \%$ \\
\hline Specificity & $\operatorname{Pr}(-\mid \sim D)$ & $78.39 \%$ \\
\hline Correctly classified & & $85.58 \%$ \\
\hline \multicolumn{3}{|l|}{ Año 2009} \\
\hline Sensitivity & $\operatorname{Pr}(+\mid D)$ & $93.02 \%$ \\
\hline Specificity & $\operatorname{Pr}(-\mid \sim D)$ & $71.29 \%$ \\
\hline Correctly classified & & $87.37 \%$ \\
\hline
\end{tabular}

Elaboración propia con base en la GEIH año 2008 y GEIH año 2012 del DANE 


\section{Bibliografía}

Alcaldía de Villavicencio. (2010). Expediente Municipal. Unidad VI. Tránsito y Transporte. Villavicencio.

Alcaldía de Villavicencio. (2012). Plan de Desarrollo de Villavicencio, 2012-2015. Villavicencio.

Alvis, G. (2010). Fecundidad y participación de la mujer en el Mercado laboral. Revista Gerencia Politicas de salud Vol.9 Nro.19. Bogotá: Pontificia Universidad Javeriana..

Anisi, D. (1983). El papel de los salarios en la economía postkeynesiana. Cuadernos de economía, 231-247.

Asociación Nacional de Industriales (2011). Industria colombiana con el mayor crecimiento en América Latina en segundo semestre de 2011. Bogotá. Obtenido de: http://www.andi.com.co/pages/noticias/noticia_detalle.aspx ?ldNews=247.

Bacchetta, M. (2009). Trabajo informal y globalización en los países en desarrollo. Génova: Organización Mundial del Comercio y Organización Internacional del trabajo. 
Banco de la Republica- DANE (2009) . Informe de Coyuntura Económica Regional, 2009. Bogotá.

Banco de la República- DANE. (2012). Informe de Coyuntura Económica Regional, 2011. Bogotá.

Banco de la República-DANE. (2012). Informe de coyuntura Económica Regional. Bogotá: Departamento de Documentación y Editorial Banco de la República.

Beltrán Díaz, S. M., \& Gómez Ramos, V. (2005). Caracterización de los empleados informales de la ciudad de Villavicencio. Tesis de grado. Villavicencio: Universidad de los Llanos.

Beneria, L. (2006). Trabajo productivo/reproductivo, pobreza y políticas de conciliación. Revista Nómadas. Bogotá: Universidad Central.

Benjumea Yepes, H. (2007). Aproximación a la historia empresarial del Meta, 1960-2005. Villavicencio: Electrificadora del Meta. S.A. y Fondo Mixto de Promoción y Cultura de las Artes del Meta.

Berthomieu, C., Ehrhart, C., \& Hernández-Bielma, L. (2005). El neoestructuralismo como renovación del paradigma estructuralista de la economía del desarrollo. Revista latinamericana de Economía, 97.

Bielschowsky, R. (2009). Sesenta años de la Cepal: estructuralismo y neoestructuralismo. Revista de la CEPAL. 
Cabrera, E. (2007). Planeación ambiental del sector hidrocarburos para la conservación de la biodiversidad en los llanos en Colombia. Bogotá: Instituto de Investigación de Recursos Biológicos Alexander von Humboldt.

Cámara de Comercio de Bucaramanga. (2012). Indicadores económicos de Santander. Bucaramanga: Cámara de Comercio de Bucaramanga.

Cámara de Comercio de Villavicencio. (2014). Informe de Coyuntura Económica 2013. Villavicencio: Cámara de Comercio de Villavicencio.

Cámara de Comercio de Villavicencio. (2009). Censo de carretera VillavicencioBogotá. Villavicencio.

Cámara de Comercio de Villavicencio. (2011). Informe de Coyuntura Económica 2011. Villavicencio.

Capera Romero, L., \& González Arbeláez, Á. (Septiembre de 2011). Un índice de bancarización para Colombia. Resporte de estabilidad financiera. Bogotá, Colombia: Banco de la República.

Castells, M. y A. Portes (1989): «World Underneath: The Origins, Dynamics and Effects of the Informal Economy» en A. Portes, M. Castells y L. Benton (eds.): The Informal Economy. Studies in Advanced and Less Developed Countries, The Johns Hopkins University Press, Baltimore.

Castro Torres, A,T, \& Galvis López, C.R. (2002). Perfil epidemiológico de la población trabajadora de vendedores del sector informal de Villavicencio 
2002. Primer Congreso de Salud Pública . U. Javeriana. Obtenido de ttp://www.javeriana.edu.co/fcea/convocatorias/memorias_1congreso_sp/con greso_salud_compilado/ppt_present_orales/182ppt.pdf

Cataño, J. f. (2009). Lecciones de economía marxista. Bogotá: Universidad nacional de Colombia.

Centro de estudios de la construcción y el desarrollo urbano regional -CENAC-. (2012). Boletín estadístico-contexto sectorial-Villavicencio, Meta. Bogotá.

Centro de Investigaciones para el Desarrollo. (2003). Bienestar. Macroeconomía y pobreza. Bogotá: Universidad Nacional. Contraloría Gneral de la República.

Charry, A. (2003). La participación laboral de las mujeres no jefes de hogar en Colombia y el efecto del servicio doméstico. Borradores de economla No.262. Bogotá: Banco de la República.

Chen, M. (2007) Rethinking the Informal Economy: Linkages with the Formal Economy and the Formal Regulatory Environment. DESA Working Paper No. 46. Nueva York: United Nations

Cimoli, M. (2005). Heterogeneidad estructural, asimetrías tecnológicas y creimiento en América Latina. Santiago de Chile: Cepal.

Cimoli, M., Primi, A., \& Pugno, M. (2006). Un modelo de bajo:crecimiento: la informalidad con restricción estructural. Revista de la Cepal No. 88. 
Comisión Económica para América Latina y el Caribe. (2007). Progreso técnico y cambio estructural en América Latina. Santiago de Chile: Cepal

Comisión Económica para América Latina y el Caribe. (2008). La transformación productiva, veinte años después. Viejos problemas, nuevas oportunidades. Santiago de Chile: Cepal

Consejo Municipal de Villavicencio (2012). Plan de Desarrollo del Municipio de Villavicencio 2012- 2015. Villavicencio.

Contraloría Municipal de Villavicencio (2013). Informe preliminar de auditoria gubernamental al Plan de Acción y Metas del plan de desarrollo y la Secretaría de control físico del Municipio de Villavicencio. Villavicencio.

Corporación Desarrollo para la paz del Piedemonte Oriental. (2004). Conversatorios sobre el desarrollo en Villavicencio. Villavicencio: CORDEPAZ

Corredor Martínez Consuelo (1998). Colección documentos de la misión rural. Documento 10, pobreza. Bogotá: Ministerio de Agricultura y Desarrollo rural.

Delfino A. (2012) La noción de marginalidad en la teoría social latinoamericana: surgimiento y actualidad. Buenos Aires: Universidad Nacional del Rosario.

Departamento Administrativo Nacional de Estadística. (2005). Boletin Censo General 2005. Villavicencio, Meta. DANE

Departamento Administrativo Nacional de Estadísticas (2009). Metodologia informalidad gran encuesta integrada de hogares - GEIH-. Bogotá: DANE. 
Departamento Administrativo Nacional de Estadísticas (2010). Boletín de prensacuentas departamentales Base 2005. Bogotá: DANE.

Departamento Administrativo Nacional de Estadisticas. (2012). Cuentas Departamentales- Base 2005. Bogotá.

Departamento Administrativo Nacional de Estadística. (2010). Cuentas Departamentales-Base 2005: Resultados y Cambios Metodológicos. Bogotá: Departamento Administrativo Nacional de Estadística.

Departamento Administrativo Nacional de Estadística. (2011). Medición del empleo informal y seguridad social. Encuesta Nacional Agropecuaria. Bogotá.

Departamento Administrativo Nacional de Estadistica. (2014). Medición del empleo informal y seguridad social. Trimestre móvil diciembre 2013 febrero 2014. Bogotá: DANE.

Di Filippo, A., \& Franco, R. (2000). Intregración regional, desarrollo y equidad. México: Cepal/Siglo XXI Editores.

El Congreso de Colombia (2010). Ley No. 1429 de 2010. Ley de formalización y generación de empleo. Bogotá.

El Heraldo. (Octubre de 2012). El Heraldo.com. Obtenido de http://www.elheraldo.co/noticias/economia/bogota-antioquia-y-meta-losque-mas-aportaron-al-pib-2011-85173. 
Enchautegui, M. E. (2008). Departamento de Economía, Universidad de Puerto Rico. Obtenido el 2014, de Notas de clase: http://economia.uprrp.edu/notas $\% 20$ de\%20clase\%207.pdf

Espinel Riveros, N. (2007). El departamento del Meta. En H. Benjumea Yepes, Aproximación a la historia empresarial del Meta (pág. 278). Villavicencio: Electrificadora del meta, S.A. Fondo Mixto de Promoción y Cultura de las Artes del Meta.

Fajnzylber, F. (2006). Una visión renovadora del desarrollo de América Latina. Santiago de Chile: CEPAL.

Ffrench-Davis, R. (1988). Esbozo de un planteamiento neoestructuralista. Revista de la Cepal N 34. Santiago de Chile: CEPAL

Ffrench-Davis, R. (2011). Empleo decente y estabilidad macroeconòmica real. Revista Internacional del Trabajo: Organización Internacional del Trabajo.

Figueroa, C.A. (2010) . Determinantes de la informalidad laboral y el subempleo en las áreas metropolitanas de Barranquilla, Cartagena y Montería. Serie Documentos IEEC n. ${ }^{\circ} 32$. Bogotá: Universidad del Norte.

Galindo, G., Pedraza, C., Betancourth, F., Moreno, R. d., \& Cabrera, E. (2007). Planeación ambiental del sector hidrocarburos para la conservación de la biodiversidad en los Ilanos en Colombia. Bogotá: Instituto de Investigación de Recursos Biológicos Alexander von Humboldt

Gallart, M. A. (2003). Habilidades y competencias para el sector informal en América Latina: una revisión de la literatura sobre programas y metodologías de formación. Boletín Técnico Interamericano de Formación 
Profesional, 155 (Formación en la Economía Informal), Buenos Aires: CINTERFOR-OIT.

Galvis, L. A. (2012) . Informalidad laboral en las áreas urbanas de Colombia. Cartagena: Banco de la República.

García Cruz, G. A. (2009). Evolución de la informalidad laboral en Colombia: determinantes macros y efectos locales. Archivos de Economía, 26.

Gutiérrez G.E. (2008). Trayectorias de pensadores en nuestro tiempo. México: siglo XXI.

Gutierrez et al, J. (2012). Diagnóstico socieconómico y del mercado del trabajo. Departamento del Meta. Villavicencio: Red de Observatorios Regionales del Mercado de Trabajo.

Gutierrez Quiroga, J. (2012). La ley del primer empleo no ha generado ningún cambio significativo. Bogotá: El Tiempo.

Gutiérrez, L. H., \& Gamboa N., L. F. (2007). Oportunidades móviles. pobreza y acceso en América Latina y el Caribe. Lima: Dirsi.

Guzman Quintero, L. M. (2009). Influencia de los factores aceleradores del conflicto armado del Meta en la dificultad. Bogotá: Monografía de Grado. Universidad del Rosario.Instituto Mexicano de Transporte. (2002). La Permeabilidad de los Suelos en los Problemas de Transporte de contaminantes: Aplicación en la infraestructura del transporte. Méexico: Instiuto Mexicano de Transporte.Jara Urzola, A. (2012). Plan de desarrollo Económico y Social del Departamento del Meta, 2012-2015. Villavicencio: Gobernación del Meta. 
Hernández, G.H. (2004) Impacto de las regalías petroleras en el departamento del meta. Ensayos sobre economía regional. Banco de la Republica

Hernández, J. (2010). Causalidad del empleo informal en el espacio público de la zona centro de la ciudad de Villavicencio. Villavicencio: Observatorio del empleo del Departamento del Meta.

Katz, J. (2006). Tecnologías de la Información y la comunicación e industriales culturales. Una perspectiva lationamericana. Santiago de Chile: Cepal, Europeaid.

Klein. E. Tokman V. (2000). La estratificación social bajo tensión en la era de la globalización. Revista de la Cepal No. 72. Santiago de Chile: Cepal.

Ladino, W. (2012). La suerte de Colombia. Revista Colombia Nueva No. 4. Bogotá: Editorial Mayo.

La nota digital. Producción industrial $2 \%$ por debajo del crecimiento de la economía en el $2011 . \quad$ (2012). Bogotá. htpp: http://www.lanotadigital.com/business/produccion-industrial-2-por-debajodel-crecimiento-de-la-economia-en-el-2011-31857.html

Lesmes. A. (febrero de 2013). El tiempo. Los cuatro aspectos que 'trasnochan' al Banco de la República. Bogotá. Obtenido de http://www.eltiempo.com/archivo/documento/CMS-12573624

León Camargo, A., \& Caicedo Mora, H. G. (2011). La economía informal en Villavicencio. Finanzas y Política Económica, 130 pág.. 
León, A. ( 2011, mayo). [Entrevista con Consuelo Hernández, funcionaria de la secretaria de salud de Villavicencio]. Gastos de la salud a los informales. Grabación en audio.

Lustig, N. (2010). Los grandes problemas de México: crecimiento económico y equidad. México, D.F.: El Colegio de México.

Machinea, J. L. (2004). Palabras del señor José Luis Machinea, secretario ejecutivo de la Cepal en la inauguración del trigésimo periodo de sesiones. Santiago de Chile: Cepal.

Maldonado, A. (2010). La evolución del crecimiento industrial y transformación productiva en Colombia 1970-2005. Patrones y determinantes. Bogotá: Tesis de maestría. Universidad Nacional.

Maul, H. (2010). La economía informal: un enfoque neoinstitucional. Guatemala. Universidad Francisco Marroquin.

Méndez, O., \& Cubillos, R. (2010). Caracterización de la economía informal en Villavicencio,2002-2009 (Trabajo de pregrado). Universidad de los Llanos, Villavicencio.

Ministerio de la protección social (2010). Informalidad, mercado laboral y acciones para su mejoramiento. Bogotá. Obtenido en http://search.snapdo.com/? category $=$ Web\&p=1\&st=ds\&q=MINISTERio+de+proteccion+social+2010++ de+la+informalidad

Ministerio de Comercio, Industria y Turismo. (2011). Circular 181 de 2011. Bogotá: Ministrerio de Comercio, Industria y Comercio. 
Ministerio del Trabajo. (2011). Diagnóstico Villavicencio. Bogotá.

Neffa, J. C. (2006). Teorias económicas sobre el mercado de trabajo. Tomo I. Marxistas y keynesiano. Buenos Aires: Fondo de Cultura Económica.

Neffa, J. C. (2007). Teorías económicas sobre el mercado de trabajo. Tomo II. Neoclásicos y Nuevos Keynesianos. . Buenos Aires: Fondo de Cultura Económica.

Neffa, J.C. (2008). Sector informal, precariedad, trabajo no registrado. El trabajo como cuestión central. Buenos Aires.CEIL-PIETTE, CONICET y Ministerio de Trabajo de la Pcia.de Buenos Aires.

Nuñez A. \& Chiñas C. (2008). Controversia y debate actual sobre el sector informal. México: Universidad Autónoma Metropolitana Azcapotzalco

Ocampo, J. (2003). Luces y sombras de las reformas estructurales de lationamerica. I Encuentro del grupo de Biarritz: "América Latina: La Gobernabilidad Amenazada" (pág. 38). Biarritz: Corporación Escenarios, CAF, CMEAL, Alcaldía de Biarritz.

Ocampo, J. A. (1999). La crisis y el empleo. Notas de la Cepal, Santiago de Chile, $120 \mathrm{p}$.

Ocampo, J. A. (2001). Un futuro económico para Colombia. Santiago de Chile: Cepal 
Organización de las Naciones Unidas. (2008). Creación de un entorno institucional conducente al aumento de la inversión extranjera y al desarrollo sustentable. Conferencia de las Naciones Unidas sobre Comercio y Desarrollo. Accra: ONU

Organización Internacional del Trabajo (1991). El dilema del sector no estructurado. Memoria del director general:Conferencia Internacional del trabajo. 78a. . Ginebra: OIT.

Organización Internacional del Trabajo. (2002). Conferencia Internacional del Trabajo, $90^{a}$ reunión. El trabajo decente y la economía informal. Ginebra: OIT

Organización Internacional del Trabajo. (2003). Conferencia Internacional del Trabajo, $91^{a}$ reunión. Actividades normativas de la OIT en el ámbito de la seguridad y la salud en el trabajo: estudio detallado para la discusión con miras a la elaboración de un plan de acción sobre dichas actividades. Ginebra: OIT.

Organización Internacional del Trabajo. (2012). Informe mundial sobre salarios. Ginebra: OIT.Ortiz, C., Uribe , J., \& García, G. (2007). Informalidad y Subempleo: Un Modelo Probit bivariado aplicado al Valle del Cauca. Archivos de Economía, 31.

Organización Panamericana de la Salud. (2003) . Características generales de la población desplazada a diciembre de 2003. Bogotá: OPS. De http://www.saberespractico.com/apa/como-citar-una-pagina-web-en-apa/ 
Ortiz, C., Uribe , J., \& García, G. (2007). Informalidad y Subempleo: Un Modelo Probit bivariado aplicado al Valle del Cauca. Sociedad y Economía. No. 13. Cali: Universidad del Valle.

Osorio Duque, C. (2011). Caracteristicas del tejido empresarial de pereira. Informe mensual de coyúntura económica y social. Documentos de analisis y/o evaluacion tematicas sociales y economicas. Pereira: Alcaldía de Pereira.

Pérez Sainz, J.P. (1995). Globalización y neoinformalidad en América Latina. Revista Nueva Sociedad Nro. 135, Costa Rica: Facultad latinoamericana de ciencias sociales, FLACSO.

Perry, G. \& Maloney W. (2007). Informalidad: escape y exclusión. (2007) Washington: Banco Mundial.

Petroff, J. (2002). peoi.org. Recuperado el 4 de Febrero de 2013, de peoi.org/Courses/Coursessp/D-ec/mac/mac8/mac7.html

Pinto, A. (1970). Naturaleza e implicaciones de la heterogeneidad estructural de Ameríca Latina. El trimestre Económico. México, D.F.: Fondo de Cultura Económica.

Posada, C., \& Arango, L. (2002). La participación laboral en Colombia. . Borradores de Economía, No. 217. Bogotá: Banco de la República.

Prebisch, R. (1970): Transformación y desarrollo: la gran tarea de América Latina, México, D.F. Fondo de Cultura Económica. 
Prebisch, R. (1978). Planificación, desarrollo y democracia. Conferencia Regional sobre Condiciones Sociales de la Democracia. San José de Costa Rica: CLACSO.

Ramírez, J. (1996). La capacitación laboral como instrumento de lucha contra la pobreza. Ginebra: OIT. Estudios de Políticas № 26

Ramírez M. J (2012) . Colombia, entre los 20 países con peores salarios del mundo. Portafolio. co .Bogotá. Obtenido en http://www.portafolio.co/finanzas-personales/colombia-los-20-paisespeores-salarios-del-mundo

Ramirez J., J. C., \& Parra-Peña S., R. I. (2010). Escalafón de la competitividad de los departamentos en Colombia, 2009. Bogotá: La Cepal.

Rausch, J. M. (2011). De pueblo de frontera a ciudad capital. Villavicencio: Juan XXIII Itda.

Redacción Llano 7 días. (Agosto de 2010). Petrominerales dice que la exploración de petróleo no ha afectado a pobladores ni animales. El tiempo, pág. 10.Rodriguez Castillo, D. J. (2010). Modelar la concentración de la tierra en Colombia mediante modelos econométricos espaciales. Bogotá, Colombia: Universidad Nacional .

Rosales O. (1988). Balance y renovación en el paradigma estructuralista del desarrollo latinoamericano. Revista de la Cepal, No. 34. Santiago de Chile: CEPAL. 
Rosales, O. (2013). Comercio internacional y desarrollo inclusivo: construyendo sinergias. Cepal. Recuperado el Julio de 2013, de http://www.eclac.cl/publicaciones/xml/4/49724/ComerciolnternacionalyDesa rrollolnclusivo.pdf

Rosález Älvarez, R. A., Perdomo Calvo, J. Á., Morales Torrado, C. A., \& Urrego Mondragón, J. A. (2010). Fundamentos de Econometría Intermedia: teoría y aplicaciones. Bogotá, Colomba: Universidad de los Andes.

Ruiz Granados, C. (18 de Octubre de 2013). Se evaden $\$ 11,2$ billones en seguridad social. El colombiano, pág. 9A.

Secretaría de Planeación y Desarrollo Territorial. Gobernación del Meta. (2011). Análisis de cifras económicas departamento del Meta. Primer semestre de 2010 y 2011. Villavicencio.

Schneider F. (2002). Size and measurement of the informal economy in countries around the world. Recuperado el día 5 de febrero de 2014. http://www.davidmlast.org/Supervisions/Gousienov_files/schneider,\%20size \%20and\%20measurement\%20of\%20informal\%20economy,\%202002.pdf

Souza R. y Tokman V. (1976). El sector informal urbano, El Empleo en América Latina. México: Siglo XXI editores.

Sunkel, O. (1991). Del desarrollo hacia adentro al desarrollo desde dentro. En O. Sunkel (Compilador), El desarrollo desde dentro. Un enfoque neoestructuralista para la América Látina. México: Fondo de Cultura Económica. 
Tobón A., A., \& Gálvis, D. (2009). Análisis sobre la evolución reciente del transporte en Colombia. Perfil de Coyuntura Económica, 14.

Tokman, V. (2001). De la informalidad a la modernidad. Santiago de Chile: Organizaciòn internacional del Trabajo.

Tokman, V. (2003). Hacia una visión integrada para enfrentar la inestabilidad y el riesgo. Revista de la Cepal, 210.

Tokman, V. (2004). Las dimensiones laborales de la transformación productiva con equidad. Serie financiamiento del desarrrollo. Santiago de Chile: Naciones Unidas.

Tokman, V. E. (2004). Una voz en el camino. Empleo y equidad en América Latina: 40 años de búsqueda. Santiago de Chile: Fondo de Cultura Económica.

Torres Rincon D. (2007). Analisis sobre las principales causas relacionadas con la informalidad del comercio en la ciudad de villavicencio. Tesis de grado. Villavicencio: Universidad de los Llanos.

Trejo, J. (2003). La ocupación en el sector informal, 1995-2003. México: Instituto Nacional de Estadística Geografía e Informática.

Valenzuela A. \& Monroy R. (2014). Formal/Informal//legal: Los Tres Circuitos de la Economía Espacial en América Latina. México: Universidad Autónoma del Estado de Morelos. 
Wooldridge, J. (2009). Introducción a la econometria un enfoque moderno. México D.F.: Cengage Learning.

Wooldridge, J. M. (2010). Introducción ala econometría:un enfoque moderno. México, D.F.: Cengage Learning Editores. 